\title{
Cost Benefit Analysis Modeling Tool for Electric vs. ICE Airport Ground Support Equipment - Development and Results
}

Kevin Morrow

Dimitri Hochard

James Francfort

February 2007

The INL is a U.S. Department of Energy National Laboratory operated by Battelle Energy Alliance

Idaho National Laboratory 
INL/EXT-07-12270

\title{
Cost Benefit Analysis Modeling Tool for Electric vs. ICE Airport Ground Support Equipment - Development and Results
}

\author{
Kevin Morrow ${ }^{1}$ \\ Dimitri Hochard ${ }^{1}$ \\ James Francfort ${ }^{2}$ \\ ${ }^{1}$ Electric Transportation Engineering Corporation \\ ${ }^{2}$ Idaho National Laboratory
}

February 2007

Idaho National Laboratory
Idaho Falls, Idaho 83415

Prepared for the

U.S. Department of Energy

Assistant Secretary for Energy Efficiency and Renewable Energy

Under DOE Idaho Operations Office

Contract DE-AC07-05ID14517 


\section{Disclaimers}

This document highlights work sponsored by agencies of the U.S. Government. Neither the U.S. Government nor any agency thereof, nor any of its employees, makes any warranty, express or implied, or assumes any legal liability or responsibility for the accuracy, completeness, or usefulness of any information, apparatus, product, or process disclosed, or represents that its use would not infringe privately owned rights. Reference herein to any specific commercial product, process, or service by trade name, trademark, manufacturer, or otherwise does not necessarily constitute or imply its endorsement, recommendation, or favoring by the U.S. Government or any agency thereof. The views and opinions of authors expressed herein do not necessarily state or reflect those of the U.S. Government or any agency thereof.

This report was prepared by the Electric Transportation Engineering Corporation in the course of performing work sponsored by the U.S. Department of Energy's Advanced Vehicle Testing Activity, Electric Power Research Institute, Southern California Edison Company, Sacramento Municipal Utility District, Southwest Airlines, Georgia Power Company, and Delta Airlines ("Sponsors"). The opinions expressed in this report do not necessarily reflect those of the Sponsors, and reference to any specific product, service, process, or method does not constitute an implied or expressed recommendation or endorsement of it. Further, the Sponsors and the contractor make no warranties or representations, expressed or implied, as to the fitness for particular purpose or merchantability of any product, apparatus, or service, or the usefulness, completeness, or accuracy of any processes, methods, or other information contained, described, disclosed and/or referred to in this report. The Sponsors and the contractor make no representation that the use of any product, apparatus, process, method, or other information will not infringe privately owned rights and will assume no liability for any loss, injury, or damage resulting from, or occurring in connection with, the use of information contained, described, or referred to in this report. 


\begin{abstract}
This report documents efforts to develop a computer tool for modeling the economic payback for comparative airport ground support equipment (GSE) that are propelled by either electric motors or gasoline and diesel engines. The types of GSE modeled are pushback tractors, baggage tractors, and belt loaders. The GSE modeling tool includes an emissions module that estimates the amount of tailpipe emissions saved by replacing internal combustion engine GSE with electric GSE. This report contains modeling assumptions, methodology, a user's manual, and modeling results. The model was developed based on the operations of two airlines at four United States airports.
\end{abstract}




\section{TABLE OF CONTENTS}

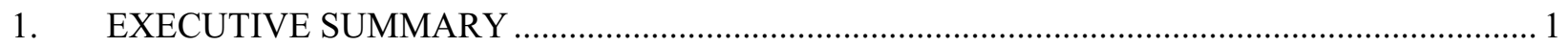

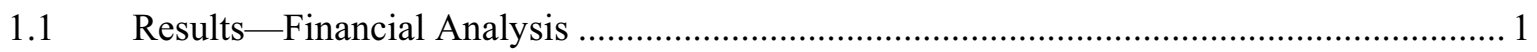

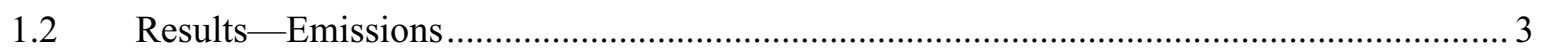

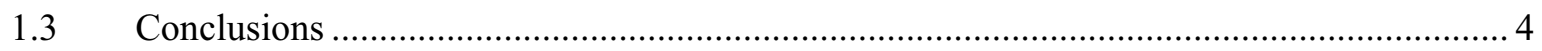

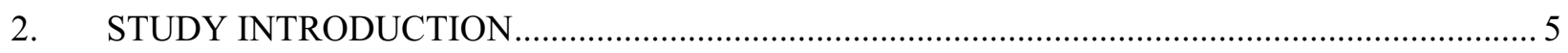

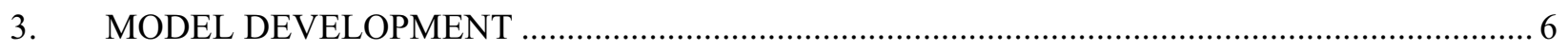

3.1 Task 1: Development of High-Level Input Variables for the Ground Support Equipment

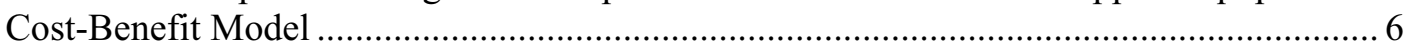

3.2 Task 2: Development of Logic Data Tree Structures for Each High-Level Input Variable.. 7

3.3 Task 3: Incorporation of Participant Comments on Tasks 1 and 2 Deliverables and Development of the Model Code ..................................................................................... 7

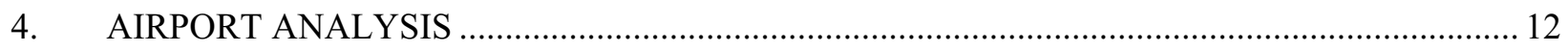

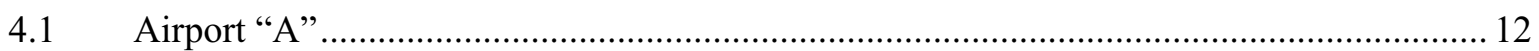

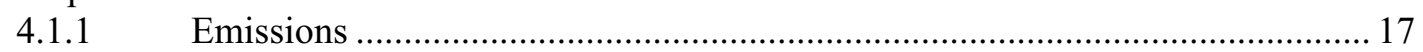

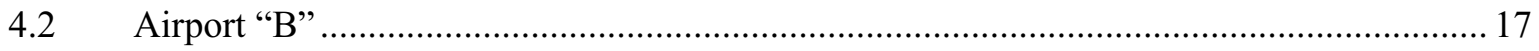

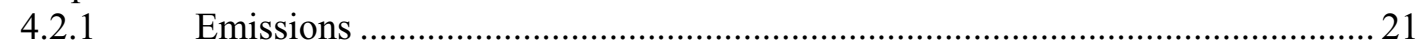

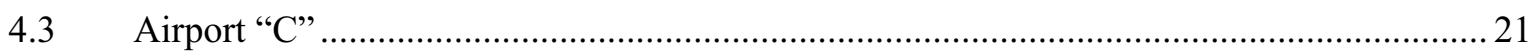

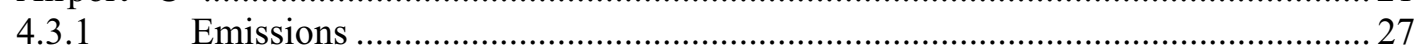

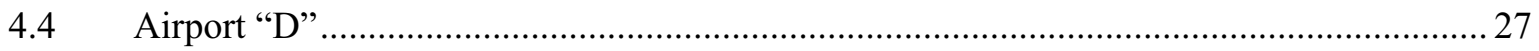

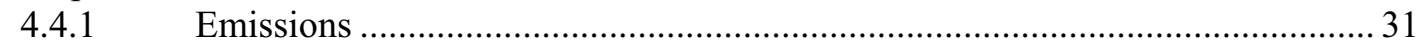

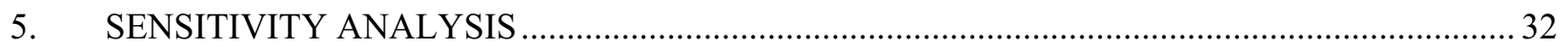

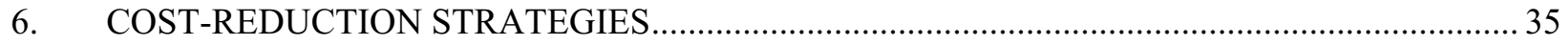

6.1 Ground Support Equipment Capital Cost-Reduction Strategies ...................................... 35

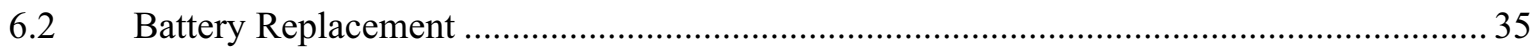

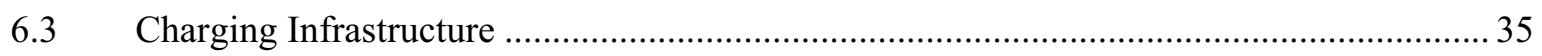

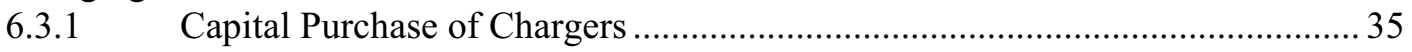

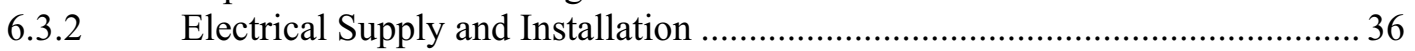

6.3.3 Operating and Maintenance Expenses (Including Electricity Costs) ................ 36

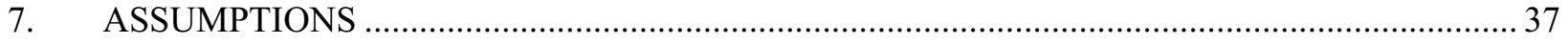

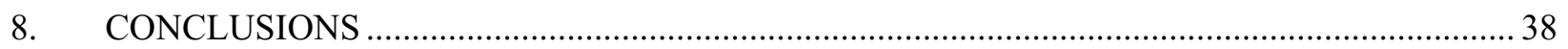

Appendix A - Airport “A” Input Data and Results Summary .............................................................. A-1

Appendix B - Airport "B” Input Data and Results Summary ……................................................... B-1

Appendix C - Airport “C”" Input Data and Results Summary ……..........................................................

Appendix D - Airport “D” Input Data and Results Summary ......................................................... D-1

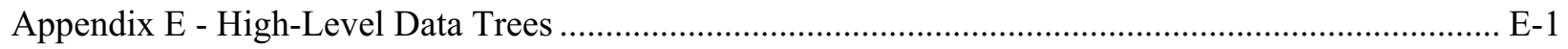

Attachment A - Ground Support Equipment Cost Model Operating Guide ............................................ 1 


\section{FIGURES}

1-1. Airport "A" sensitivity analysis for all three ground support equipment types combined................ 2

1-2. Airport "A" sensitivity analysis for baggage tractors .................................................................. 2

1-3. Airport "A" sensitivity analysis for belt loaders......................................................................... 3

1-4. Airport "A" sensitivity analysis for pushback tractors ................................................................. 3

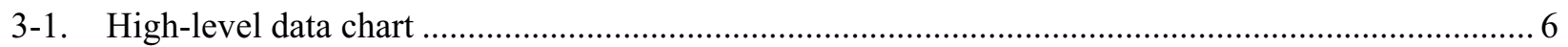

3-2. Ground support equipment cost model main page ….......................................................... 8

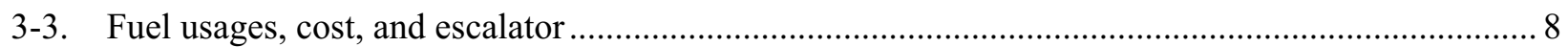

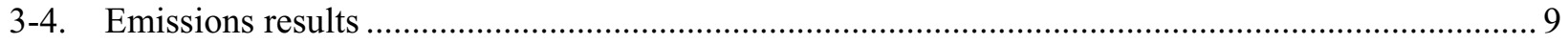

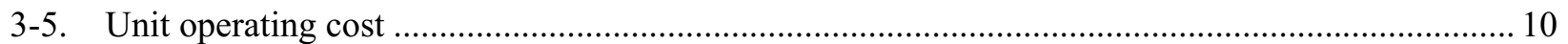

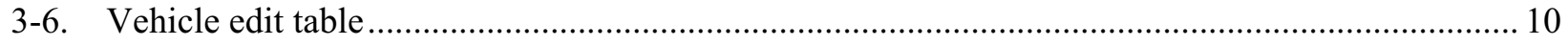

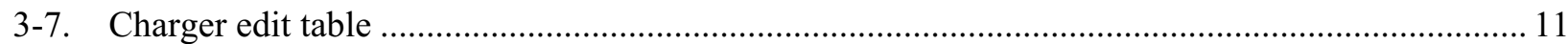

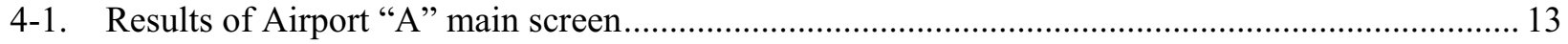

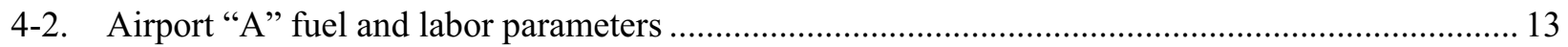

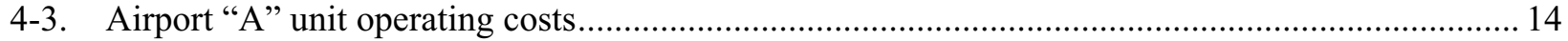

4-4. Airport "A" breakeven point for electric ground support equipment versus internal combustion engine ground support equipment for all three types of ground support equipment ....................... 14

4-5. Airport " $A$ " sensitivity analysis for all three ground support equipment types.............................. 15

4-6. Airport "A" sensitivity analysis for baggage tractors.................................................................... 16

4-7. Airport "A" sensitivity analysis for pushback tractors .................................................................. 16

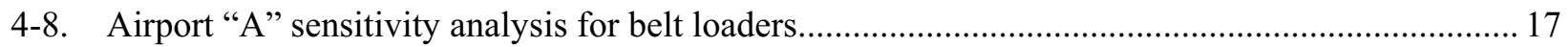

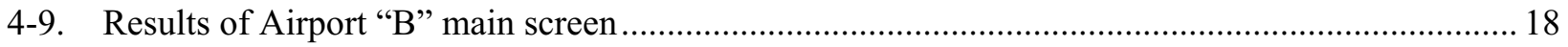

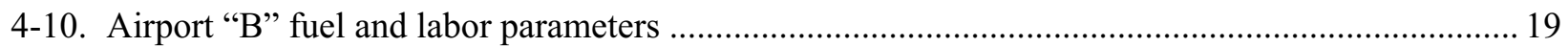

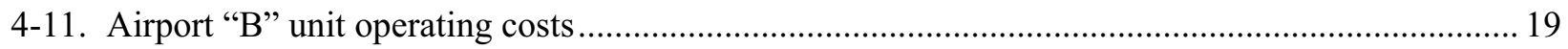

4-12. Airport "B" breakeven point for electric ground support equipment versus internal combustion

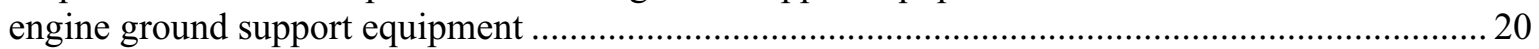

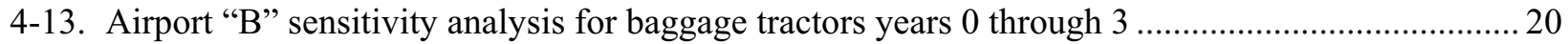

4-14. Airport "B" sensitivity analysis for baggage tractors years 3 through 20 .................................. 21

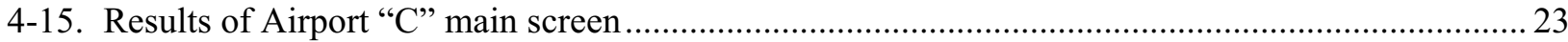

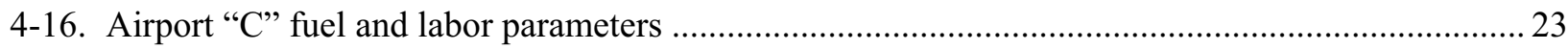

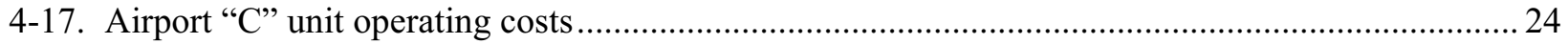

4-18. Airport "C" breakeven point for electric ground support equipment versus internal combustion engine ground support equipment for all ground support equipment......................................... 24

4-19. Airport " $C$ " sensitivity analysis for all three ground support equipment types ............................ 25

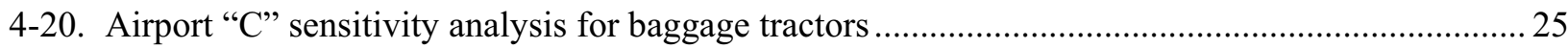

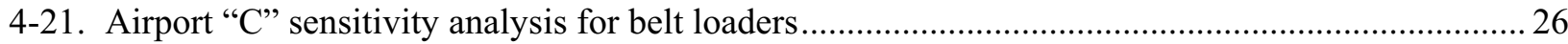

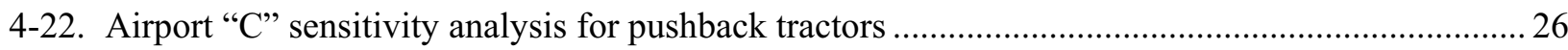

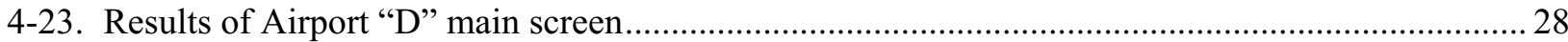

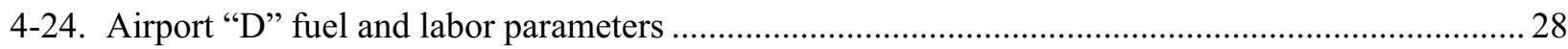

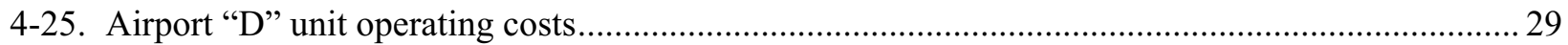


4-26. Airport "D" breakeven point for electric ground support equipment versus internal combustion engine ground support equipment for the bag tractor and belt loader

4-27. Airport " $D$ " sensitivity analysis for baggage tractor and belt loader............................................ 30

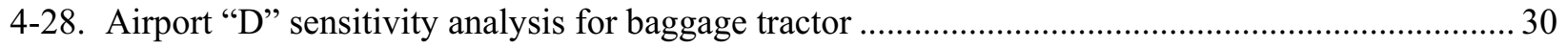

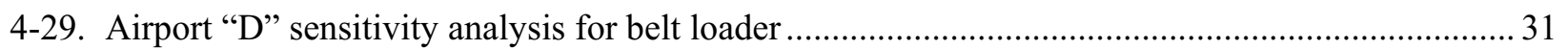

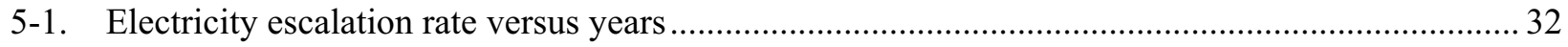

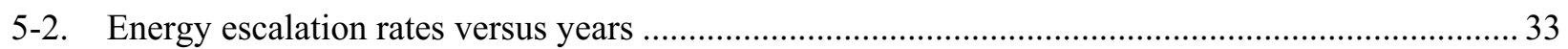

5-3. Electric ground support equipment capital cost subsidy versus years .......................................... 33

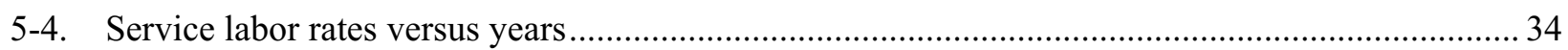

\section{TABLES}

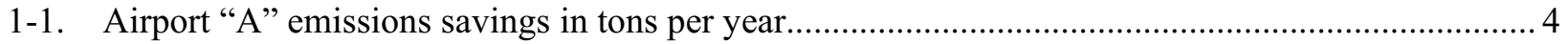

4-1. Airport "A" electric ground support equipment included in study................................................. 12

4-2. Airport "A" electric ground support equipment battery chargers................................................... 12

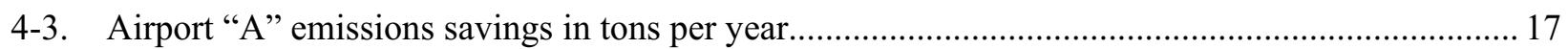

4-4. Airport "B" ground support equipment included in the study ..................................................... 18

4-5. Airport "B" electric ground support equipment battery chargers .................................................. 18

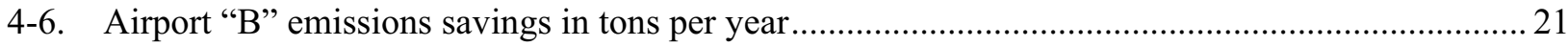

4-7. Airport " $\mathrm{C}$ " ground support equipment included in the study ....................................................... 22

4-8. Airport " $\mathrm{C}$ " electric ground support equipment battery chargers .................................................. 22

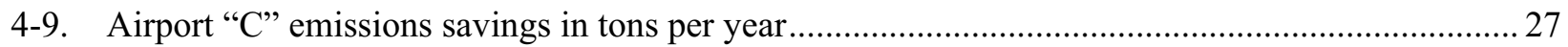

4-10. Airport "D" ground support equipment included in the study ....................................................... 27

4-11. Airport " $D$ " electric ground support equipment battery chargers.................................................. 27

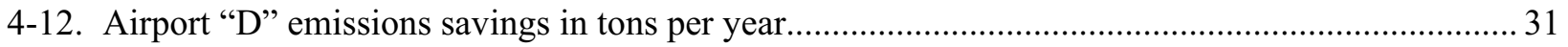




\section{EXECUTIVE SUMMARY}

Airlines are going through a very challenging period; they are faced with many cost pressures, compliance issues, and operational challenges caused by competition and growth in the industry. Ground support equipment (GSE) operations are an area impacted by these challenges, including the rising cost of fuel and pressure to reduce air pollutants in many of the cities airlines operate in. This is especially true in Environmental Protection Agency (EPA)-designated non-attainment cities. Many airlines, power utilities, and other GSE industry stakeholders are examining the cost-effectiveness of utilizing electric ground support equipment (eGSE) versus gasoline and diesel-fueled internal combustion engine (ICE) alternatives.

This study evaluates the costs associated with operating three main types of GSE — baggage tractors, belt loaders, and pushback tractors. A cost model was developed as part of this project to assist airlines and other stakeholders in future evaluations of deploying GSE. The approach included visiting four airports (two west coast, one mid-west, and one in the northeast) and working directly with two airline study participants to obtain available data on every aspect of GSE costs. These costs include capital costs, operating and maintenance (O\&M) costs, and any associated infrastructure costs. Where costs were undocumented, or otherwise unavailable, methodologies were established to collect or determine the undocumented data and are described herein.

\subsection{Results-Financial Analysis}

Sensitivity analyses were performed to understand and identify the significant cost drivers that would help airline executives make informed GSE decisions when looking solely at economics. Fuel costs for ICE GSE were found to be the single largest variable impacting costs. Therefore, airports with higher fuel-use amounts typically resulted in a faster return on investment when purchasing eGSE over the lower fuel-use airports. Figure 1-1 shows Airport "A" eGSE payback results in years for fossil fuel escalation rates from 0 to $20 \%$ per annum. In this case, the model was run for a period of 20 years. This airport was designated a "medium-use" airport based on a review of the tarmac terrain, distances required of the GSE to travel, and number of daily flights at the airport. The analysis for Airport " $A$ " assumed that a mix of 40 ICE GSE vehicles were replaced with eGSE, including 17 baggage tractors, 16 belt loaders, and 7 pushback tractors. The charger system is defined as a fast-charge, multi-port type system, providing one port for every two vehicles. For example, when looking at Figure 1-1 and assuming an average annual $9 \%$ increase in fuel costs, eGSE has a payback within approximately 5 years.

Again referring to Figure 1-1, if fuel cost increases remain relatively low with a $4 \%$ average annual increase, the payback for eGSE is approximately 13 years. Figures 1-2, 1-3, and 1-4 show the sensitivities of each individual piece of equipment with all other parameters treated the same as before. Electric baggage tractors have by far the fastest payback of the three types of GSE vehicles analyzed in this study, followed by belt loaders, and lastly pushback tractors. Not surprisingly, baggage tractors are also the heaviest fuel users of the three GSE-type vehicles.

Because pushback tractors have a higher initial capital cost and lower fuel use, the pushback tractors have a longer payback than the baggage tractors and belt loaders. If capital costs to the user could be significantly lowered through grant cost-share programs, or in the case of vehicle conversions of gas or diesel to electric, payback can be much sooner, making the electric pushback tractors also attractive. 


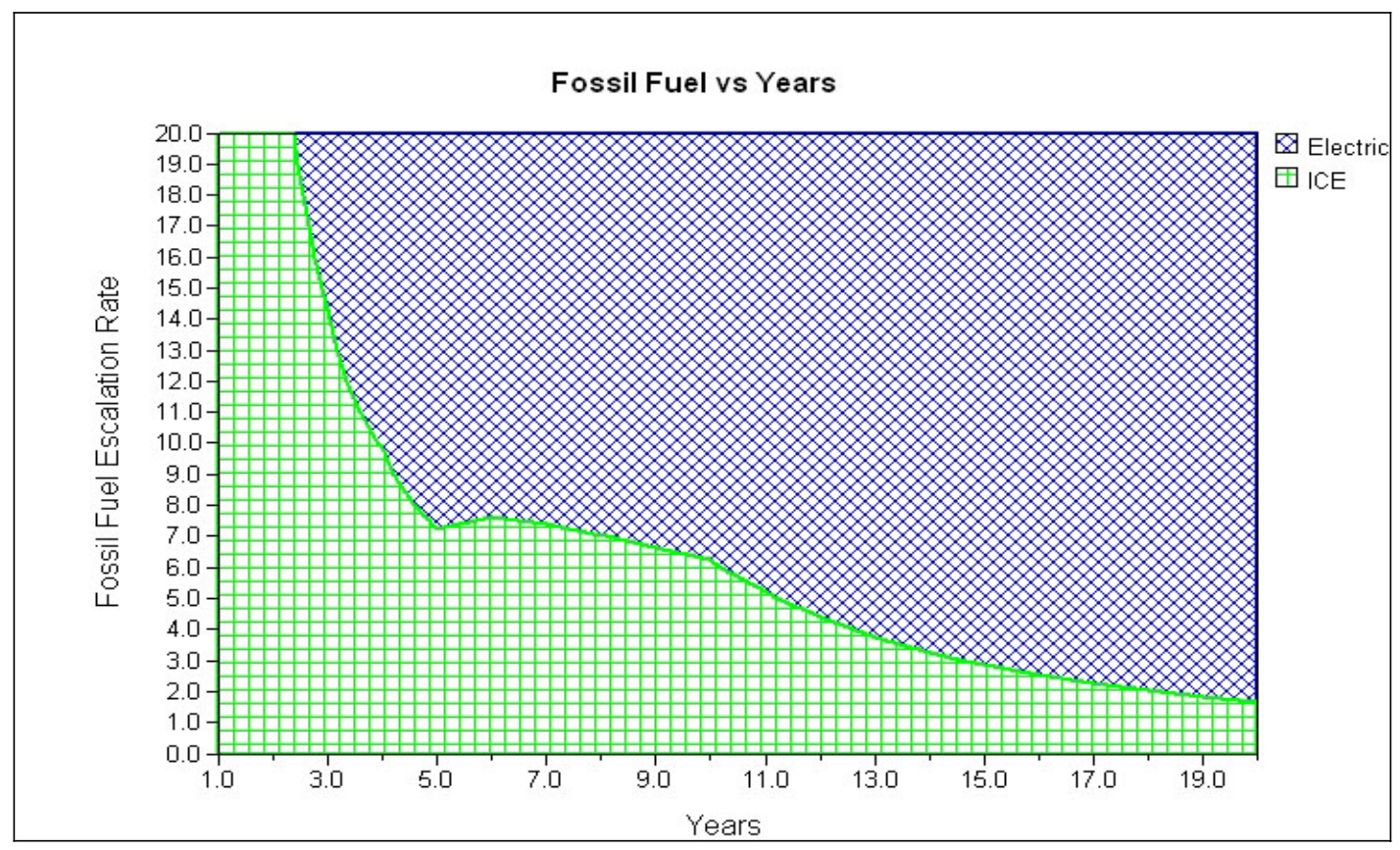

Figure 1-1. Airport "A" sensitivity analysis for all three ground support equipment types combined.

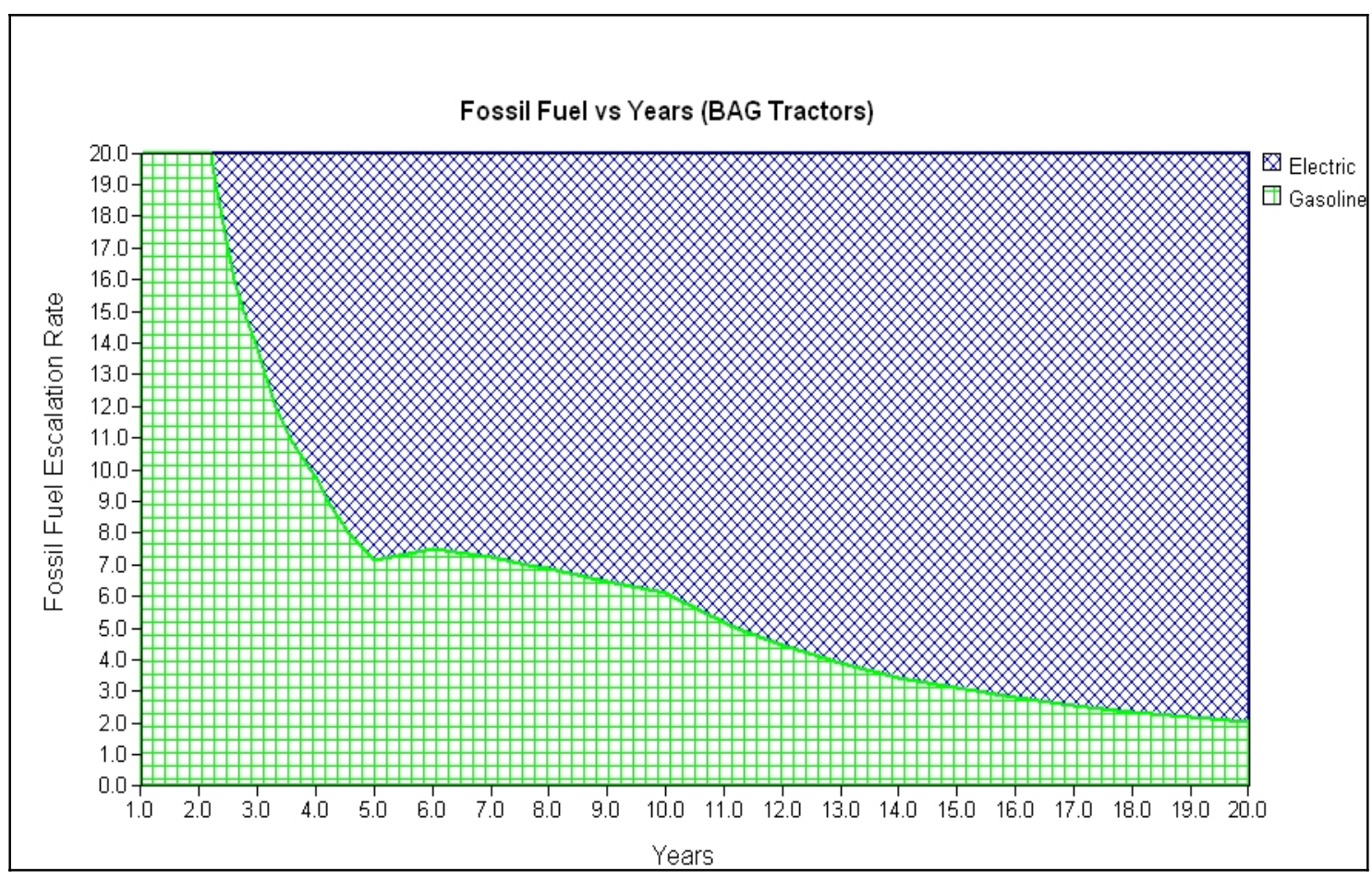

Figure 1-2. Airport "A" sensitivity analysis for baggage tractors. 


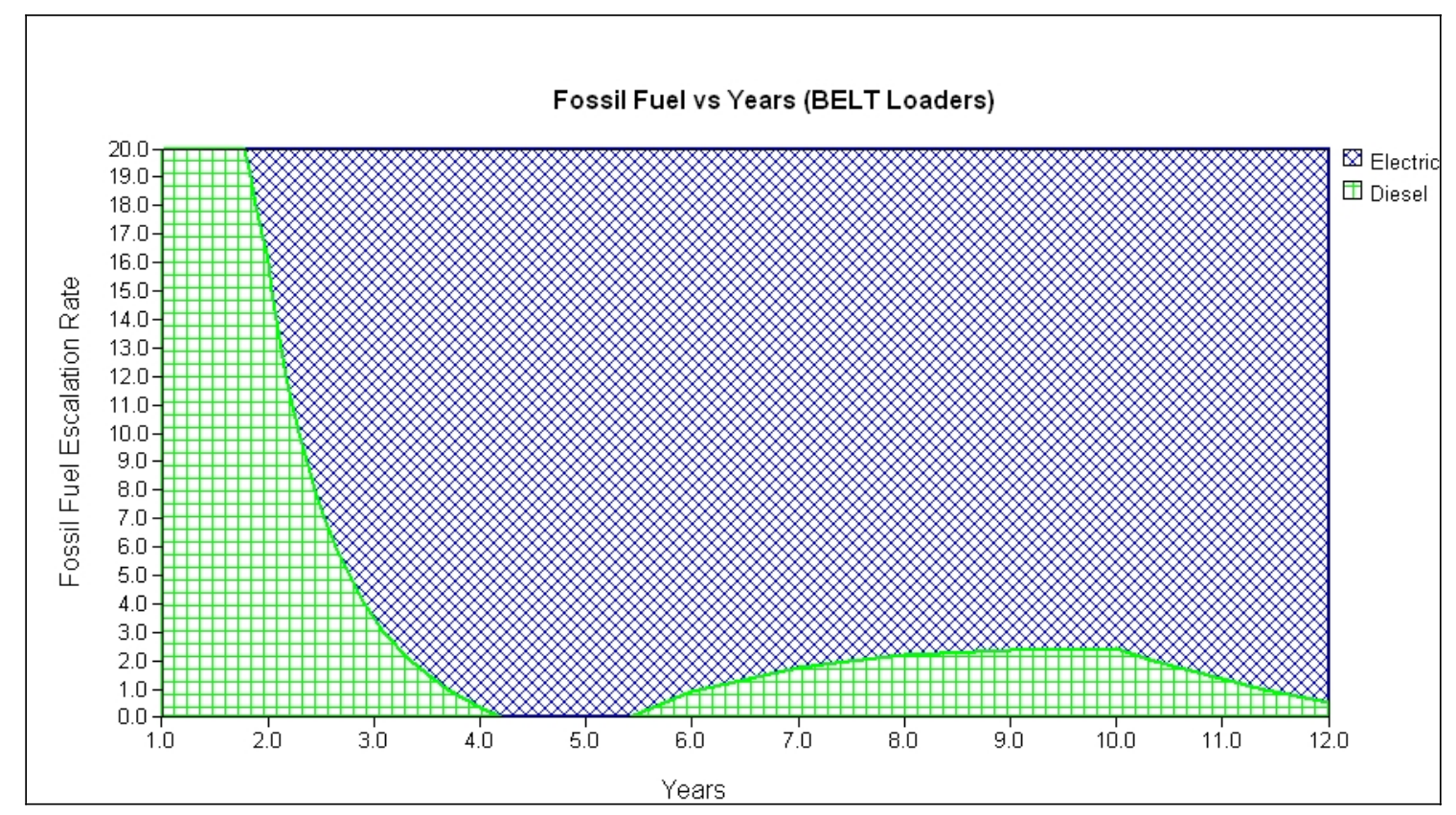

Figure 1-3. Airport "A" sensitivity analysis for belt loaders.

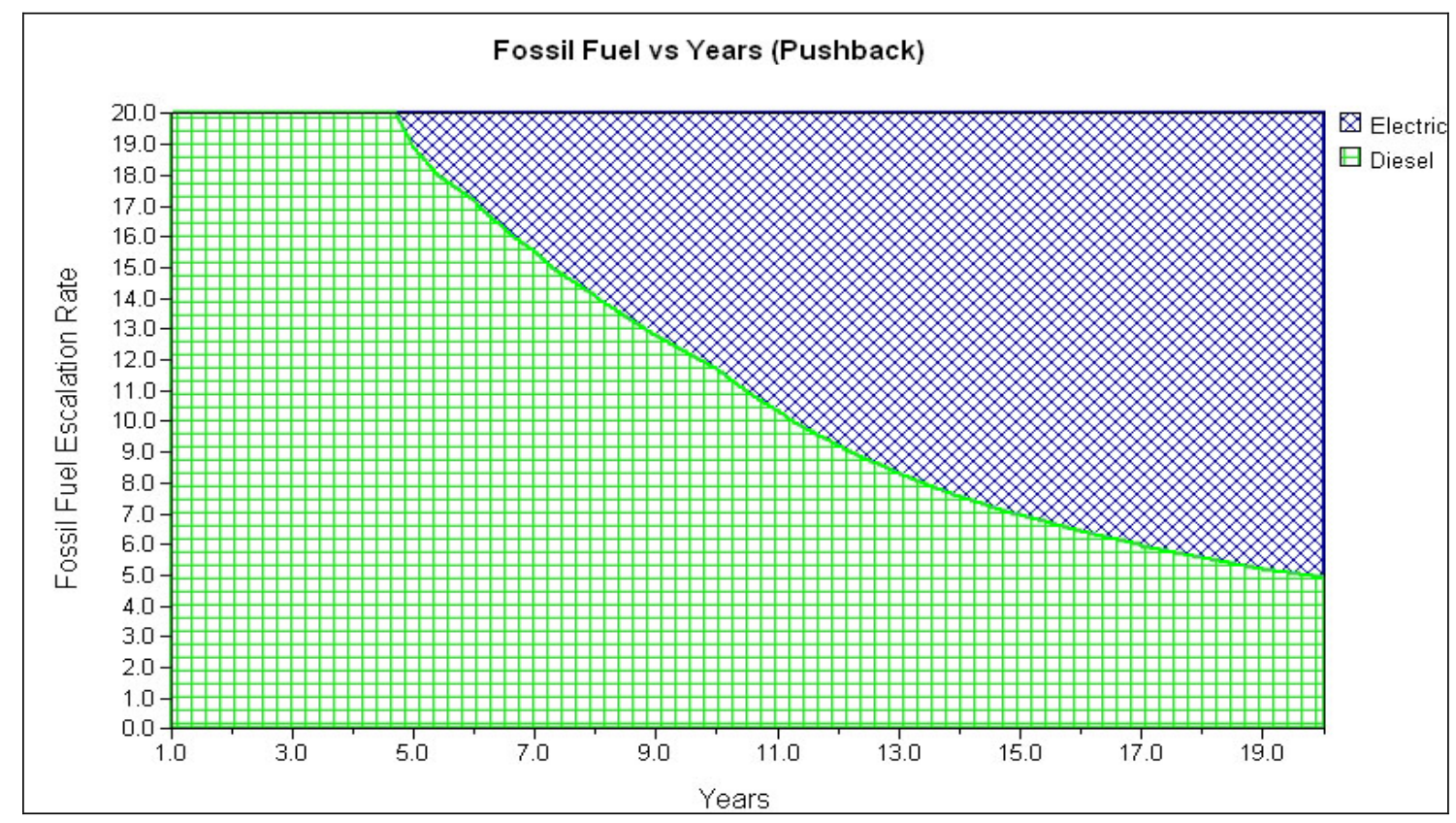

Figure 1-4. Airport "A" sensitivity analysis for pushback tractors.

\subsection{Results-Emissions}

The GSE modeling tool includes an emissions module that estimates the amount of tailpipe emissions saved by replacing ICE GSE with eGSE. Table 1-1 shows the emissions results for Airport "A." The base emission rates were provided the Federal Aviation Administration (FAA) Emissions and Dispersion Model System (EDMS) Emissions Model Version 4.12, which provides emissions rates for each type of GSE. 
Table 1-1. Airport "A" emissions savings in tons per year.

\begin{tabular}{|llrrrr|}
\hline Quality & \multicolumn{1}{c}{ Description } & CO & HC & NOx & PM \\
\hline 17 & Baggage Tractors & 700.308 & 25.560 & 14.551 & 0.137 \\
16 & Belt Loaders & 2.802 & 0.675 & 5.686 & 0.640 \\
7 & Pushback Tractors & 1.751 & 0.345 & 4.441 & 0.338 \\
\hline Totals & & 704.861 & 26.58 & 24.678 & 1.115 \\
\hline CO = carbon monoxide, HC = total hydrocarbons, NOx = oxides of nitrogen, PM = particulate matter & \\
\hline
\end{tabular}

\subsection{Conclusions}

The GSE cost-benefit analysis study provides airline and industry stakeholders the background, strategies, and tools needed to evaluate whether eGSE would be a cost-effective approach for a particular application. Additionally, emissions results and cost-saving strategies are provided in the analysis.

Generally, electric baggage tractors and belt loaders are a cost-effective replacement, with a reasonable payback period, over similar performance ICE GSE for most applications. At this time, pushback tractors have a much longer payback period mostly because of the premium capital cost for the eGSE and low fuel-use requirements. When taking into consideration potential cost sharing, conversions of existing equipment, and other variables, payback for all three types of GSE can be shortened, and even pushback tractors can be a very cost-effective option. 


\section{STUDY INTRODUCTION}

The purpose of this study is to better understand the costs of deploying eGSE versus ICE GSE (that uses gasoline or diesel) and, based on the findings, to provide strategies to make eGSE use more cost effective. The approach of this study was to evaluate four different airports in the continental United States - two on the west coast, one in the mid-west, and one in the northeast area. Based on data collected from these locations, a model was developed as a tool for this project and for use by the general airline industry, electric utilities, and other interested stakeholders.

In order to complete the analysis and develop the model tool, data was collected at each location through onsite evaluation, interviews, and review of existing data files. Where data was unavailable, strategies were developed to determine or estimate missing data values and incorporate them into the model.

The four airport scenario details and modeling results comparing eGSE to gas or diesel GSE that would be replaced is reported in this document. Additional sensitivity analyses were performed to determine which cost parameters had the most influence on the overall costs, especially parameters with high elasticity, such as fuel costs.

This report was prepared by the Electric Transportation Engineering Corporation in the course of performing work sponsored by the U.S. Department of Energy's Advanced Vehicle Testing Activity, Electric Power Research Institute, Southern California Edison Company, Sacramento Municipal Utility District, Southwest Airlines, Georgia Power Company, and Delta Airlines. The Advanced Vehicle Testing Activity is part of U.S. Department of Energy's FreedomCAR and Vehicle Technologies Program. The Idaho National Laboratory conducts these and other Advanced Vehicle Testing Activity testing activities for U.S. Department of Energy's FreedomCAR and Vehicle Technologies Program. 


\section{MODEL DEVELOPMENT}

The model development was divided into three specific tasks as follows:

- $\quad$ Task 1: Development of High-Level Input Variables for the GSE Cost-Benefit Model

- Task 2: Development of Logic Data Tree Structures for Each High-Level Input Variable

- Task 3: Incorporation of Participant Comments on Tasks 1 and 2 Deliverables and Development of Model Code.

\subsection{Task 1: Development of High-Level Input Variables for the Ground Support Equipment Cost-Benefit Model}

This task developed the first draft of the GSE Cost Model, outlining the high-level input variables necessary to provide a reasonable cost comparison of eGSE and ICE GSE.

The high-level data are broken into two major categories: (1) capital costs, which include the purchase price of GSE, GSE alterations required before putting GSE in service, battery chargers, and installation costs of the charging system; and (2) expenses, which include GSE maintenance, charging infrastructure maintenance, and fuel costs. A draft high-level data chart was initially provided to project team members for review; comments were incorporated and presented to the project team (see Figure 3-1).

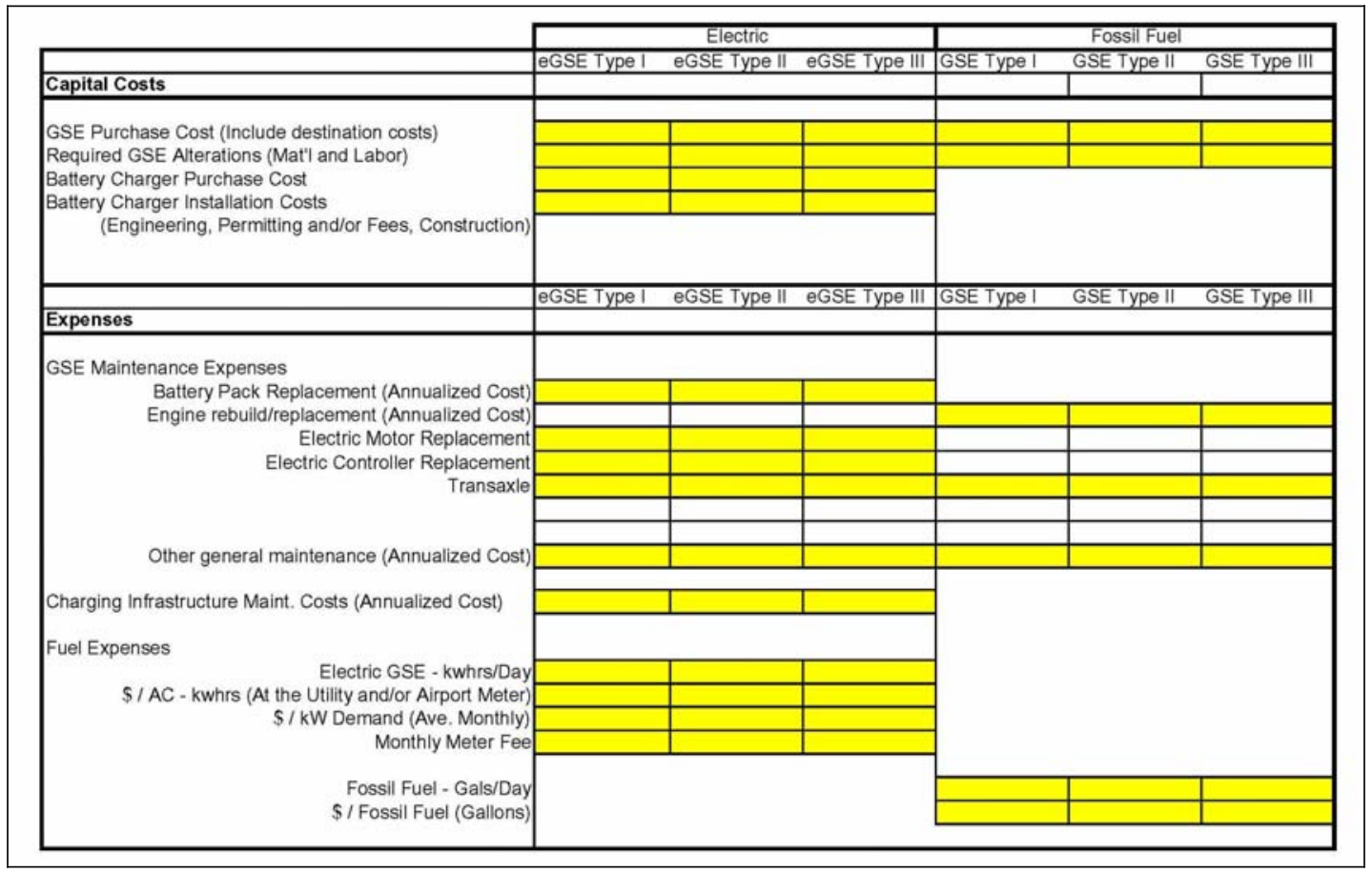

Figure 3-1. High-level data chart.

In many cases, some of the data parameters are not known, and therefore, a detailed data tree module (built in Task 2) must be relied on, allowing users to input the data required, if known, or calculate the high-level data based on previous assumptions built into the model as provided by the airline participants. 


\subsection{Task 2: Development of Logic Data Tree Structures for Each High-Level Input Variable}

This task developed the draft data tree charts that provided the logic required for development of the GSE Cost Model. Each major category provided in the high-level data chart (Figure 3-1) was broken down into enough detail that either the user could provide the data required (if available) or the model would make some assumptions (as provided by project team members) based on input from the user. The user is given multiple opportunities throughout the process to provide data that may be available to assist the model in providing the most accurate results possible.

The following is a list of each separate high-level data parameter that was developed into a detailed data tree chart required for the model:

- $\quad$ GSE equipment purchase price

- $\quad$ GSE alterations required

- $\quad$ Battery charging system

- $\quad$ Battery charger installation costs

- $\quad$ Charging infrastructure maintenance

- $\quad$ GSE maintenance

- Fuel expenses.

Where detailed data were not available, project team members were asked to complete the assumptions made. Each detailed data tree chart is provided in Appendix E.

\subsection{Task 3: Incorporation of Participant Comments on Tasks 1 and 2 Deliverables and Development of the Model Code}

This task was built on the deliverables of Tasks 1 and 2, which defined the high-level cost model and the detailed data tree interface. The result of this task is a working GSE Cost Model that is easy to use, but has the flexibility to either use default input data or user-provided data.

The model's main page (shown in Figure 3-2) provides main input to the program, including the number and type of GSE. The user is prompted to input the number of each type of GSE in the three main categories of baggage tractors, belt loaders, and pushback tractors. A choice of either diesel or gasoline ICE vehicles is available, and with the electric, the user can select either a DC or AC drive system and specify flooded or sealed batteries.

The model can run various time periods between 1 to 5 years and 1 to 25 years. The life of the equipment is established in the main data files, which can be changed by the user, if so desired. In order to categorize airport usage, the user can select three general intensity settings: low, medium, or high. These settings impact daily fuel (i.e., gas, diesel, or electricity) consumption of the GSE. Upon selection of these items, the user can select "Run Analysis," and the model pulls up a page of fuel cost estimates and the GSE labor rate (shown in Figure 3-3). These parameters can either be changed or left as the default parameters. Upon selecting "Okay," the model calculates costs and produces the emission results table as shown in Figure 3-4 and found under the "Tools" header. The GSE emissions are generated utilizing emission rates from the EDMS Version 4.3. This produces annual estimates based on GSE usage selected for input by the user. The model also is designed to run and compare two different scenarios so the user can review different alternatives. 


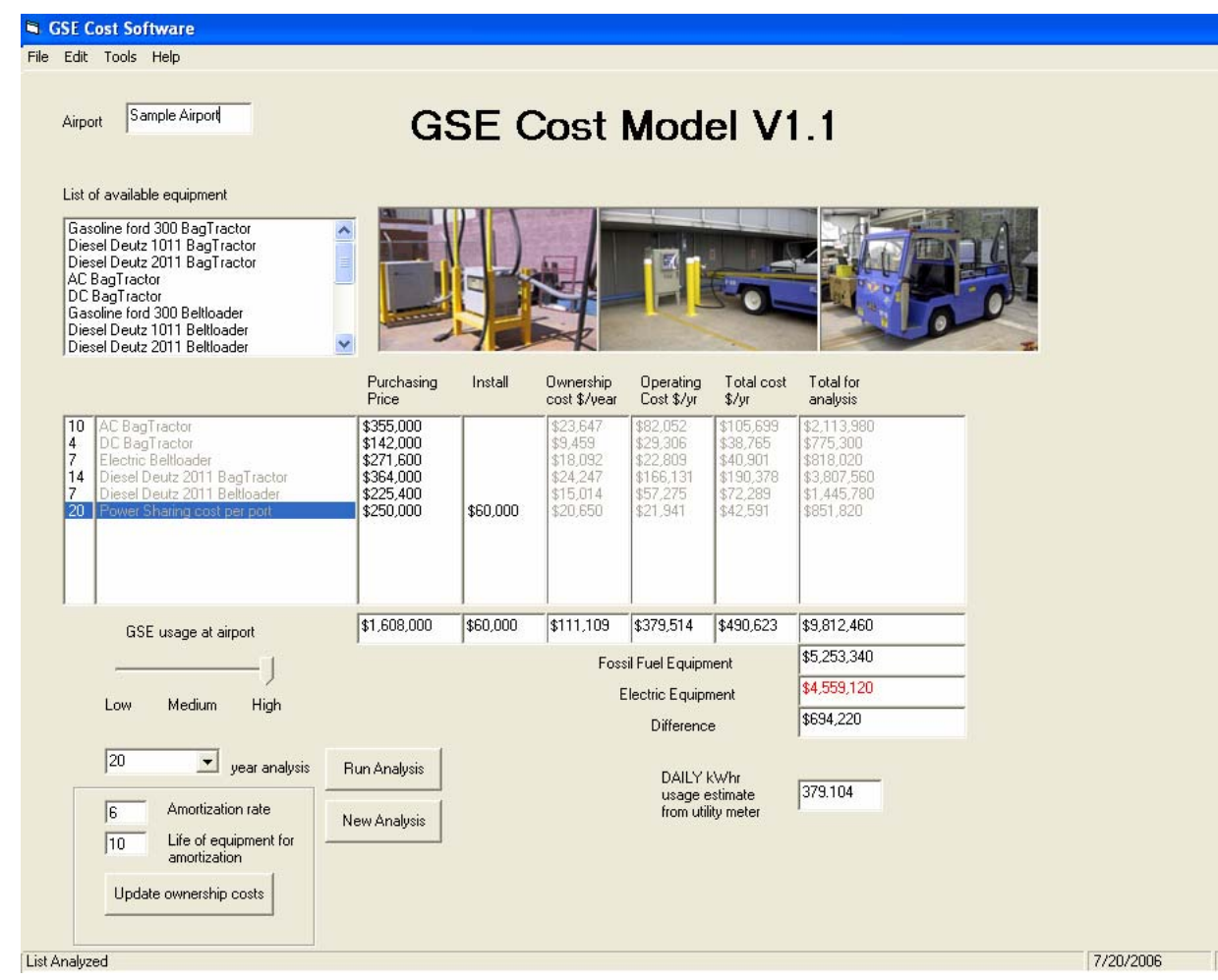

Figure 3-2. Ground support equipment cost model main page.

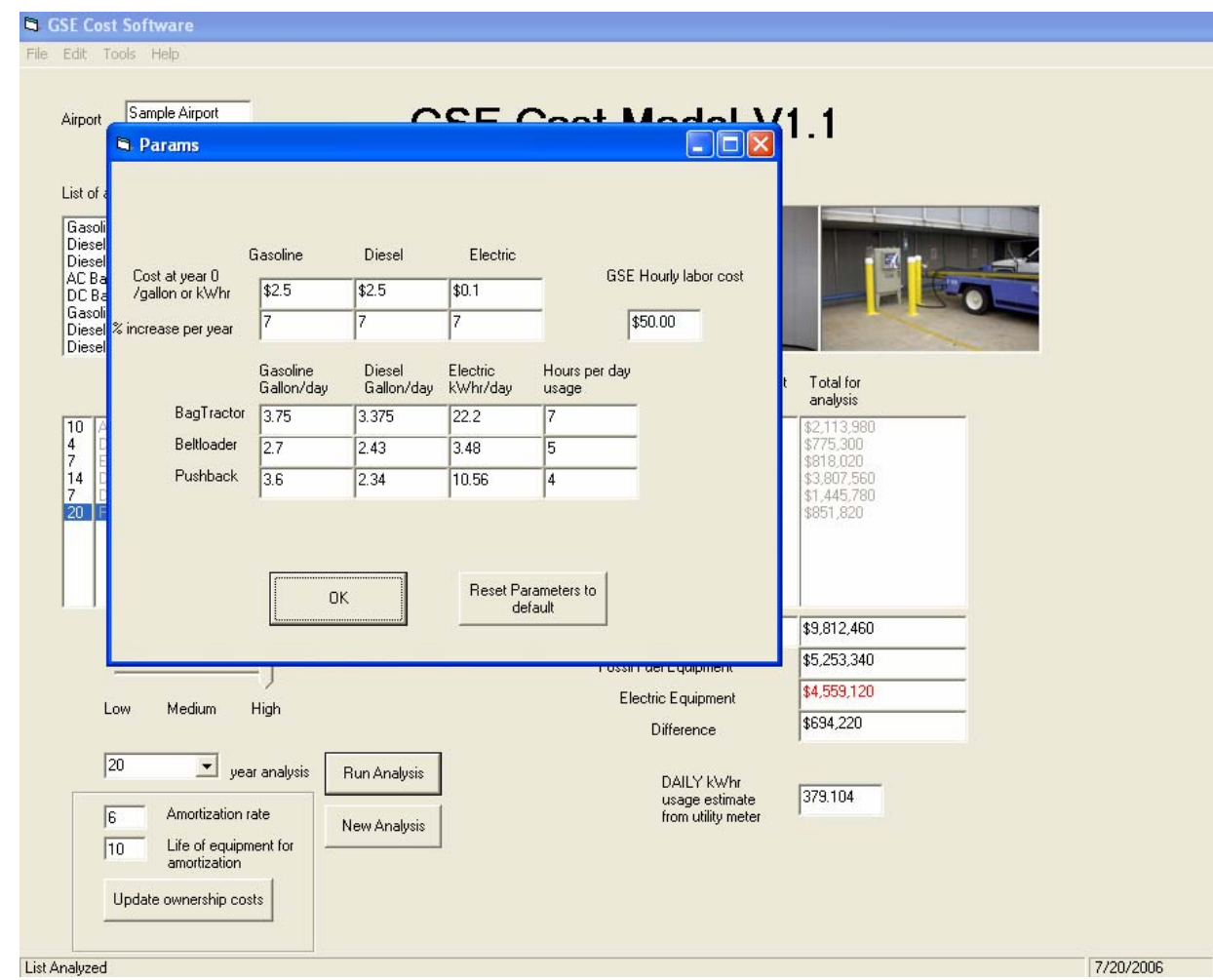

Figure 3-3. Fuel usages, cost, and escalator. 


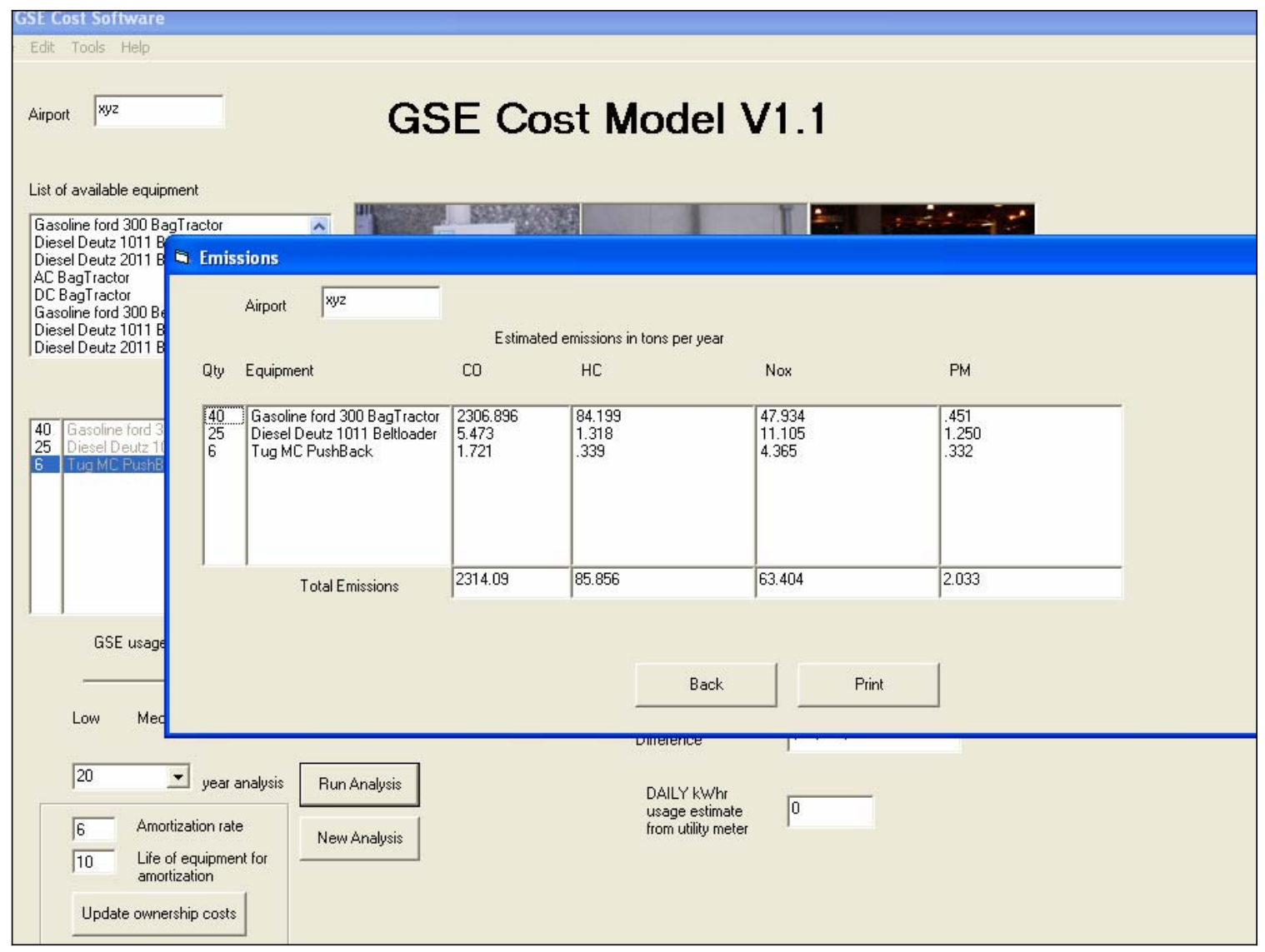

Figure 3-4. Emissions results.

Another feature under the "Tools" section is a table that itemizes O\&M costs for each piece of equipment selected (shown in Figure 3-5). This provides the user with a quick rundown of the individual O\&M cost components. It is important to note that for eGSE, the initial battery pack is included in the purchase of the equipment, and replacement battery purchases are treated as an O\&M expense and fall under the "General Maintenance" category in the unit operating cost table.

The model provides a database of both vehicles and chargers, but also allows the user to input their own vehicle or charger data for customized model runs. Figures 3-6 and 3-7 show an example of the vehicle input table and charger input table. The tables are accessed by selecting "Edit" at the top of the main page. Under the "Help" section of the model, there is an "Assumptions" write-up and a user "Manual" to assist with understanding and using the model. 


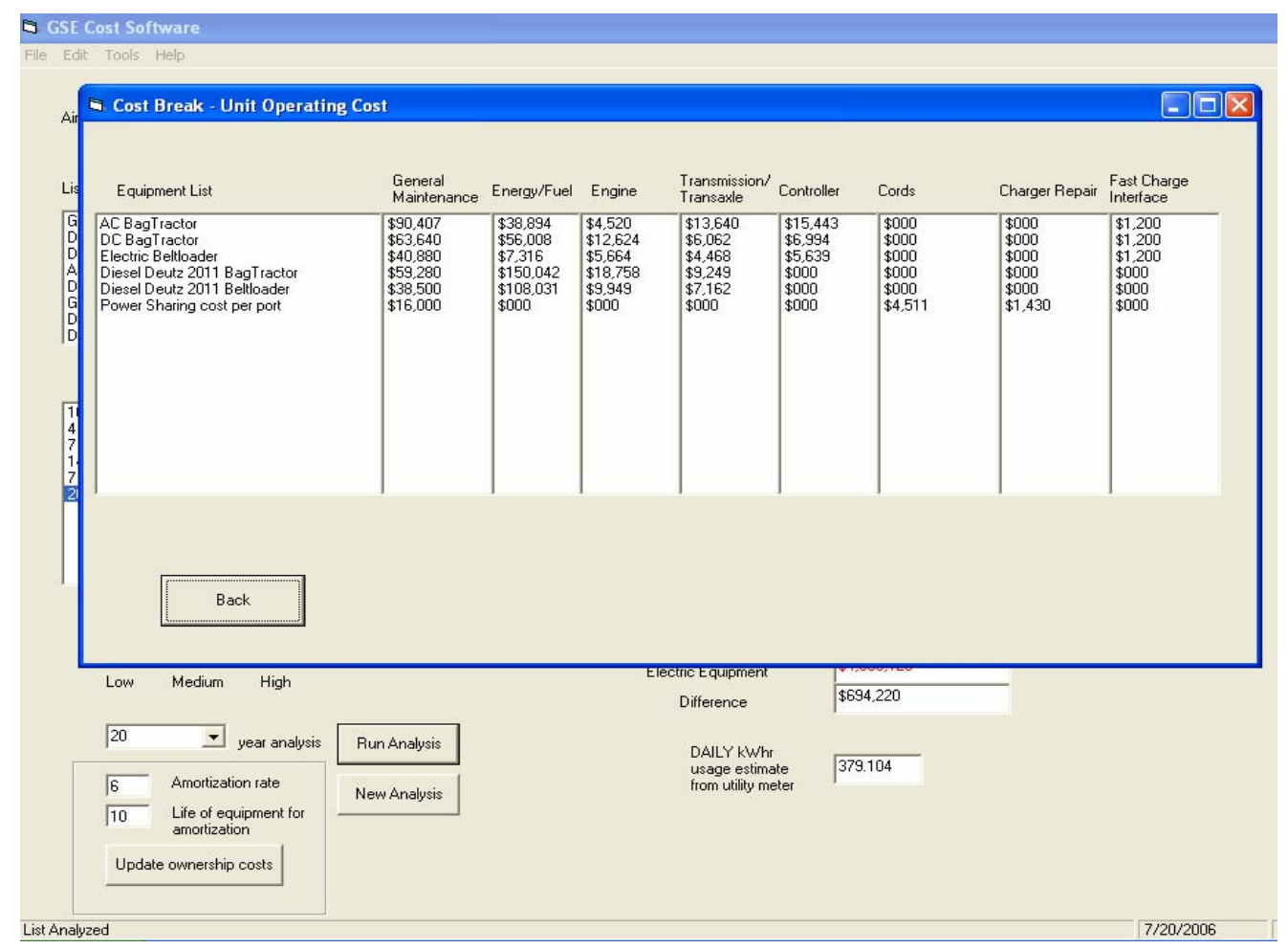

Figure 3-5. Unit operating cost.

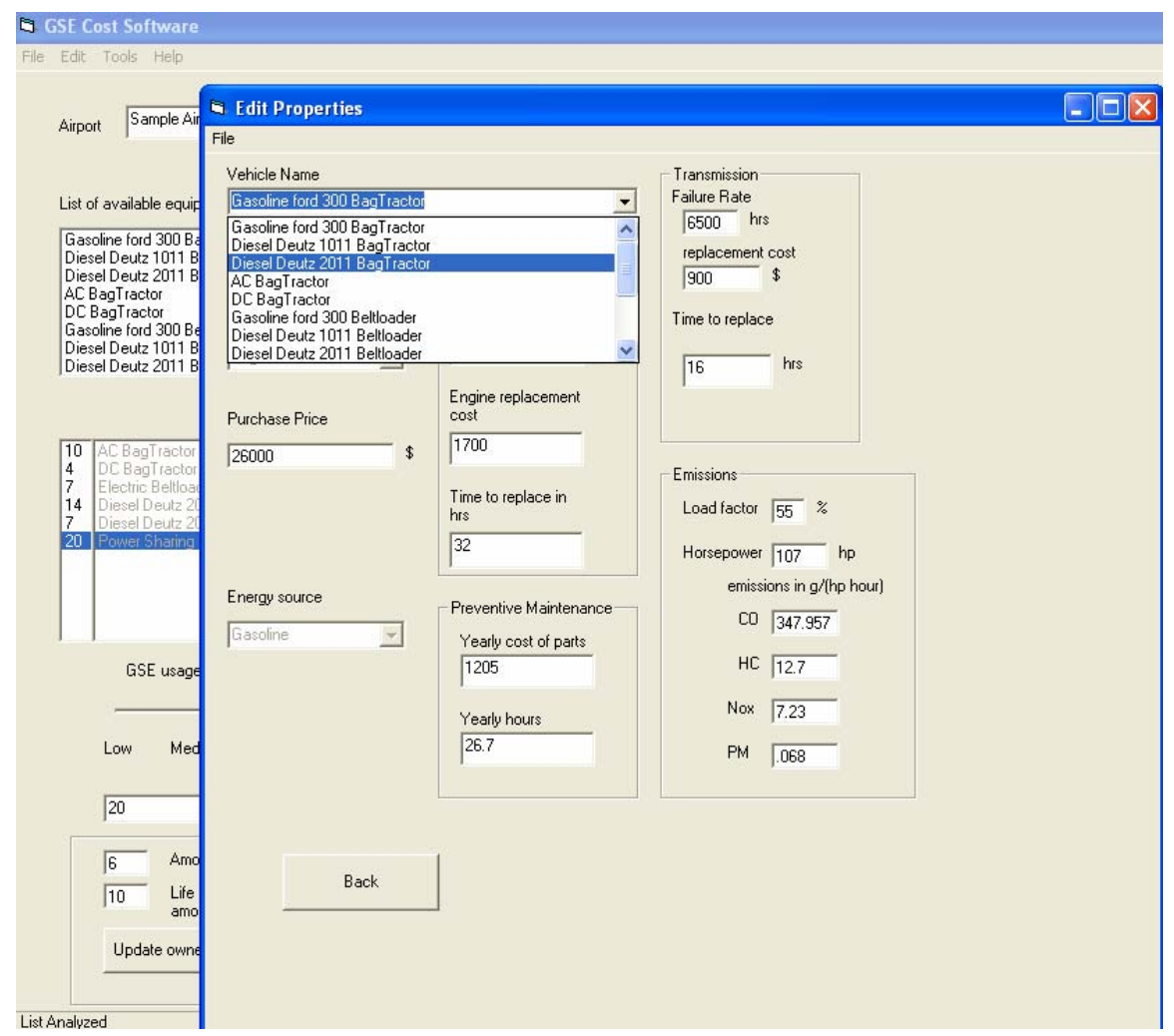

Figure 3-6. Vehicle edit table. 


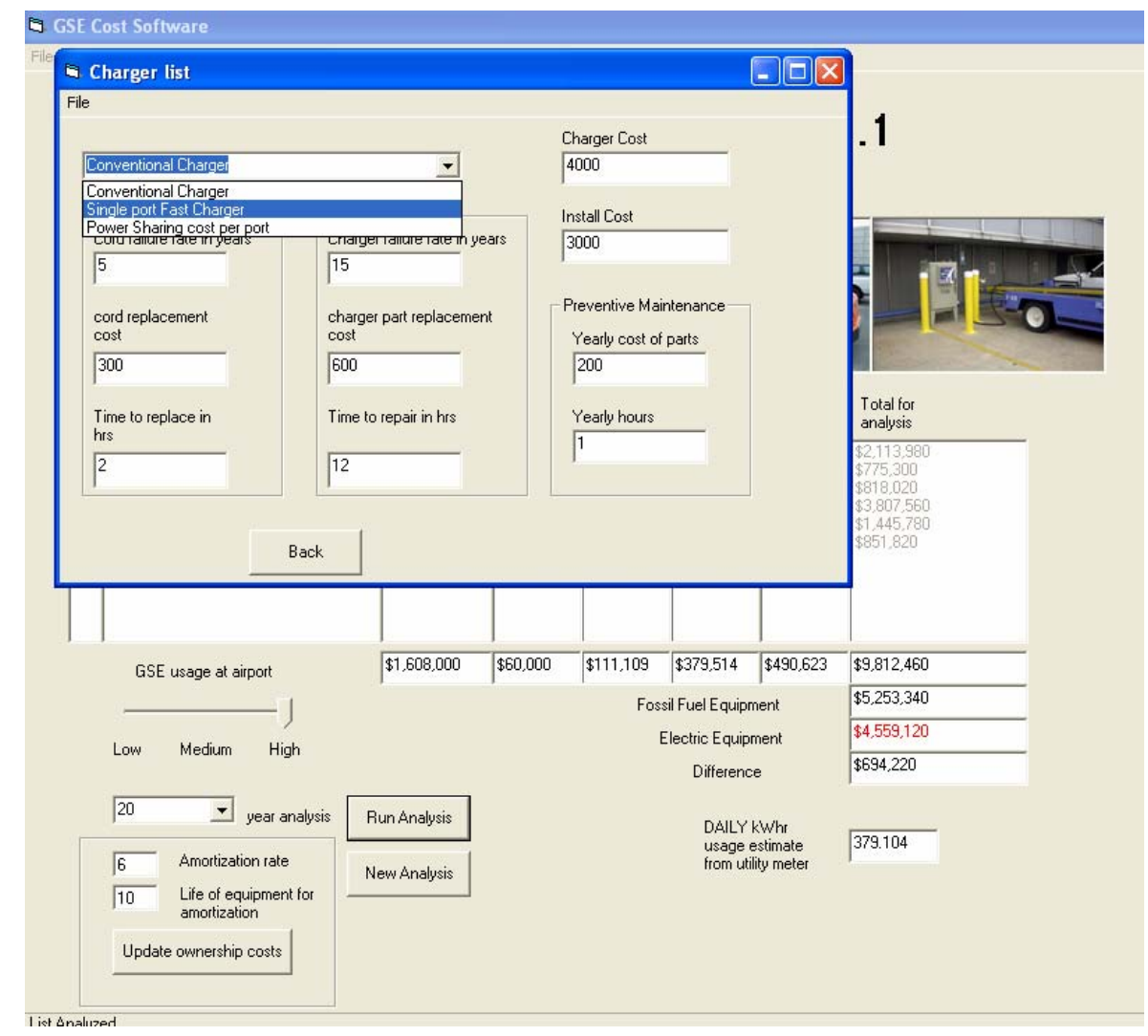

Figure 3-7. Charger edit table. 


\section{AIRPORT ANALYSIS}

This project reviewed four existing airport operations to accomplish the following objectives:

- Understand and retrieve available data to develop default parameters for the model, and run specific cost analysis at each airport location

- $\quad$ Develop strategies for achieving data that is not readily available

- $\quad$ Analyze a diverse group of airports to ensure the GSE Cost Model is flexible enough to be applied to a broad mix of airport scenarios.

The four airports scenarios analyzed in this study are labeled "A," "B," "C," and "D." Each airport is a major commercial airport and is described in general terms in order to justify the parameters selected in the model analysis. Each airport in the four scenarios either currently has, or expects to have in the near future, eGSE as described in each analysis.

\subsection{Airport "A"}

Airport "A" has a mild winter climate, with warm to hot summer months, and very flat terrain with no ramps or grades to contend with. Based on a review of the number of flights per day (approximately 80 flights per day), the number of equipment, and the terrain, Airport " $\mathrm{A}$ " is considered a medium-duty airport in regards to fuel use and hours of operation. The eGSE equipment and battery chargers analyzed for the Airport "A" scenario are shown in Tables 4-1 and 4-2, respectively.

Table 4-1. Airport "A" electric ground support equipment included in study.

\begin{tabular}{|llllr|}
\hline GSE Type & Original GSE Equipment & Replacement GSE & Battery Type & Quantity \\
\hline Baggage & Gasoline Ford 300 Baggage & Electric Baggage Tractor- & Flooded & 17 \\
Tractor & Tractor & DC Drive Type & & \\
Belt Loaders & Diesel Deutz 1011 Belt Loader & Electric Belt Loader & Flooded & 16 \\
Pushback & GT 1628/GT35 Diesel & 350E Pushback Tractors & Flooded & 7 \\
Tractors & Pushback Tractors & & & 40 \\
\hline Total & & & & 40 \\
\hline
\end{tabular}

Table 4-2. Airport "A" electric ground support equipment battery chargers.

\begin{tabular}{|lr|}
\hline Charger Type & Quantity \\
\hline Multi-port Fast Chargers (number of ports) & 4 \\
Single Port Fast Chargers & 8 \\
\hline Total Ports & 12 \\
\hline Total DC Output Capacity-153 kW \\
\hline
\end{tabular}

Financial results of running scenario Airport "A" are shown in Figure 4-1, which is a screen print of the main page of the model after inputting all parameters and running the model. Also provided in Figure 4-1 are some of the initial input parameters, including the vehicle type and amounts and the charger(s) selected for this airport. Additionally, the number of years selected by the user to run the model, amortization rates, and equipment life are shown. Figure 4-2 provides fuel consumption estimates, based on a medium-duty airport, starting point for the fuel with escalation rates, and the labor rate. 


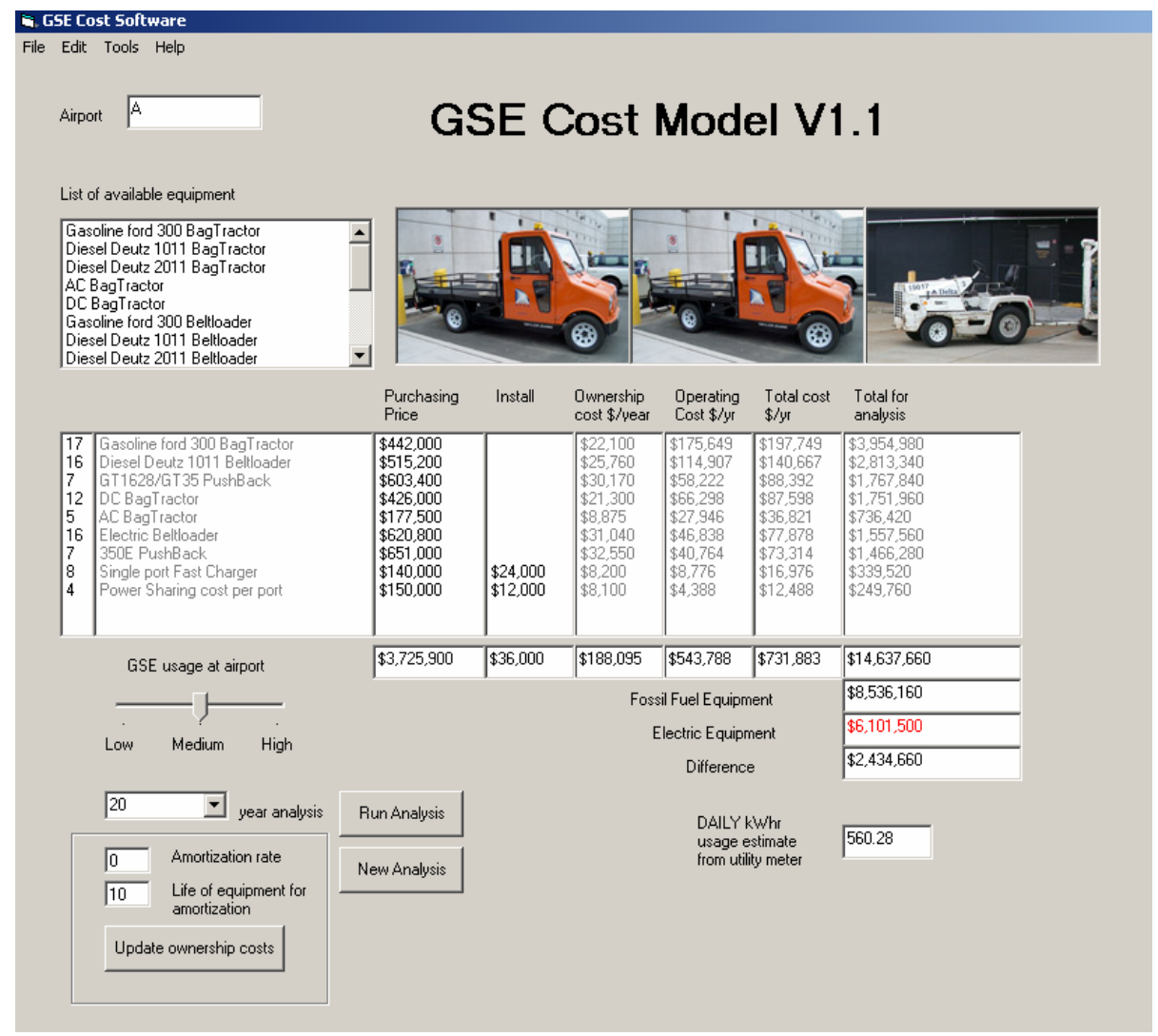

Figure 4-1. Results of Airport “A” main screen.

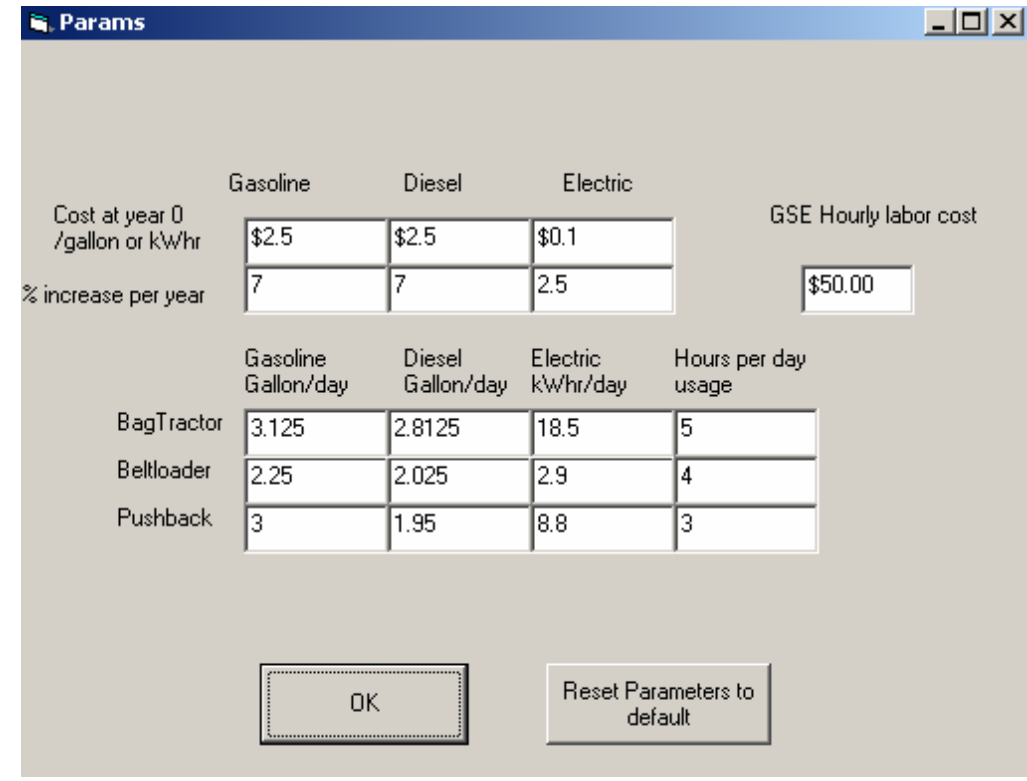

Figure 4-2. Airport "A" fuel and labor parameters.

Figure 4-3 provides operating costs on a unit basis for all equipment, including the charge stations. As can be seen, energy fuel costs for ICE GSE is by far the largest cost component driving overall economics of the model. 


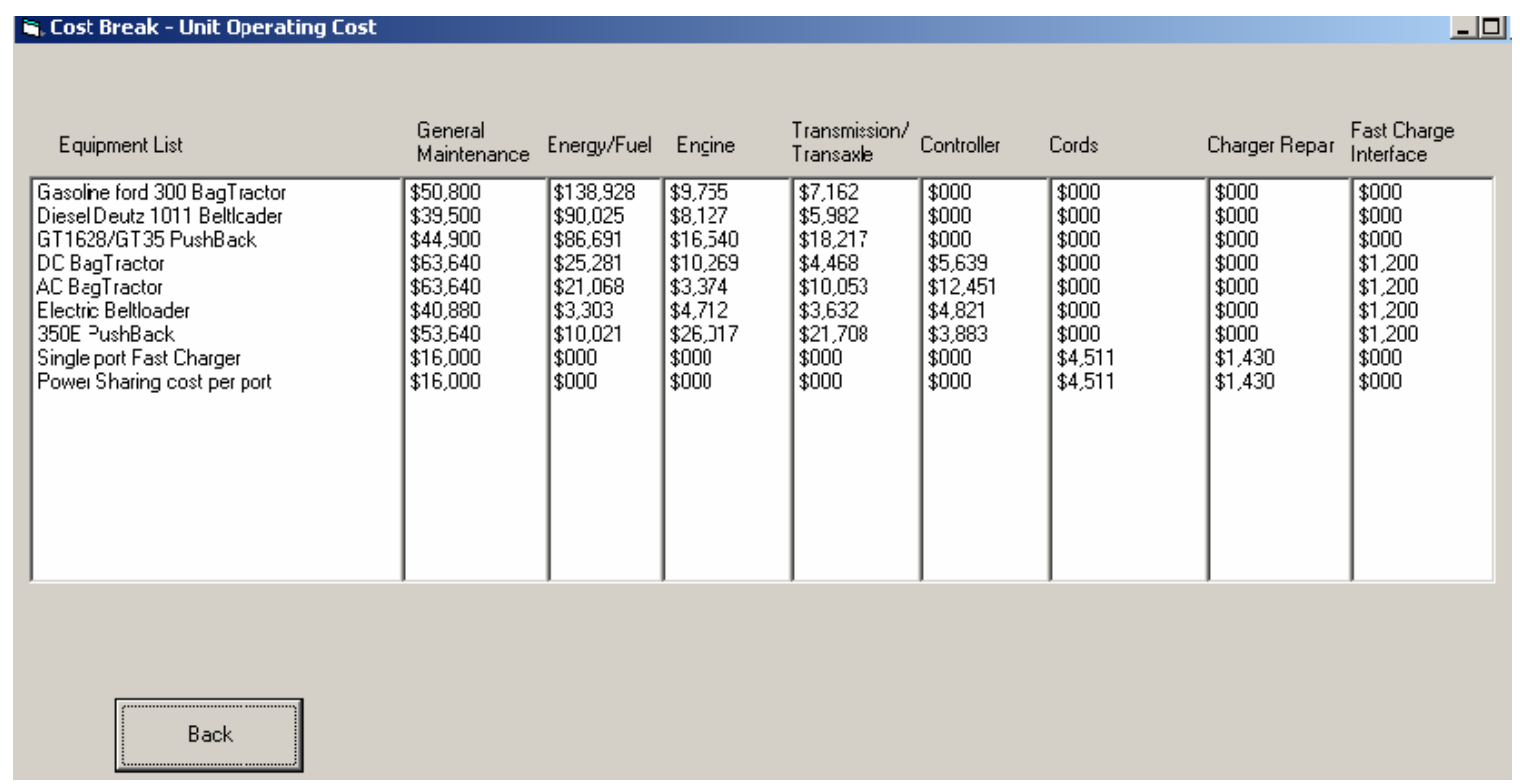

Figure 4-3. Airport "A" unit operating costs.

Figure 4-4 shows results of Airport "A" being analyzed in this study by plotting the total cumulative costs versus years.

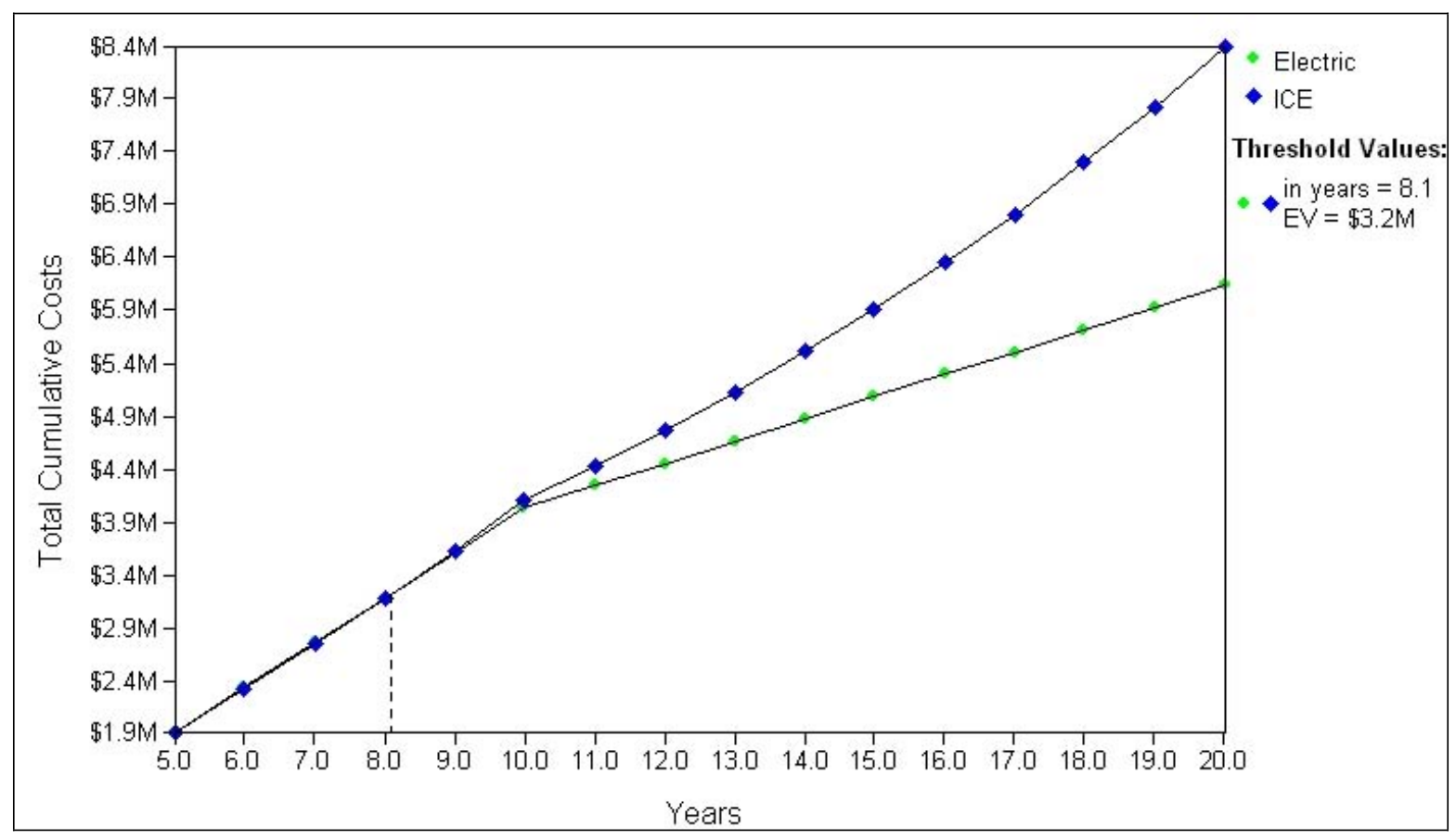

Figure 4-4. Airport "A" breakeven point for electric ground support equipment versus internal combustion engine ground support equipment for all three types of ground support equipment.

This airport is a medium-use airport from a fuel-use standpoint. This airport replaced a mix of 40 ICE GSE vehicles (17 baggage tractors, 16 belt loaders, and 7 pushback tractors) with eGSE. The charger system is a fast-charge, multi-port type that provides one port for every two vehicles. The 
breakeven point in this scenario is 8.1 years with annual fuel escalators at $7 \%$ for fossil fuel and $2.5 \%$ for electricity.

To further understand the impacts of varying fossil fuel escalation rates, Figure 4-5 plots a varying fossil fuel escalation rate per year versus years of analysis. In Figure 4-5, if there is a 9\% average annual increase in fossil fuel costs, then eGSE has a payback within approximately 5 years. If fuel cost increases remain relatively low at $4 \%$ annually, then the payback for eGSE is approximately 13 years.

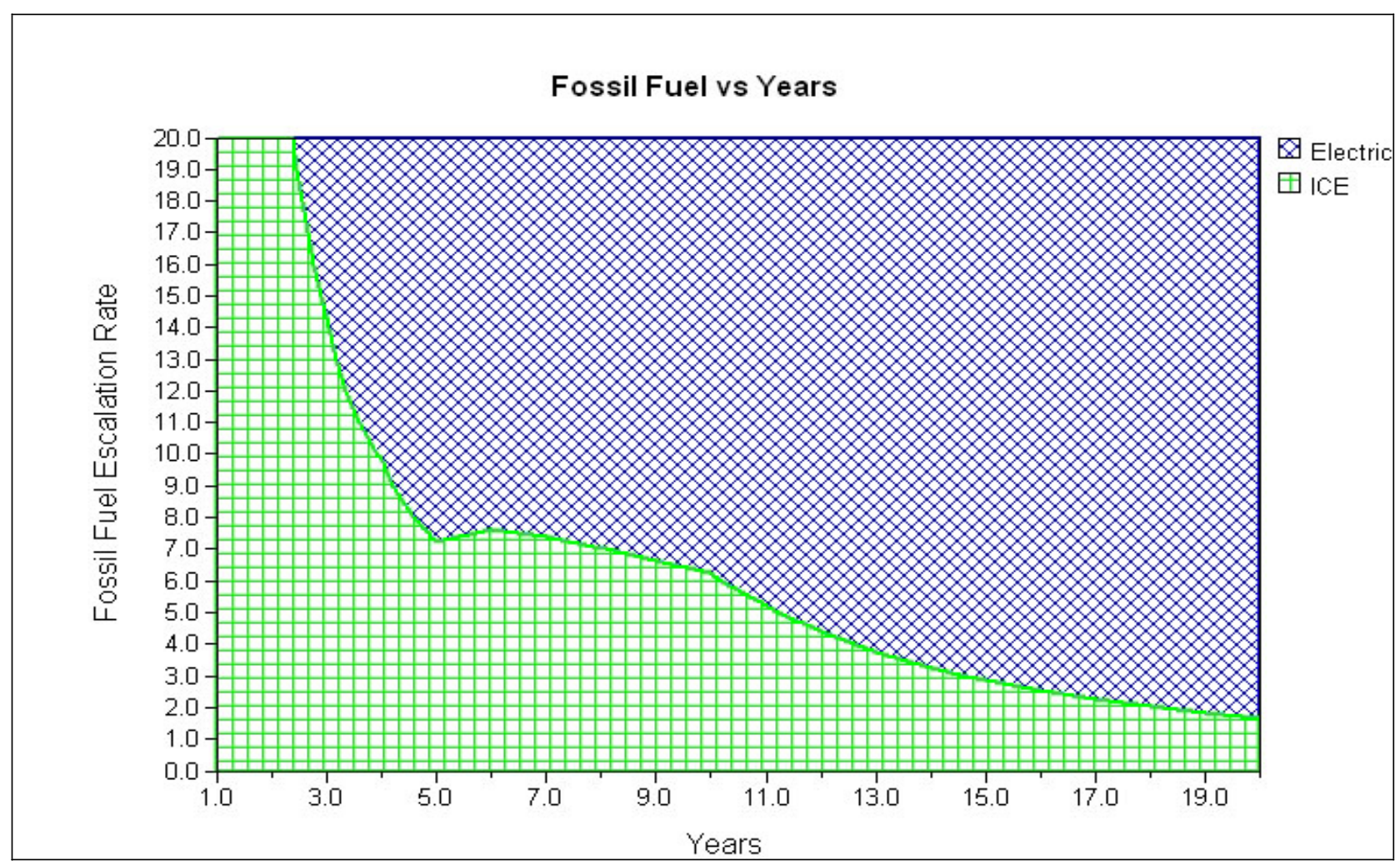

Figure 4-5. Airport "A" sensitivity analysis for all three ground support equipment types.

Figures 4-6 through 4-8 show the sensitivities of each individual piece of equipment with all other parameters treated the same as before. The electric baggage tractors have by far the fastest payback of the three GSE vehicles presented in this study, followed by the belt loaders and then the pushback tractors. Not surprisingly, the baggage tractors are also the heaviest fuel users of the three GSE vehicles. Figures 4-7 and 4-8 also show payback sensitivity of the pushback tractors and belt loaders when purchased new.

Because of higher capital cost and lower fuel use, the pushback tractors have a longer payback than the baggage tractors and belt loaders. If capital costs are significantly lowered through grant cost-share programs or conversion of gas or diesel to electric, payback can occur much sooner, making the electric pushback tractors very attractive. 


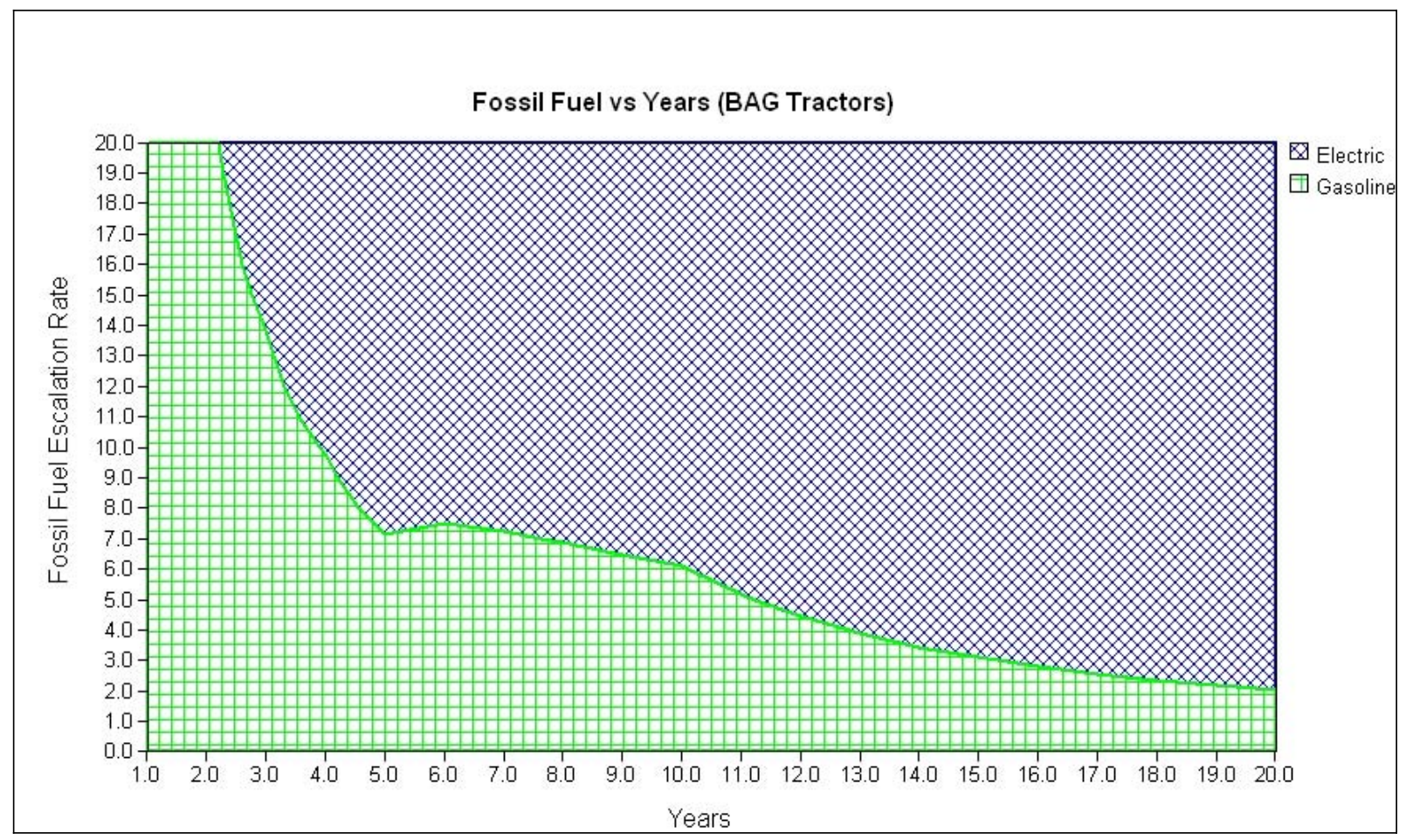

Figure 4-6. Airport "A" sensitivity analysis for baggage tractors.

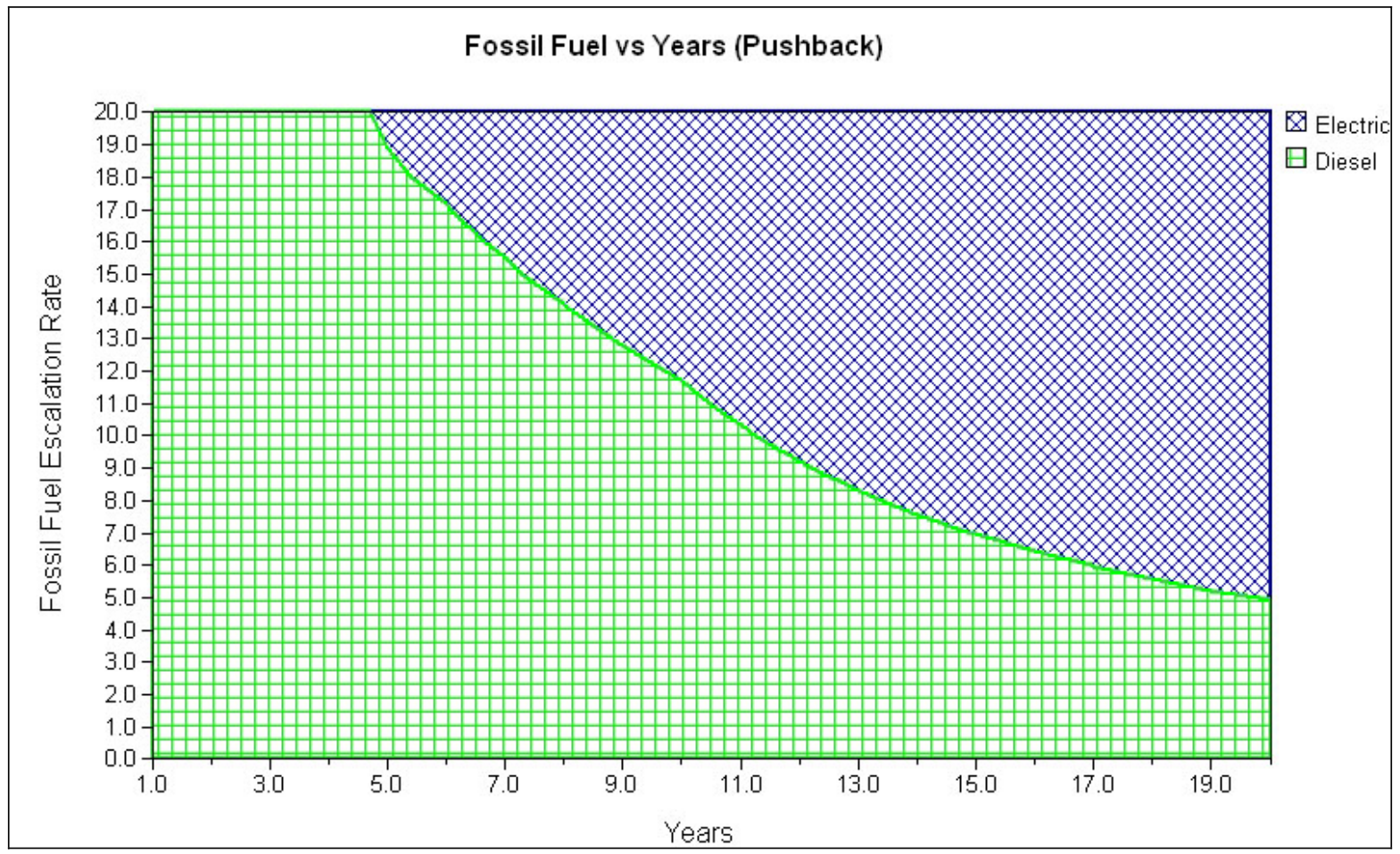

Figure 4-7. Airport "A" sensitivity analysis for pushback tractors. 


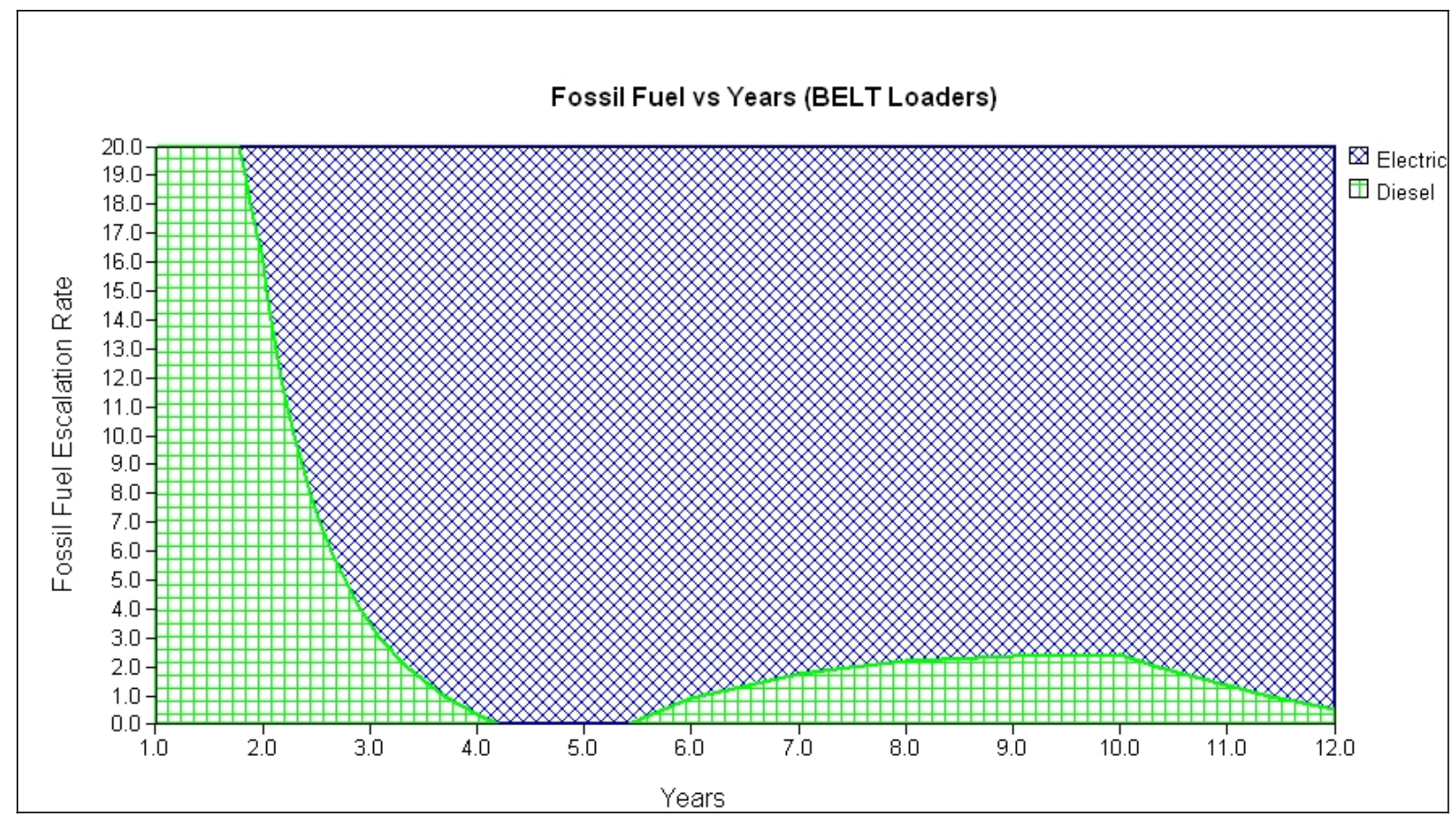

Figure 4-8. Airport "A" sensitivity analysis for belt loaders.

\subsubsection{Emissions}

The GSE Cost Model includes an emissions module that estimates the amount of tailpipe emissions saved by replacing ICE GSE with eGSE. Table 4-3 shows emissions results for Airport "A." The base emissions rates were provided by the FAA EDMS Emissions Model Version 4.12, which provides emissions rates for each type of GSE.

Table 4-3. Airport "A" emissions savings in tons per year.

\begin{tabular}{|llrrrr|}
\hline Quantity & Description & CO & HC & NOx & PM \\
\hline 17 & Baggage Tractors & 700.308 & 25.560 & 14.551 & 0.137 \\
16 & Belt Loaders & 2.802 & 0.675 & 5.686 & 0.640 \\
7 & Pushback Tractors & 1.751 & 0.345 & 4.441 & 0.338 \\
\hline \multicolumn{5}{|l}{$\mathrm{CO}=$ carbon } & monoxide, $\mathrm{HC}=$ total hydrocarbons, NOx $=$ oxides of nitrogen, $\mathrm{PM}=$ particulate matter \\
\hline
\end{tabular}

\subsection{Airport "B"}

Airport "B" has a cold winter climate with mild to warm summer months. Terrain is very challenging with a long, steep ramp underground to the baggage make-up area. Airport " $\mathrm{B}$ " has only baggage tractors included in this analysis. Based on a review of the number of flights per day (approximately 209 flights per day), the number of equipment, and the terrain, Airport "B" is designated as a high-duty airport scenario. The GSE equipment and battery chargers analyzed for the Airport "B" scenario are shown in Tables 4-4 and 4-5, respectively. 
Table 4-4. Airport "B" ground support equipment included in the study.

\begin{tabular}{|llllr|}
\hline GSE Type & Original GSE Equipment & Replacement GSE & Battery Type & Quantity \\
\hline Baggage Tractor & Diesel Deutz 1011 & $\begin{array}{l}\text { Electric Baggage } \\
\text { Tractor-AC Drive Type }\end{array}$ & Sealed-GEL & 27 \\
\hline
\end{tabular}

Table 4-5. Airport "B" electric ground support equipment battery chargers.

\begin{tabular}{|lr|}
\hline Charger Type & Quantity \\
\hline Multi-port Fast Chargers & 0 \\
Single Port Fast Chargers & 10 \\
\hline Total & 10 \\
\hline Total DC Output Capacity-150 kW & \\
\hline
\end{tabular}

As can be seen in Figure 4-9, over a 20-year period the eGSE option saved a little over $\$ 1.7$ million, with operating costs accounting for the overall savings of the eGSE. Daily energy use by the eGSE totals $599.4 \mathrm{kWh}$.

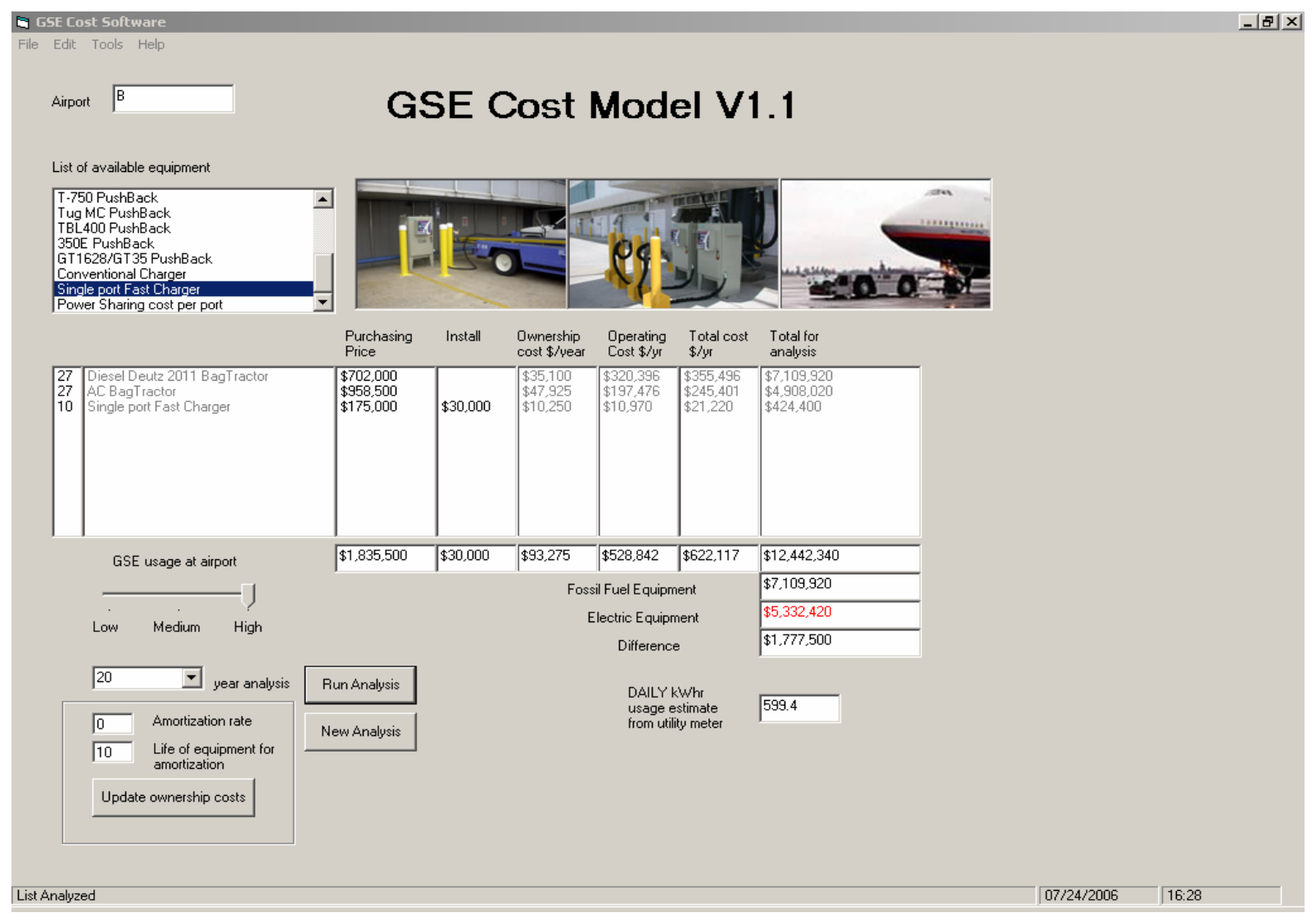

Figure 4-9. Results of Airport "B" main screen.

Figure 4-10 shows fuel costs, fuel escalators, and labor rate for this particular analysis. Default parameters were used with diesel fuel starting at $\$ 2.50 /$ gal, with an annual escalation rate of $7 \%$, and electricity starting at 10 cents per $\mathrm{kWh}$, with a $2.5 \%$ annual escalation rate. 


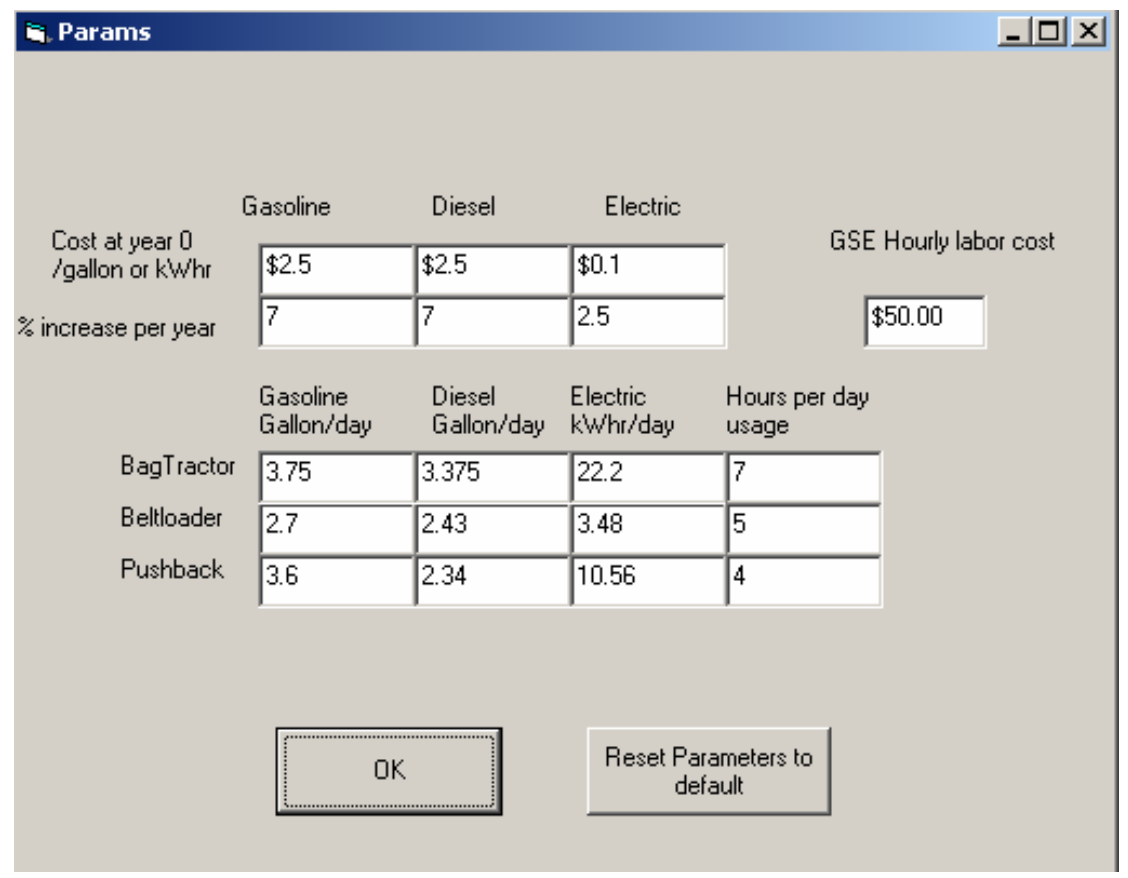

Figure 4-10. Airport "B" fuel and labor parameters.

Figure 4-11 shows unit operating costs for each type of GSE and charging equipment. The general maintenance component for eGSE includes battery pack replacement costs over a 20 -year period, which was included in this scenario.

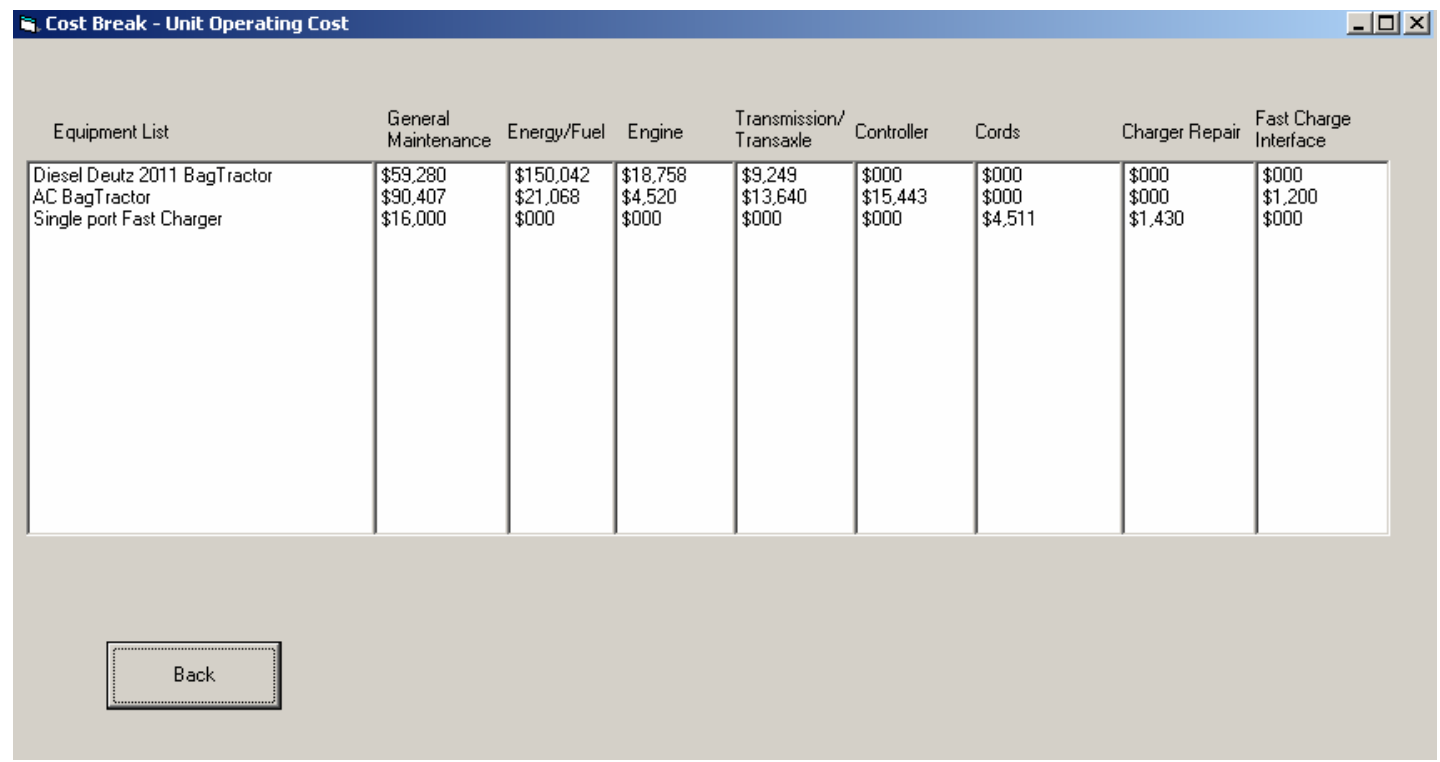

Figure 4-11. Airport "B" unit operating costs.

The breakeven point is provided in Figure 4-12, which plots total costs for Airport "B" versus years. There are three crossover points at years 2.3,3.7, and 10.1, with the last crossover point sustaining the eGSE cost advantage. The crossover point takes longer for Airport "B" because of additional battery costs due to a requirement of utilizing sealed batteries. 


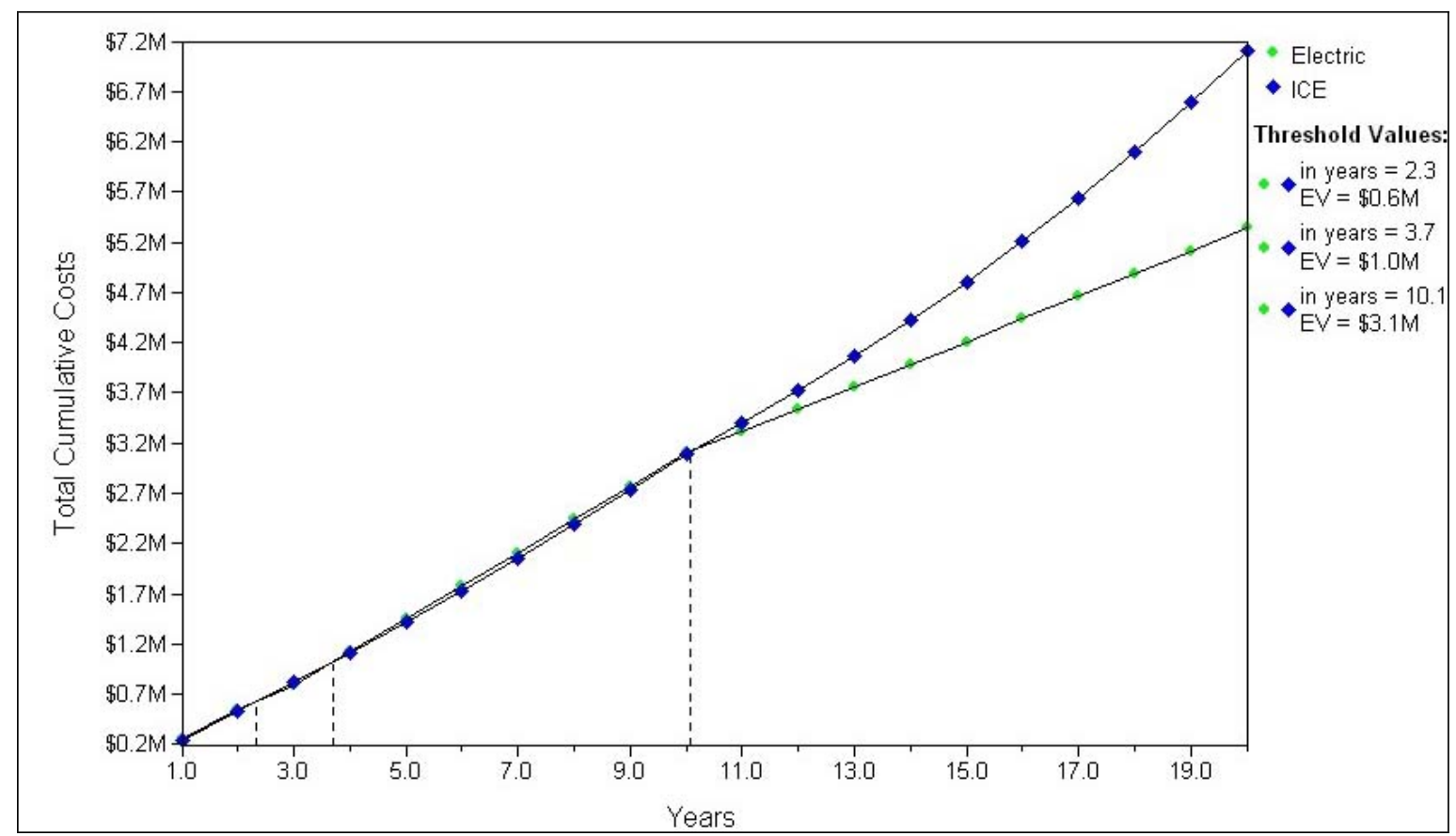

Figure 4-12. Airport "B" breakeven point for electric ground support equipment versus internal combustion engine ground support equipment.

Figures 4-13 and 4-14 are sensitivity graphs that show fossil fuel annual escalation rates versus years of operation. Figure 4-13 shows an anomaly where it appears that after the first 3 years, eGSE is cost effective at close to zero fuel escalation, but that is only temporary until the batteries are replaced at the end of the third year, increasing the costs of the eGSE. Reviewing the results of Figure 4-14 shows that after the sharp initial increase due to battery pack purchases beginning at the end of the third year, electric tops out at about a $9 \%$ annual fossil fuel escalation rate after about 5.5 years.

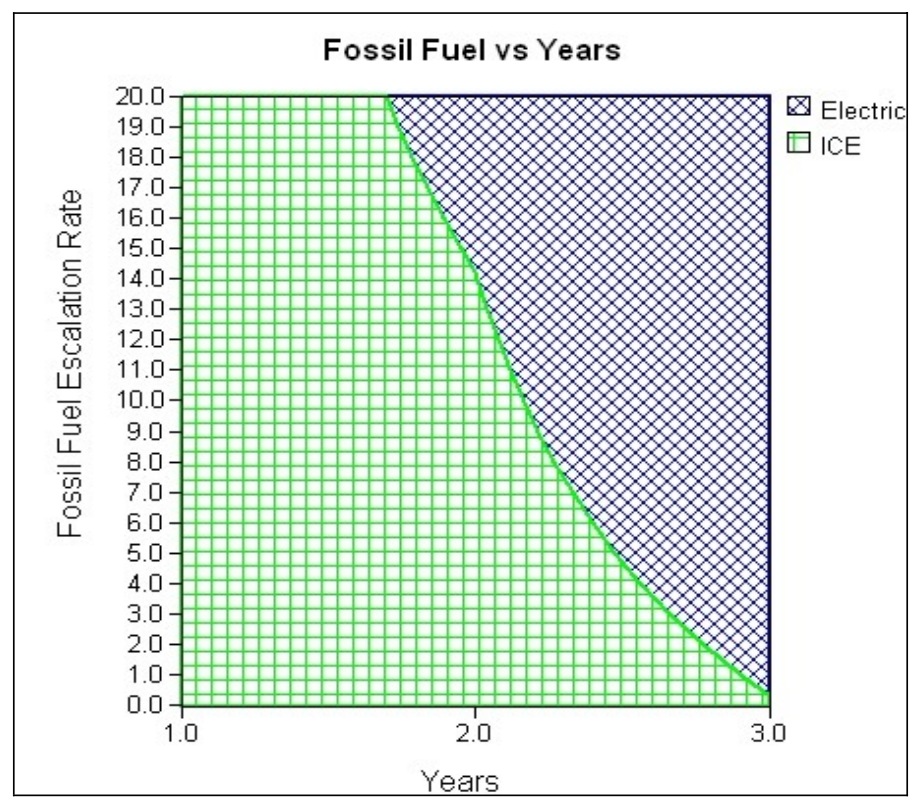

Figure 4-13. Airport “B” sensitivity analysis for baggage tractors years 0 through 3 . 


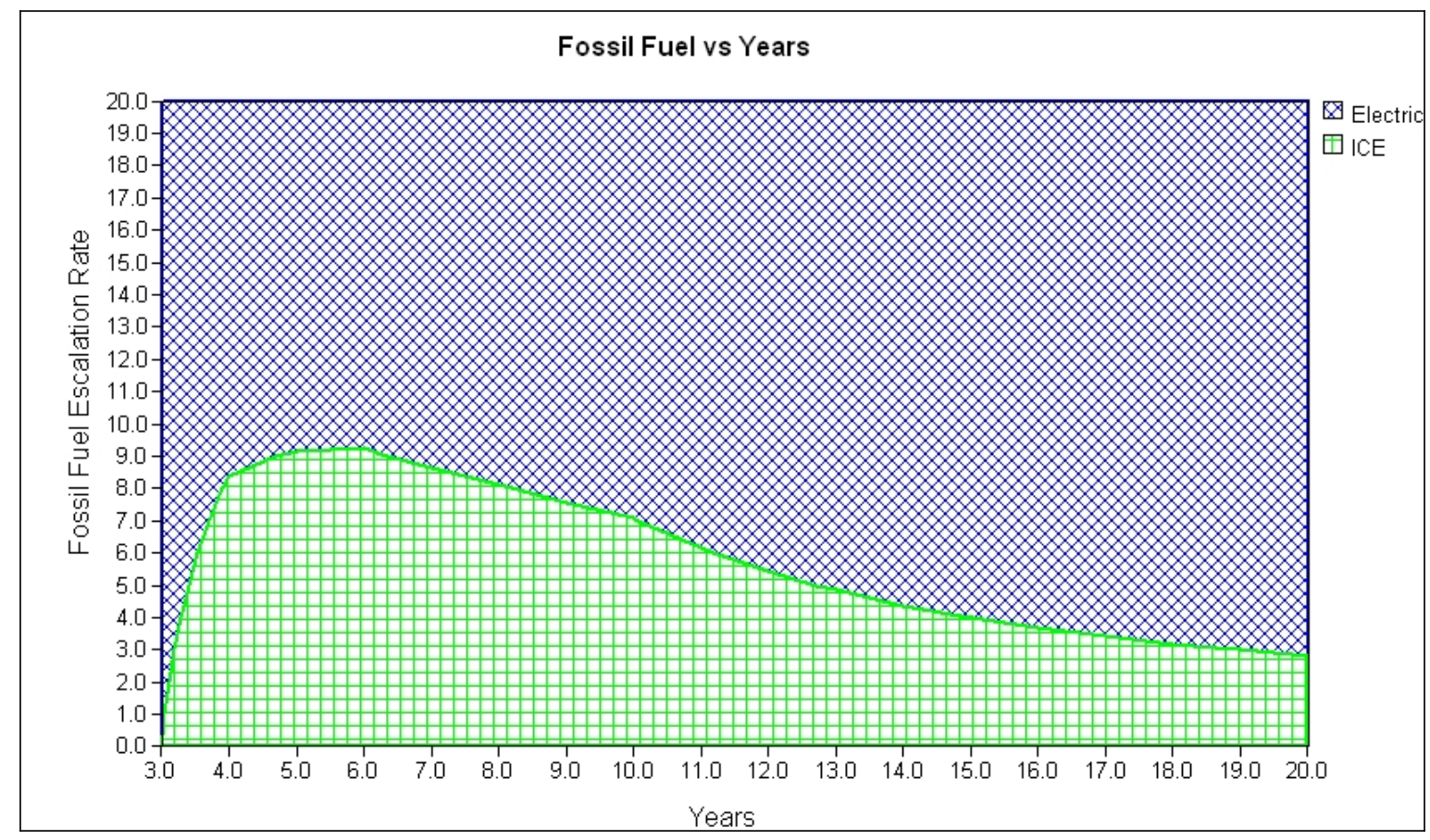

Figure 4-14. Airport "B” sensitivity analysis for baggage tractors years 3 through 20.

\subsubsection{Emissions}

Emissions results for Airport "B," where all 27 vehicles replaced were diesel baggage tractors, are shown in Table 4-6.

Table 4-6. Airport "B" emissions savings in tons per year.

\begin{tabular}{|llcccr|}
\hline Quantity & Description & CO & HC & NOx & PM \\
\hline 27 & Baggage Tractors & 5.078 & 2.138 & 17.074 & 2.480 \\
\hline $\mathrm{CO}=$ carbon & monoxide, $\mathrm{HC}=$ total hydrocarbons, NOx $=$ oxides of nitrogen, $\mathrm{PM}=$ particulate matter & \\
\hline
\end{tabular}

\subsection{Airport "C"}

Airport "C" is similar to Airport "A" in that it has a mild winter climate with warm summer months, occasional hot days, and very flat terrain with no ramps or grades to contend with. Based on the flights per day (approximately 56 flights per day), the number of equipment, and the terrain, this airport is designated as a medium-duty airport scenario. The GSE equipment and battery chargers analyzed for the Airport "C" scenario are shown in Tables 4-7 and 4-8, respectively. 
Table 4-7. Airport "C" ground support equipment included in the study.

\begin{tabular}{|c|c|c|c|c|}
\hline GSE Type & Original GSE Equipment & Replacement GSE & Battery Type & Quantity \\
\hline $\begin{array}{l}\text { Baggage } \\
\text { Tractor }\end{array}$ & $\begin{array}{l}\text { Gasoline Ford } 300 \text { Baggage } \\
\text { Tractor }\end{array}$ & $\begin{array}{l}\text { Electric Baggage Tractor- } \\
\text { DC Drive Type }\end{array}$ & Flooded & 16 \\
\hline $\begin{array}{l}\text { Belt } \\
\text { Loaders }\end{array}$ & $\begin{array}{l}\text { (7) Diesel Deutz } 1011 \text { Belt Loader } \\
\text { and (7) Ford } 300 \text { Belt Loader }\end{array}$ & $\begin{array}{l}\text { Electric Belt Loader-DC } \\
\text { Drive Type }\end{array}$ & Flooded & 14 \\
\hline $\begin{array}{l}\text { Pushback } \\
\text { Tractors }\end{array}$ & $\begin{array}{l}\text { GT 1628/GT35 Diesel Pushback } \\
\text { Tractors }\end{array}$ & 350E Pushback Tractors & Flooded & 6 \\
\hline Total & & & & 36 \\
\hline
\end{tabular}

Table 4-8. Airport "C" electric ground support equipment battery chargers.

\begin{tabular}{|lr|}
\hline Charger Type & Quantity \\
\hline Multi-port Fast Chargers & 12 \\
Single Port Fast Chargers & 0 \\
\hline Total Ports & 12 \\
\hline Total DC Output Capacity—93 kW & \\
\hline
\end{tabular}

Figure 4-15 presents the main screen of Airport "C" and shows that over a 20-year period, at a $0 \%$ amortization rate, eGSE savings over ICE GSE amount to $\$ 2.1$ million. Electricity sales from the eGSE amount to $561 \mathrm{kWh}$ daily.

Figure 4-16 shows fuel cost, fuel use, and labor use for Airport "C," a medium-duty airport. Built into this scenario is gasoline and diesel starting at $\$ 2.50$ per gallon, with a $7 \%$ annual escalator rate, and electricity starting at 10 cents per $\mathrm{kWh}$, with a $2.5 \%$ annual escalator rate. 


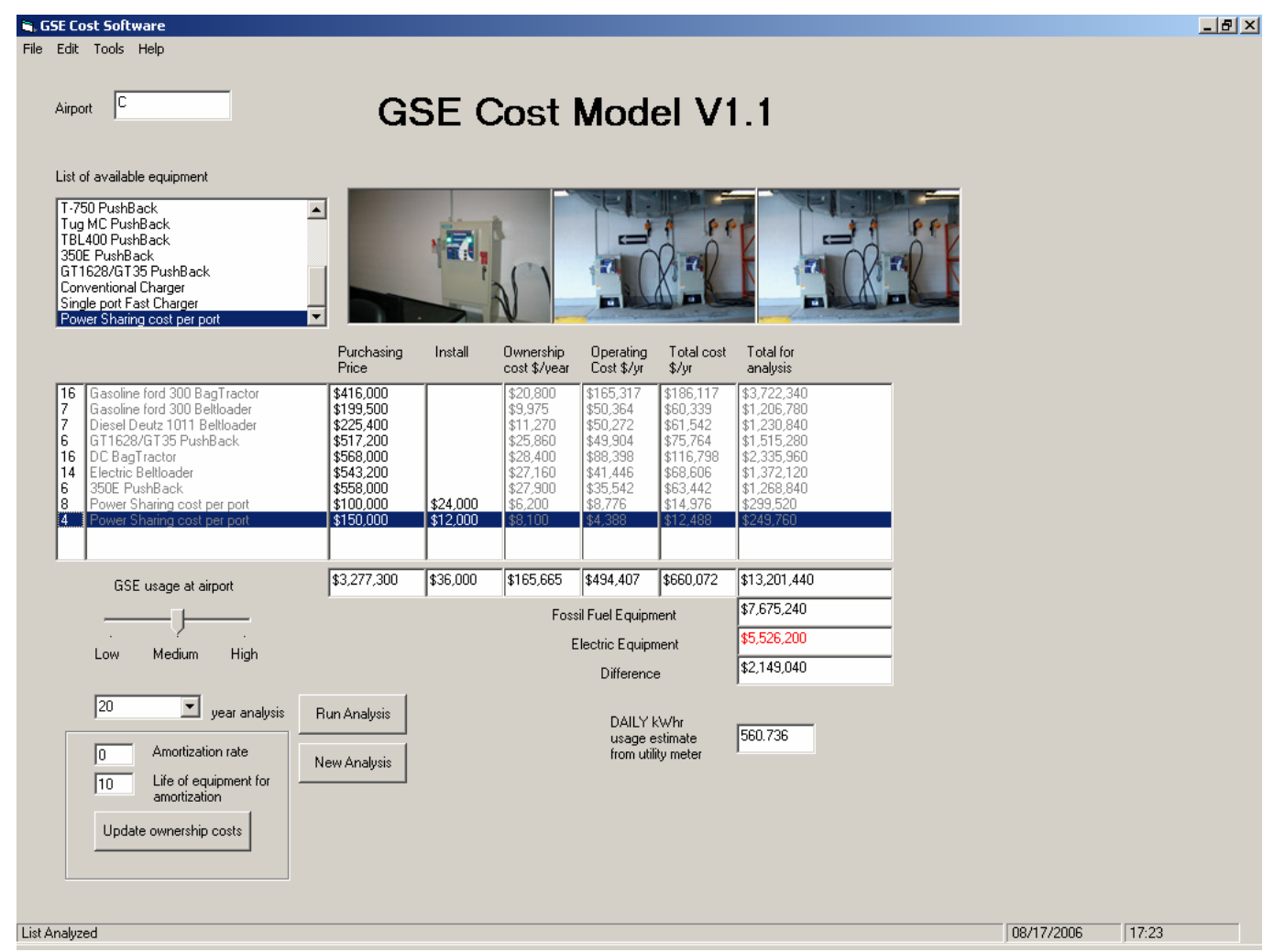

Figure 4-15. Results of Airport "C" main screen.

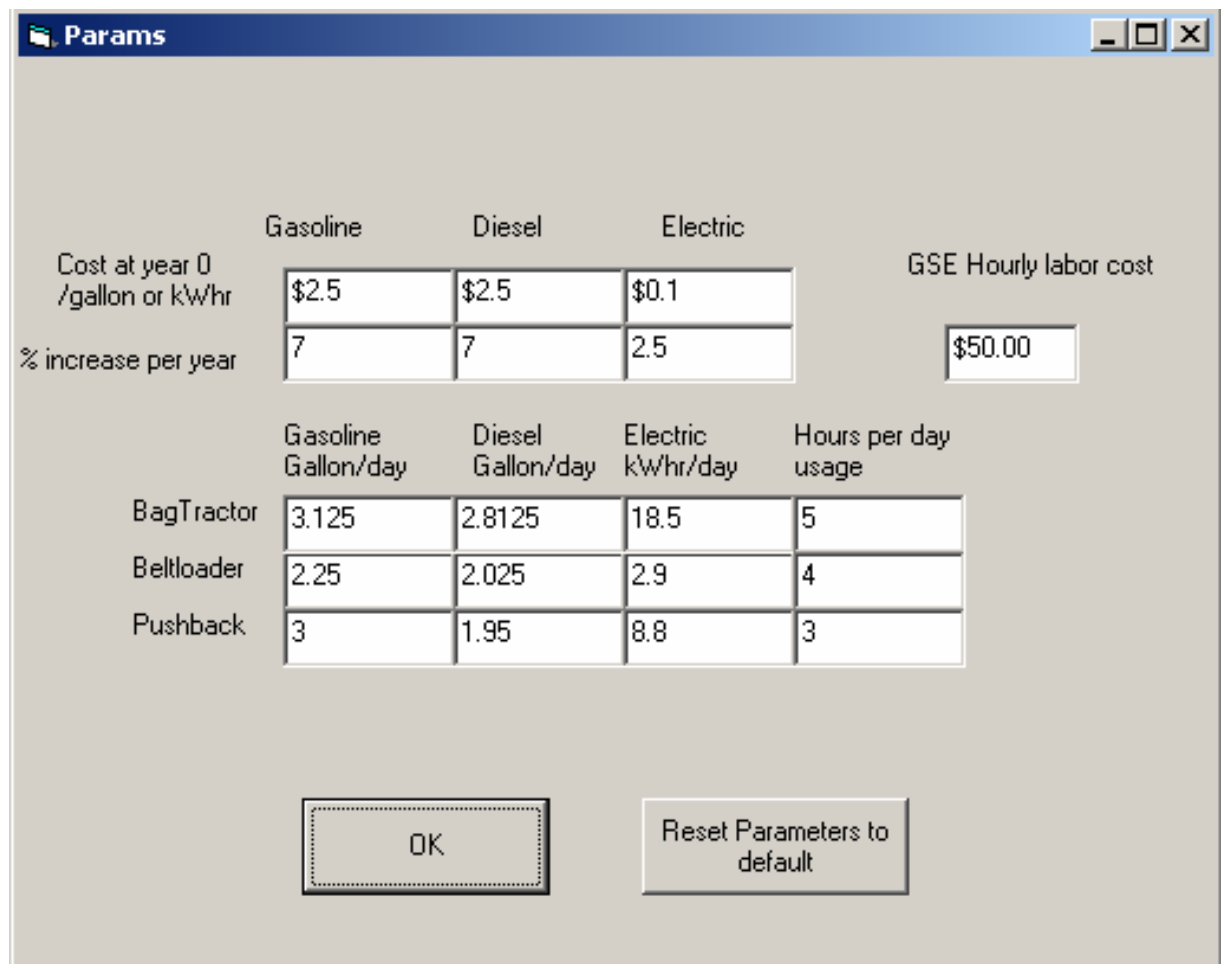

Figure 4-16. Airport "C" fuel and labor parameters. 
Unit operating costs are provided in Figure 4-17, with fuel costs being the major driver for ICE GSE, and the general maintenance category being the main driver for eGSE (mostly due to battery replacement costs).

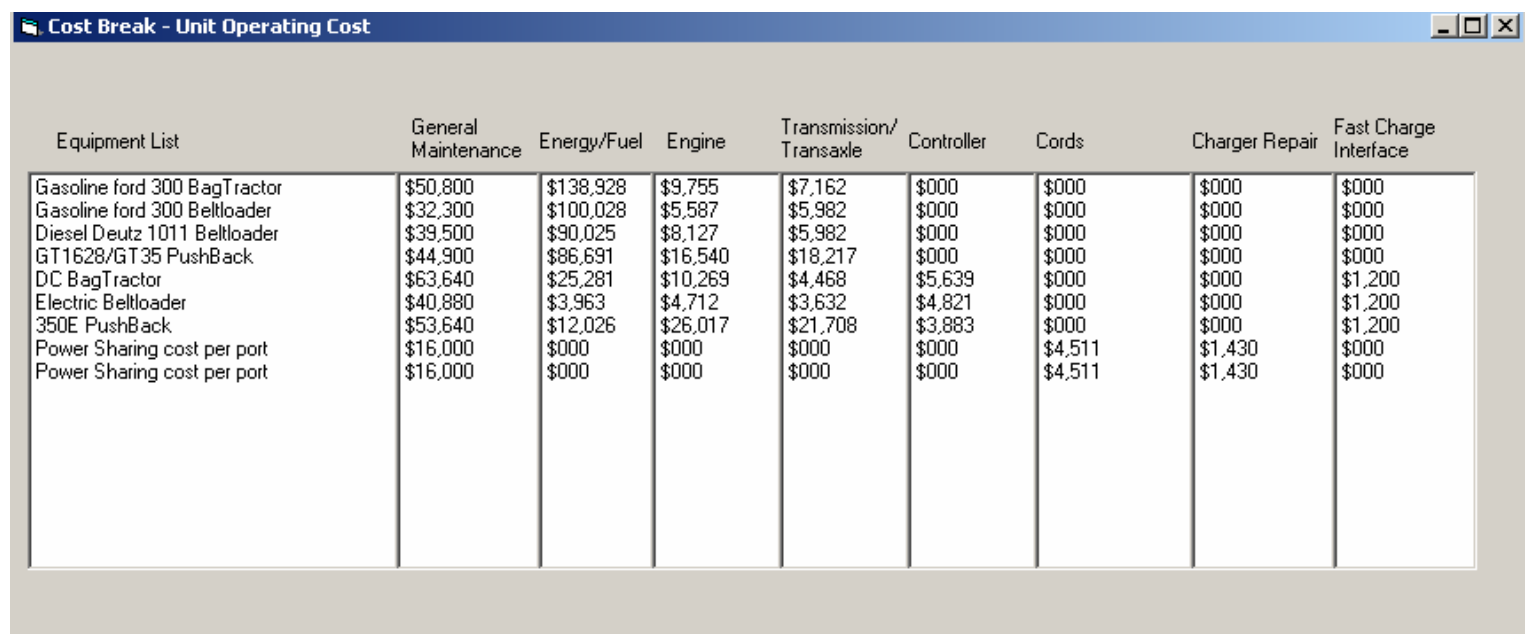

Figure 4-17. Airport "C" unit operating costs.

Figure 4-18 shows a graph of the total cost versus years using a $7 \%$ fuel escalator. The breakeven point is at 4.9 years, and a real divergence in terms of savings appears beginning in the tenth year.

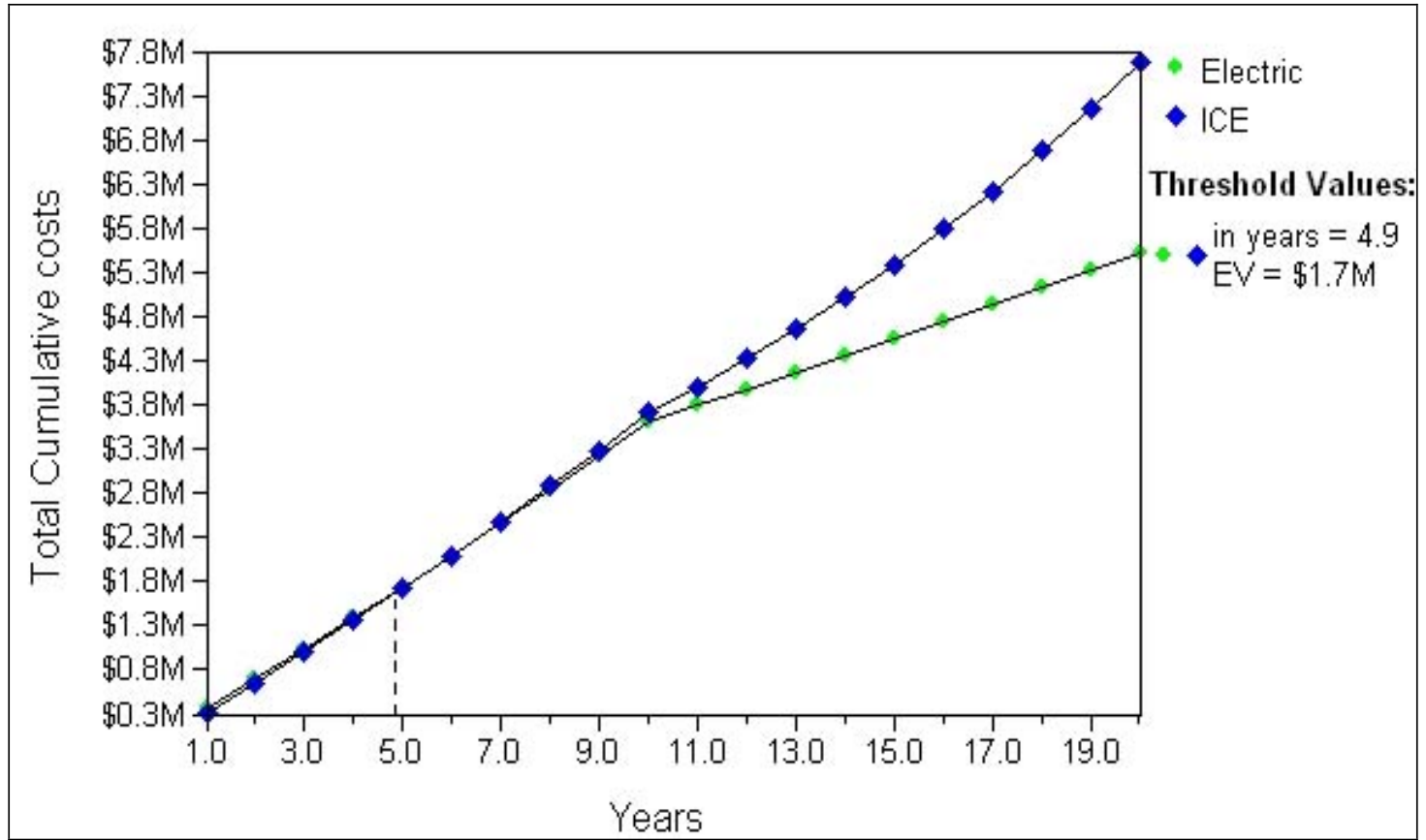

Figure 4-18. Airport "C" breakeven point for electric ground support equipment versus internal combustion engine ground support equipment for all ground support equipment.

To further understand the impacts of the varying fossil fuel escalation, Figure 4-19 plots a varying fossil fuel escalation rate per year versus years of analysis. If there is a $7 \%$ average annual increase in fossil fuel costs, then eGSE has a payback within approximately 5 years. If fuel cost increases remain relatively low at $4 \%$ annually, then the payback for eGSE is approximately 12 years. 


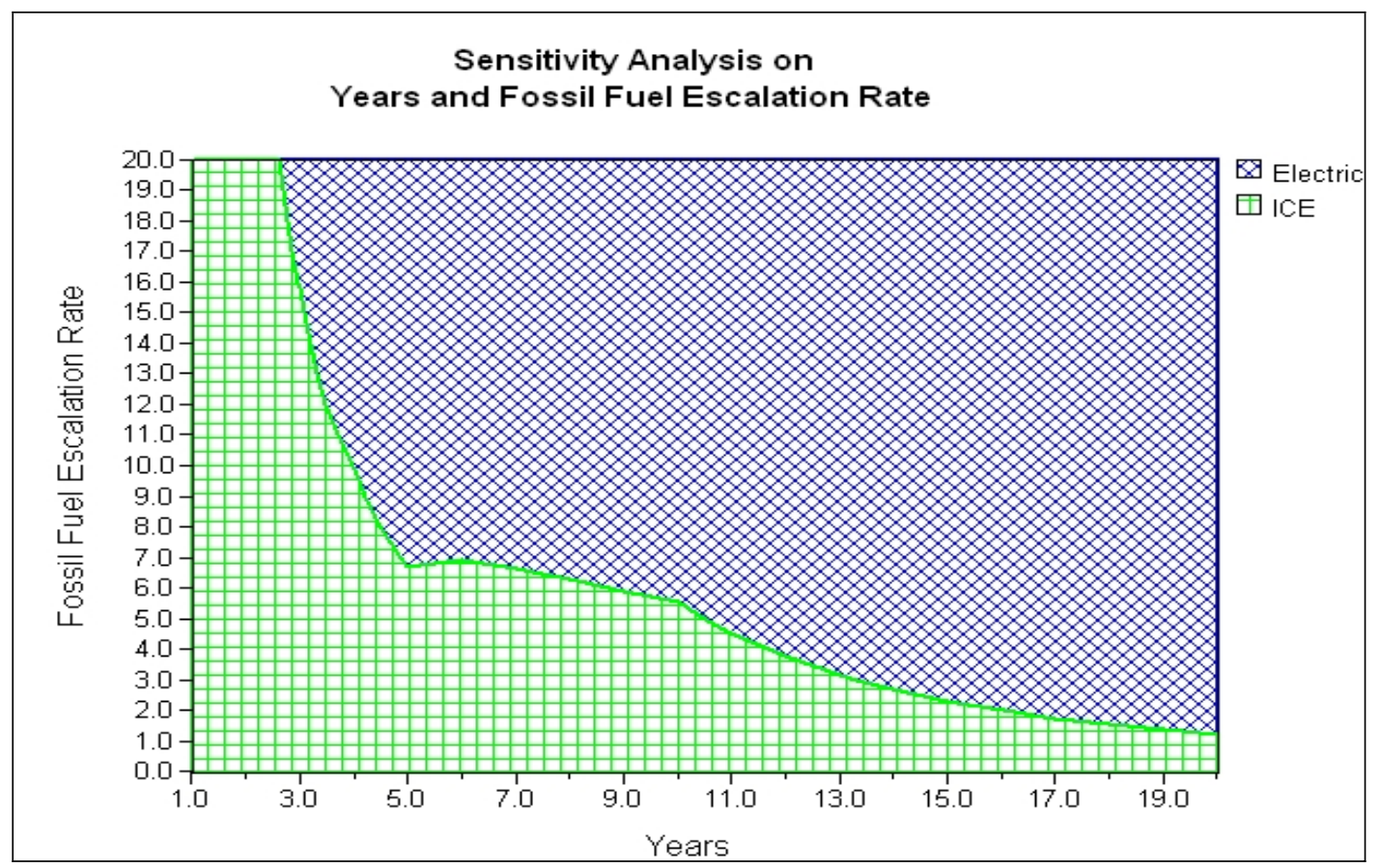

Figure 4-19. Airport "C" sensitivity analysis for all three ground support equipment types.

Figure 4-20 represents the sensitivity analysis for comparing a gasoline baggage tractor to an electric baggage tractor. In the electric configuration, one charge port was modeled for every three vehicles. Capital cost of the charge port, including installation, is assumed to be $\$ 15,500$, amortized over 10 years. Batteries are $\$ 6,000$ and replaced every 5 years. A fuel escalation rate at $4 \%$ or higher has a payback for electric within 4 years or less.

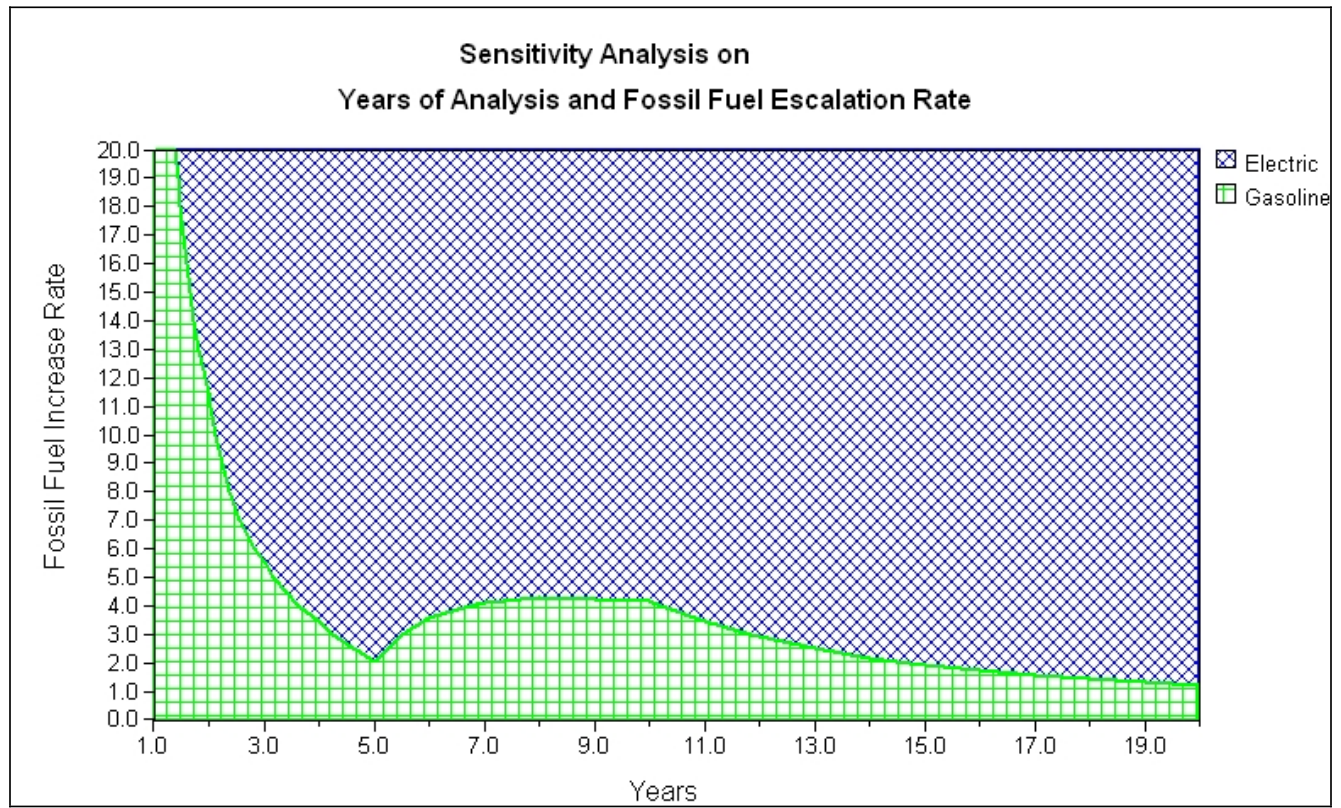

Figure 4-20. Airport "C" sensitivity analysis for baggage tractors.

Figure 4-21 shows the sensitivity analysis for comparing fossil fuel belt loaders to electric ones. The same assumptions were made as for the baggage tractors, except the battery packs are smaller and 
less expensive at $\$ 4,000$ per pack (versus baggage tractors at $\$ 6,000$ ), resulting in a faster payoff for belt loaders over baggage tractors.

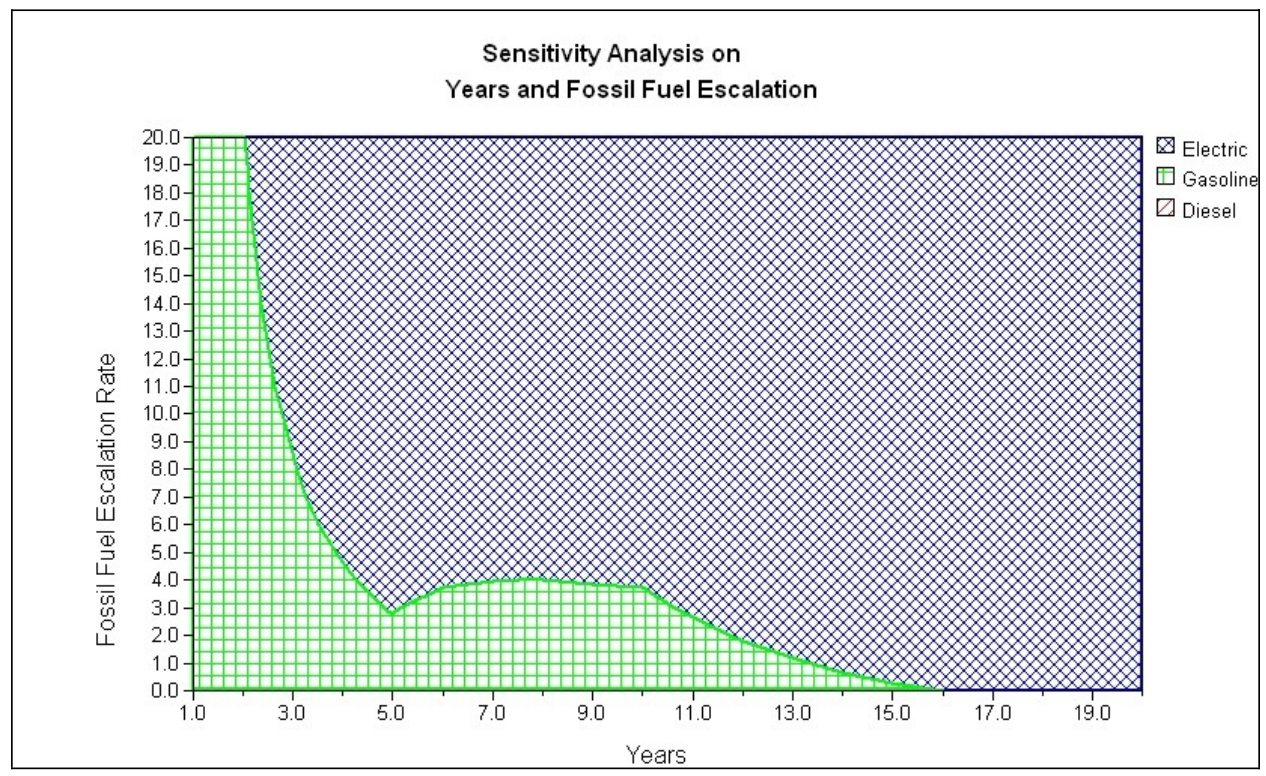

Figure 4-21. Airport "C" sensitivity analysis for belt loaders.

Figure 4-22 shows the sensitivity analysis of comparing a diesel fuel pushback tractor to an electric pushback tractor. The general assumptions were the same as for the other pieces of GSE. Pushback tractors have the longest payback of all three types of equipment due to the high capital cost of eGSE, high maintenance, cost of the batteries, and the fact that fuel does not play a large role because pushback tractors are only used for short durations; therefore, they have low fuel use.

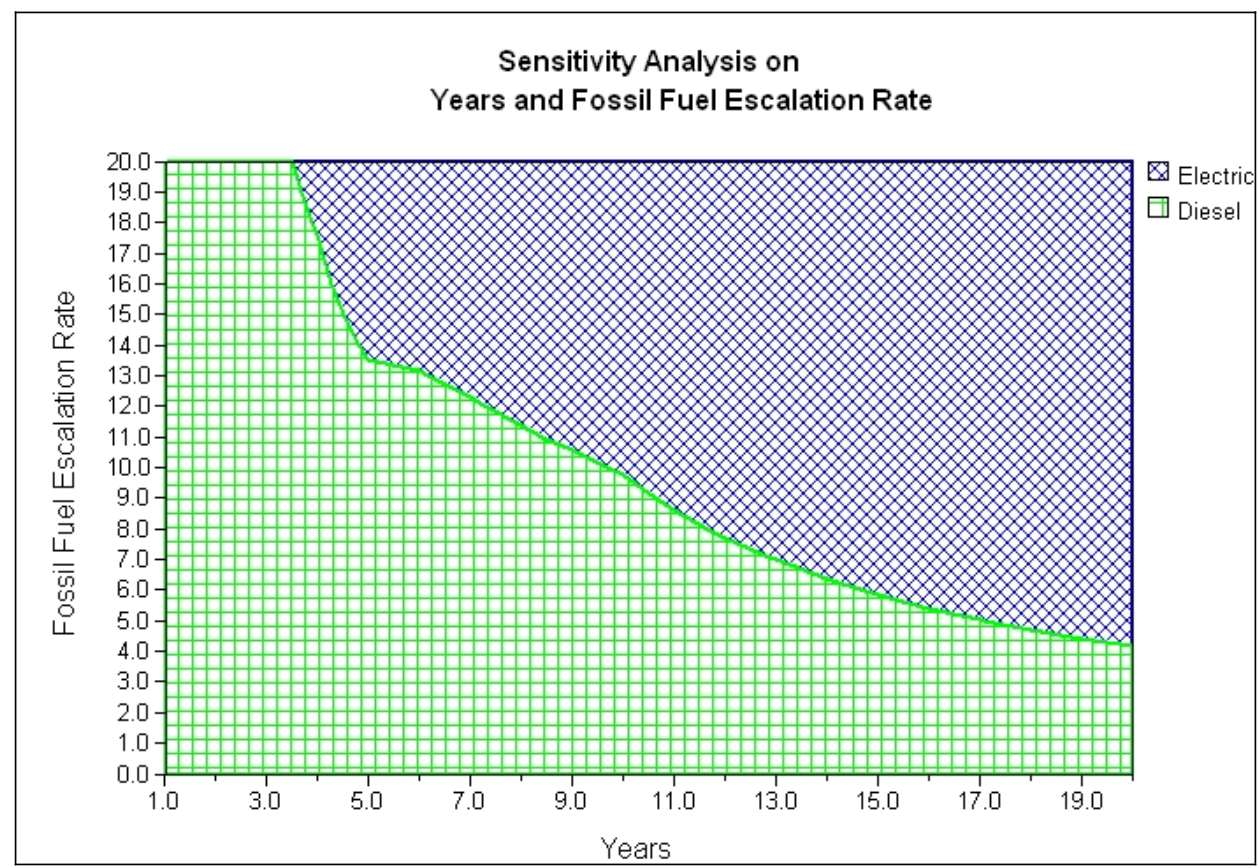

Figure 4-22. Airport "C" sensitivity analysis for pushback tractors. 


\subsubsection{Emissions}

Table 4-9 lists the emissions savings for Airport " $\mathrm{C}$," showing that replacing the gasoline baggage tractors have by far the largest reduction in emissions.

Table 4-9. Airport "C" emissions savings in tons per year.

\begin{tabular}{|llcrrr|}
\hline Quantity & Description & CO & HC & NOx & PM \\
\hline 16 & Baggage Tractors & 659.1 & 24.0 & 13.7 & 0.1 \\
14 & Belt Loaders & 146.5 & 6.3 & 6.9 & 0.3 \\
6 & Pushback Tractors & 1.5 & 0.3 & 3.8 & 0.3 \\
\hline \multicolumn{5}{|l}{$\mathrm{CO}=$ carbon monoxide, HC = total hydrocarbons, NOx = oxides of nitrogen, PM = particulate matter } \\
\hline
\end{tabular}

\subsection{Airport "D"}

Airport " $D$ " has a mild winter climate with warm to hot summer months. Terrain is flat but the travel distance to the baggage make-up area is very long. Based on actual data, a review of the flights per day (approximately 2,000 flights per day), and terrain, Airport " $D$ " is designated as a high-duty airport scenario. The GSE equipment and battery chargers analyzed for the Airport "D" scenario are shown in Tables 4-10 and 4-11, respectively.

Table 4-10. Airport "D" ground support equipment included in the study.

\begin{tabular}{|llllr|}
\hline GSE Type & Original GSE Equipment & Replacement GSE & Battery Type & Quantity \\
\hline $\begin{array}{l}\text { Baggage } \\
\text { Tractor }\end{array}$ & $\begin{array}{l}\text { Gasoline Ford 300 Baggage Tractor } \\
\text { (91) and Diesel Deutz 1011 (71) }\end{array}$ & $\begin{array}{l}\text { Electric Baggage Tractor - } \\
\text { DC Drive Type (77); AC } \\
\text { Type (85) }\end{array}$ & Flooded & 162 \\
Belt & Gasoline Ford 300 (9) and Diesel & $\begin{array}{l}\text { Electric Belt Loader - DC } \\
\text { Drive Type }\end{array}$ & Flooded & 12 \\
\hline Loader & Deutz (3) & & & 174 \\
\hline
\end{tabular}

Table 4-11. Airport "D" electric ground support equipment battery chargers.

\begin{tabular}{|lr|}
\hline Charger Type & Quantity \\
\hline Multi-port Fast Chargers & 72 \\
Single Port Fast Chargers & 0 \\
Conventional Chargers & 77 \\
\hline Total & 149 \\
\hline Estimated Total DC Output Capacity-688 kW \\
\hline
\end{tabular}

Figure 4-23 shows the main screen results for Airport " $D$ " and calculates an approximate savings of $\$ 14.5$ million for electric versus ICE GSE over a 20-year period (174 pieces of GSE equipment). 


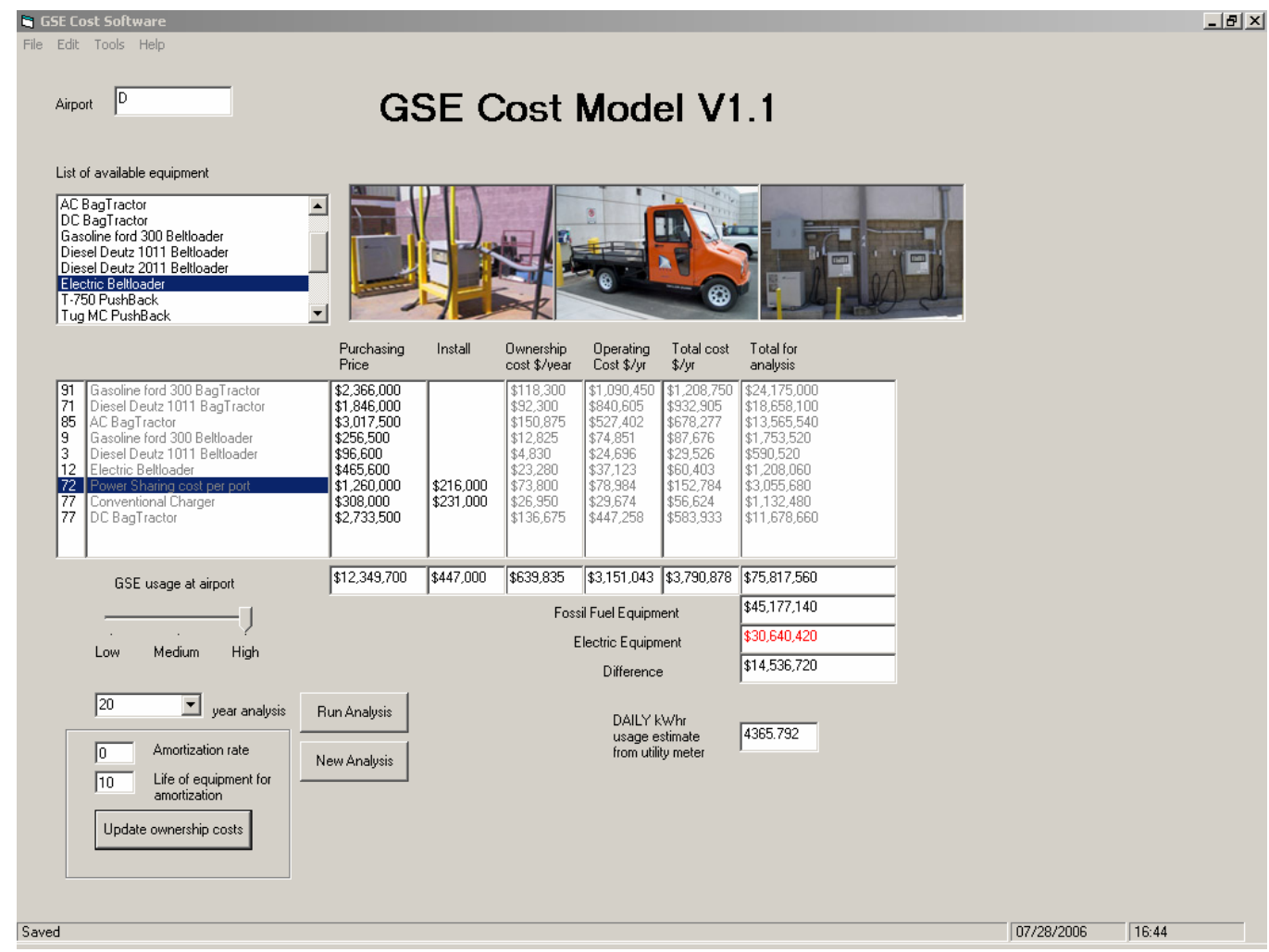

Figure 4-23. Results of Airport “D” main screen.

Figure 4-24 shows the default parameters used for fossil fuel, starting at \$2.50 per gallon, with an escalation rate of $7 \%$ per year, and electricity costs starting at 10 cents per $\mathrm{kWh}$, with an escalation rate of $2.5 \%$ per year.

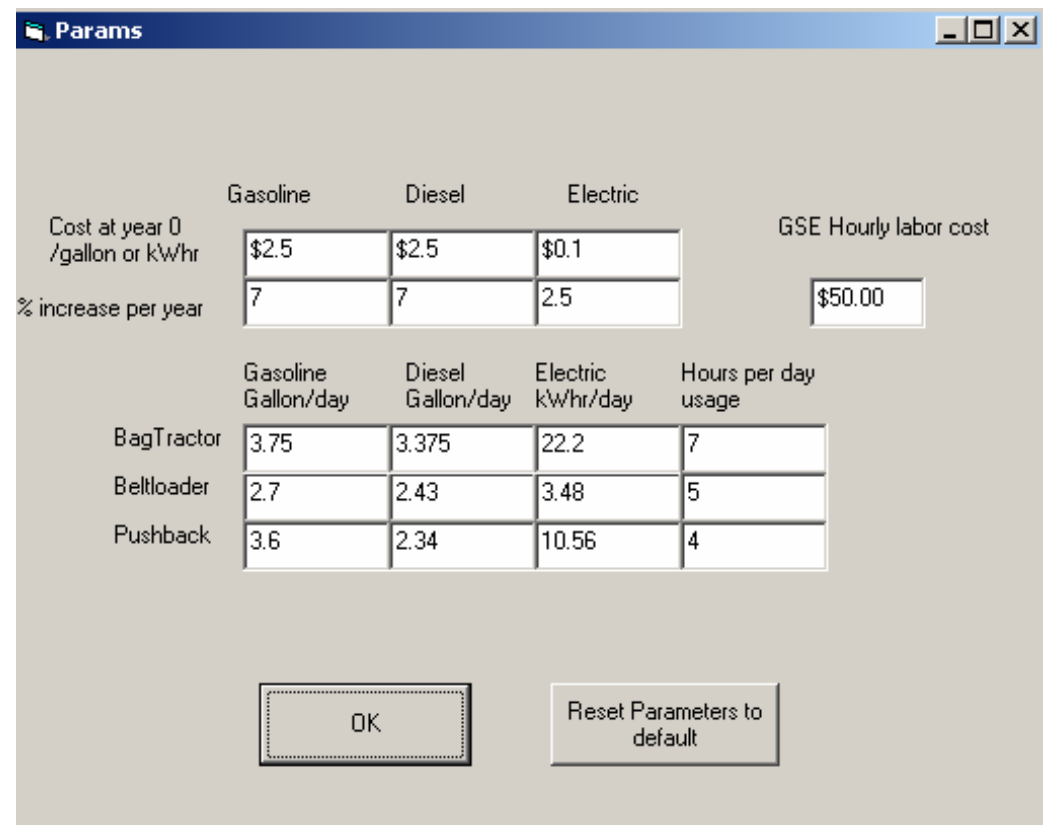

Figure 4-24. Airport "D" fuel and labor parameters. 
Figure 4-25 outlines unit operating costs for each piece of GSE and the charging infrastructure. The largest cost component for ICE GSE is fuel cost. For electric (although it is more evenly spread out) the general maintenance cost is the largest cost component due to the battery replacements.

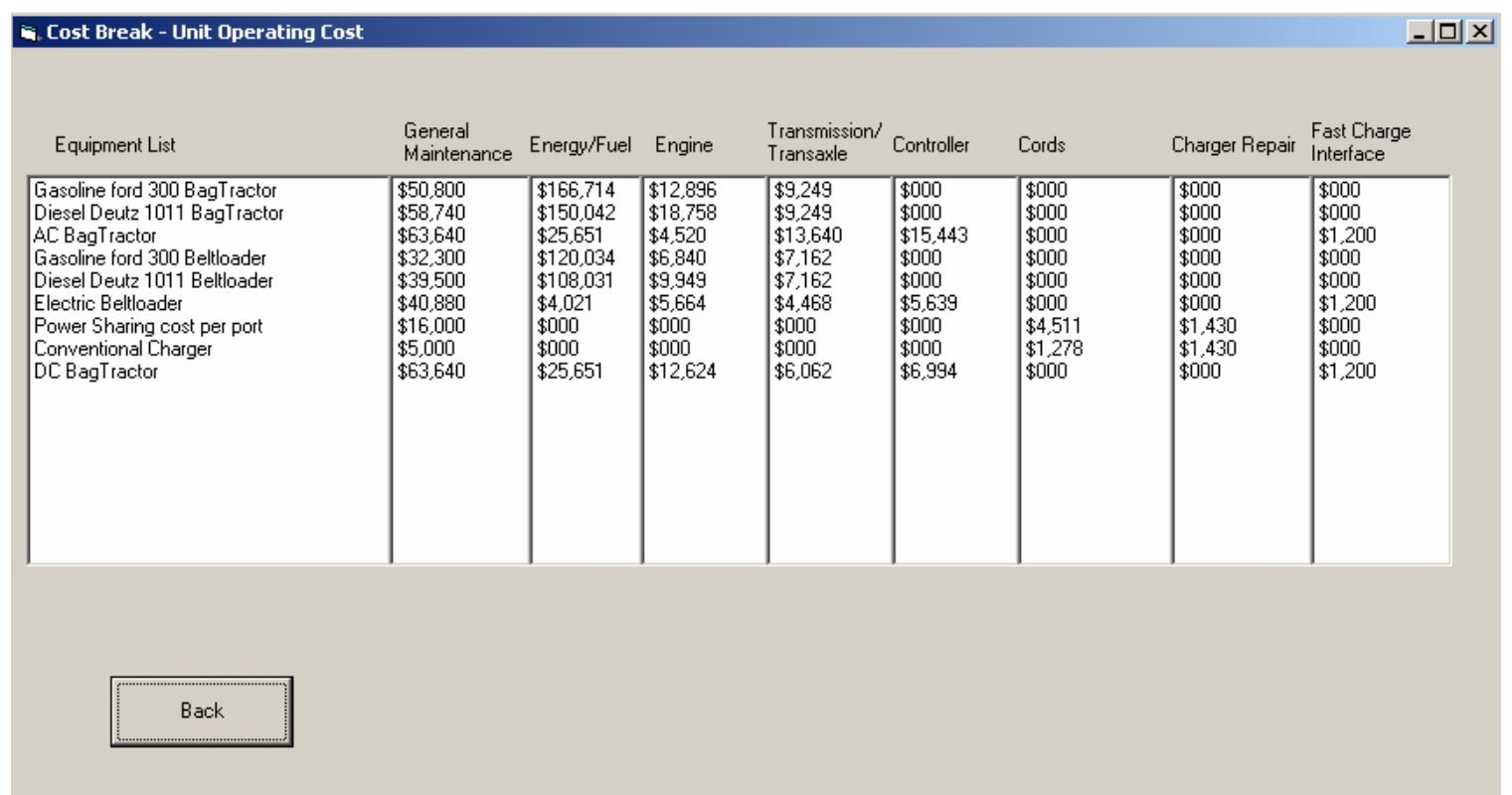

Figure 4-25. Airport "D" unit operating costs.

The breakeven point is shown in Figure 4-26 at 8.5 years for the default parameters selected. Noticeable divergence occurs at about 9.5 years into the analysis as fossil fuel costs continue to play a larger role in the overall cost components.

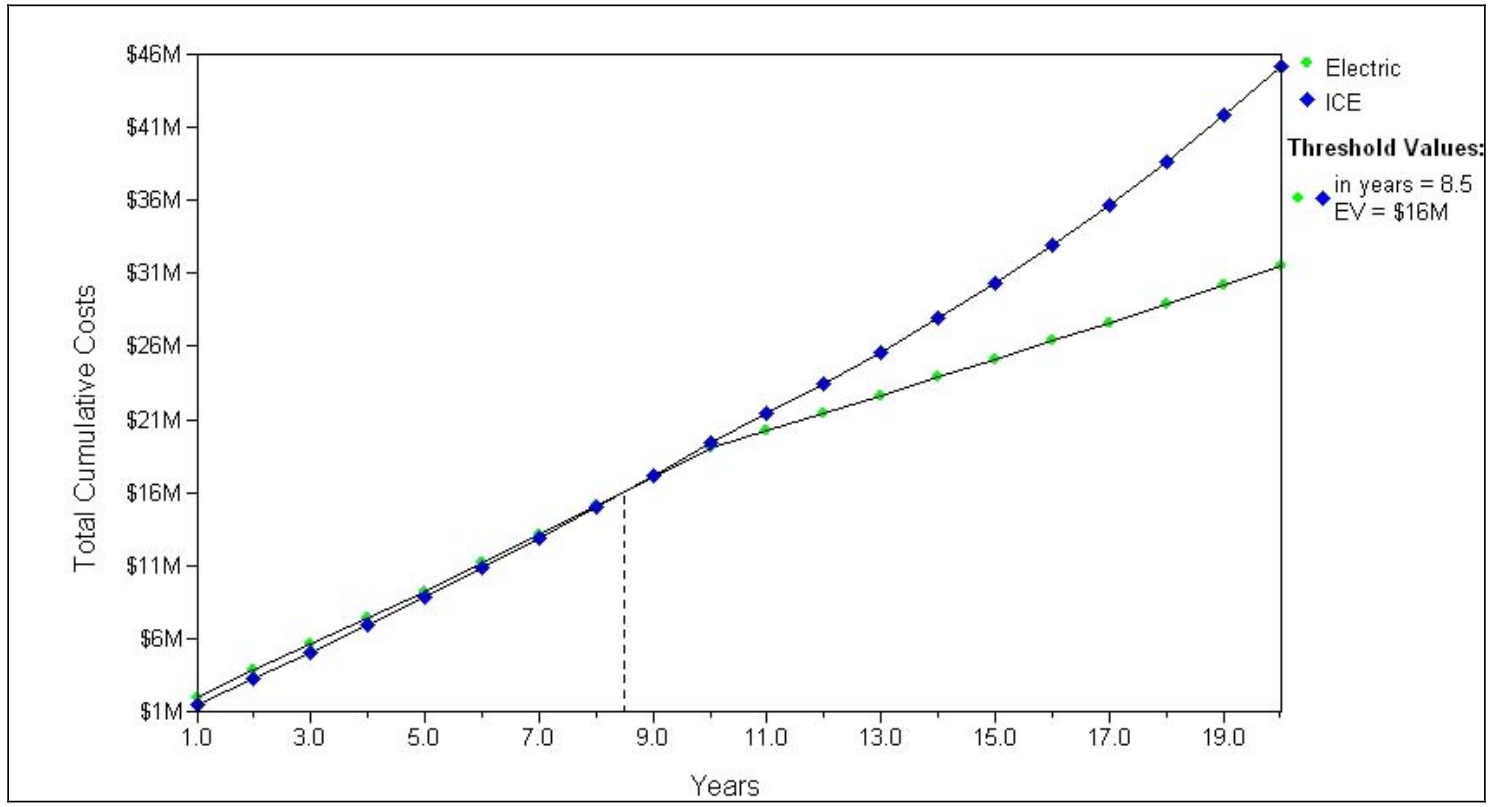

Figure 4-26. Airport "D" breakeven point for electric ground support equipment versus internal combustion engine ground support equipment for the bag tractor and belt loader. 
Figure 4-27 shows a sensitivity analysis for the fossil fuel escalation rate versus years of operation for all equipment at Airport "D." At 3\% annual fossil fuel escalation, payback is approximately 15 years. At $10 \%$ annual fossil fuel escalation, payback is reduced to 6 years.

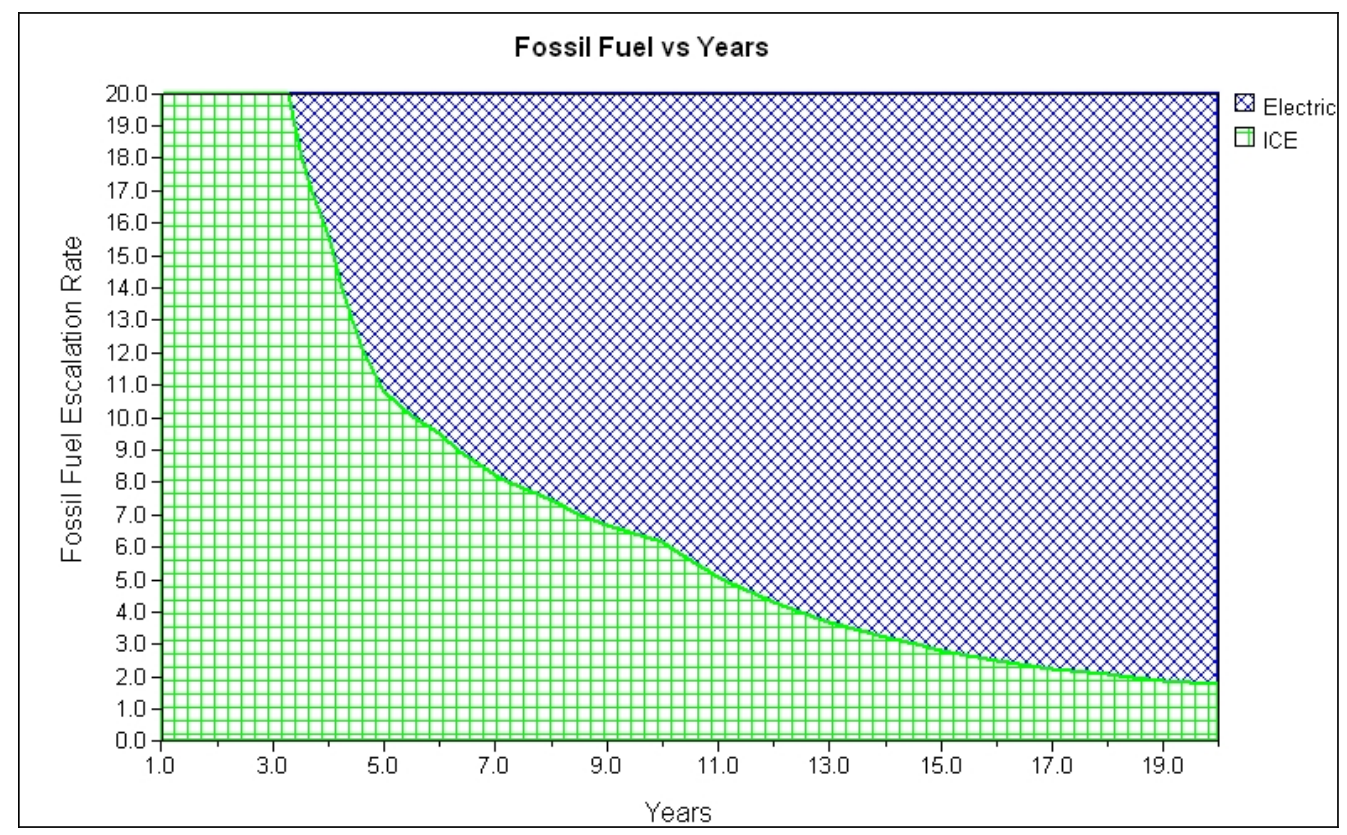

Figure 4-27. Airport "D” sensitivity analysis for baggage tractor and belt loader.

Figures 4-28 and 4-29 are sensitivity graphs that show fossil fuel escalation rates versus years for comparison of a single gasoline and a single electric baggage tractor, and a single gasoline and a single electric belt loader, respectively. For the eGSE, one charge port is assumed to support two GSE vehicles.

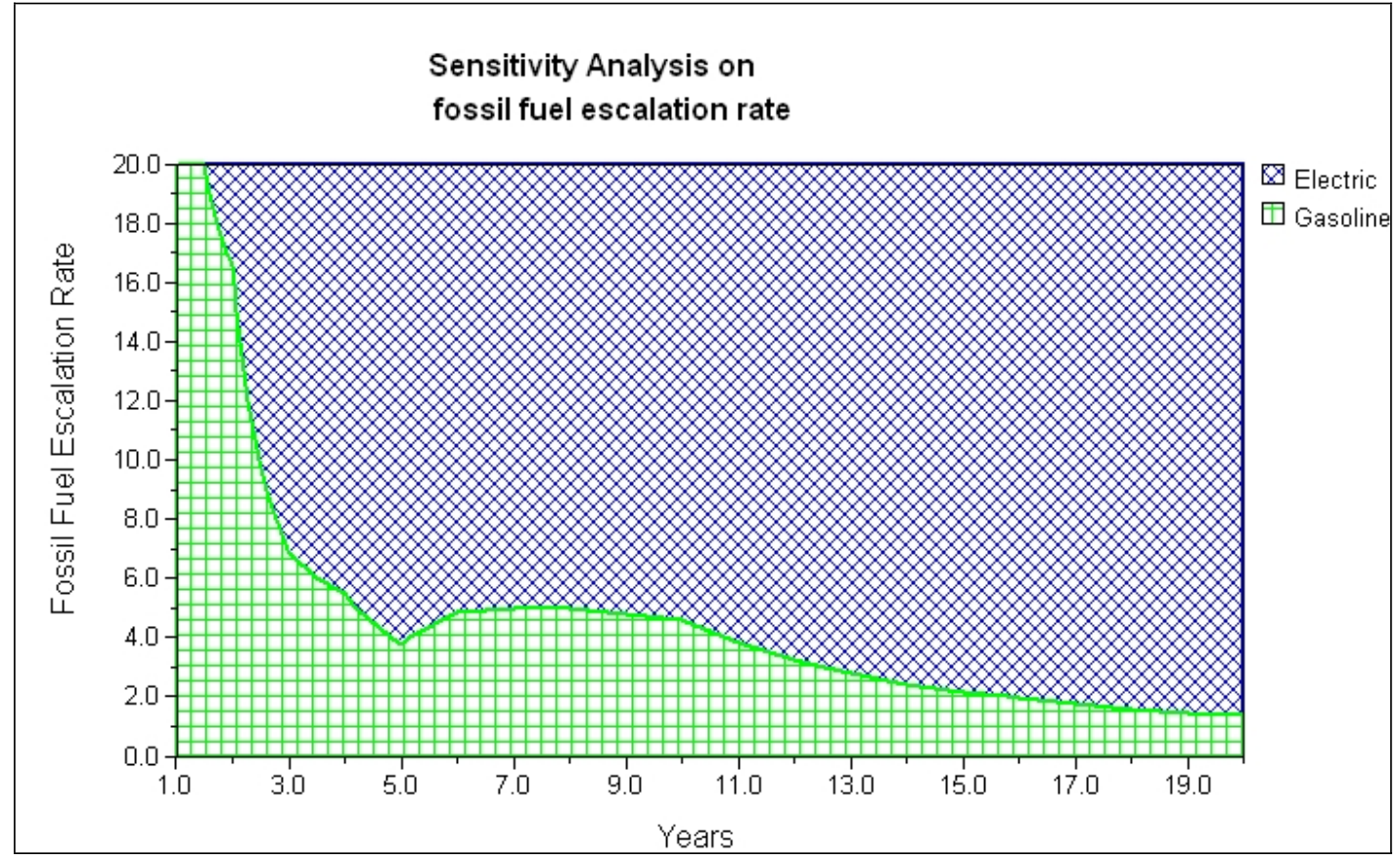

Figure 4-28. Airport “D” sensitivity analysis for baggage tractor. 


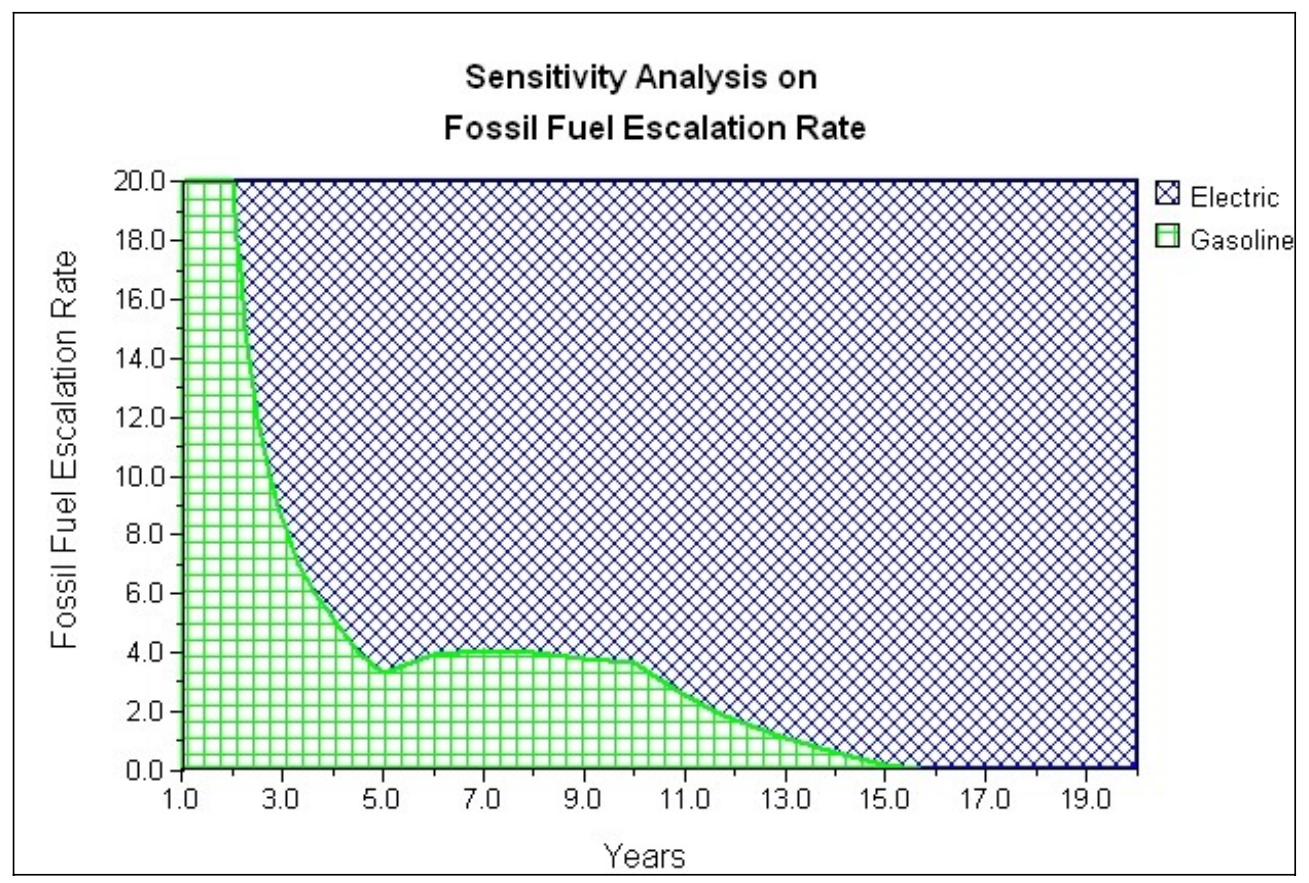

Figure 4-29. Airport "D" sensitivity analysis for belt loader.

\subsubsection{Emissions}

Table 4-12 presents the emissions savings for the Airport " $D$ " analysis. Because of the large eGSE fleet and a high-usage airport, a large amount of emissions savings is achieved.

Table 4-12. Airport "D" emissions savings in tons per year.

\begin{tabular}{|c|c|c|c|c|c|}
\hline Quantity & Description & $\mathrm{CO}$ & $\mathrm{HC}$ & NOx & PM \\
\hline 91 & Gas Baggage Tractor & 5248 & 191 & 109 & 1 \\
\hline 71 & Diesel Baggage Tractor & 35.1 & 5.62 & 44.9 & 6.52 \\
\hline 3 & Diesel Belt Loaders & 0.657 & 0.158 & 1.333 & 0.15 \\
\hline Totals & & 5517.428 & 207.018 & 162.295 & 7.762 \\
\hline
\end{tabular}




\section{SENSITIVITY ANALYSIS}

In order to better understand which cost variables most influence the economics of choosing electric versus fossil fuel GSE, various sensitivity analyses were performed. As shown in each individual airport scenario, fossil fuel inflation rates significantly alter the economic picture, especially in baggage tractors, the highest user of fuel. Other sensitivities reviewed are provided below and include:

- $\quad$ Varying electricity escalation rates only

- $\quad$ Varying energy (i.e., electricity and fossil fuel) rates only and at the same rate

- Varying the capital cost differential by varying electric equipment and installation cost subsidies from 0 to $20 \%$

- $\quad$ Varying labor rates only.

The following analyses were performed on the Airport "A" scenario, and unless otherwise noted, the parameters remain the same as previously shown for Airport "A."

Figure 5-1 shows the sensitivity of varying only the annual electric escalation rates. The graph shows that eGSE has a reasonable recovery as long as the annual electricity escalation rates stay below approximately $13 \%$.

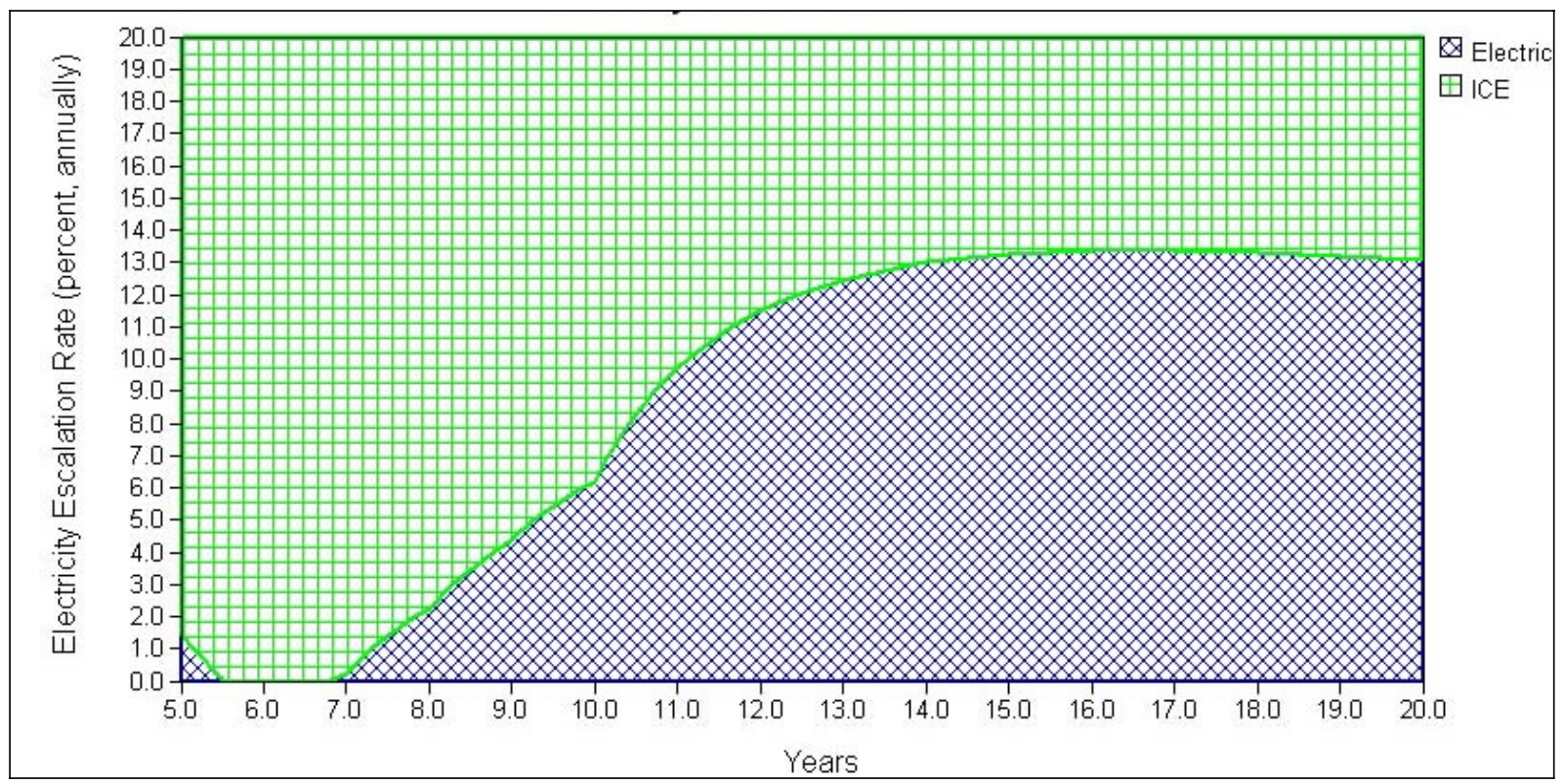

Figure 5-1. Electricity escalation rate versus years.

Figure 5-2 shows an annual energy (both electric and fossil fuel) escalation rate versus years; it shows the major influence of fossil fuel escalation on the economics for the entire operation. Even while escalating both fossil fuel and electricity at the same rates, fossil fuel has a much higher influence on the outcome. If the escalation rate is above $8.5 \%$ annually, eGSE is cost effective immediately. However, if the energy escalation rate stays below $2 \%$ annually, eGSE takes over 20 years to be cost effective. 


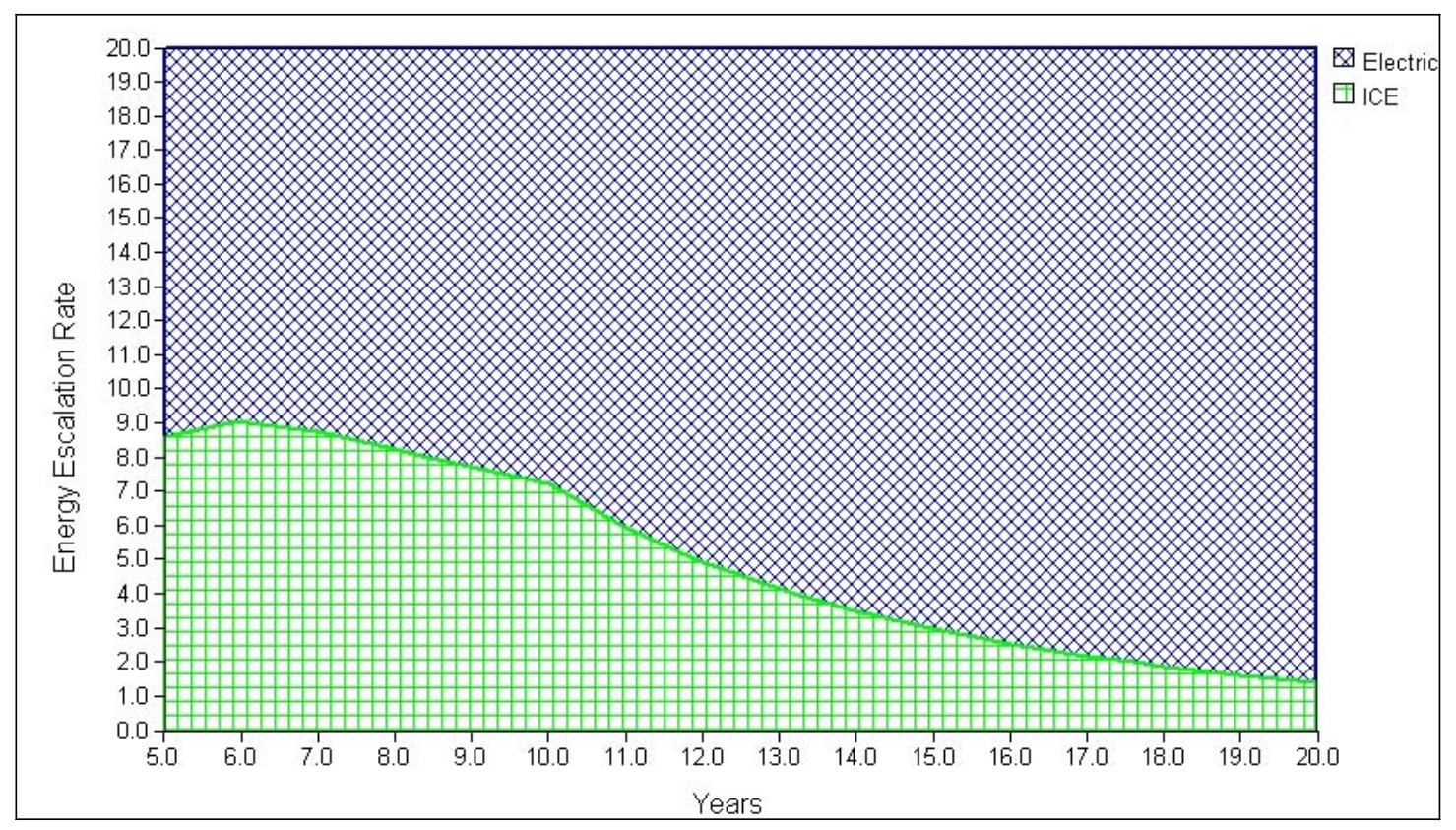

Figure 5-2. Energy escalation rates (annually) versus years.

Figure 5-3 shows GSE capital costs subsidized from 0 to $20 \%$ of the total costs, including chargers and their installations. Note that as the subsidies approach 16\%, eGSE is cost effective within 1 year.

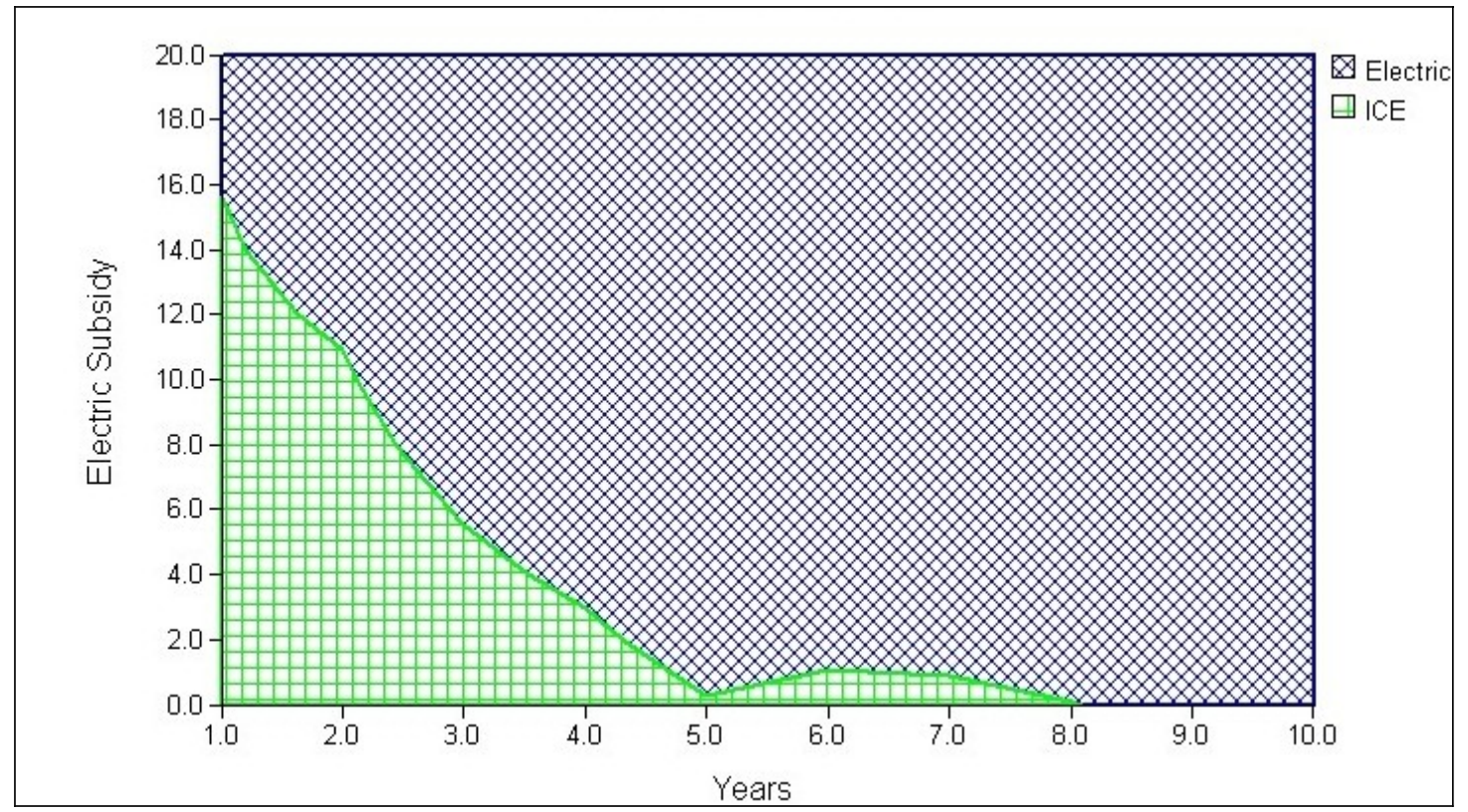

Figure 5-3. Electric ground support equipment capital cost subsidy (including charging infrastructure) versus years.

Figure 5-4 demonstrates that labor costs are almost identical between ICE GSE and eGSE with ICE GSE having a slight edge. This simply means that eGSE has a higher labor component than ICE GSE, even though ICE has a higher overall maintenance cost. This is an area that each user needs to take a close look at for their operation. Depending on various operational decisions on the eGSE, such as 
utilizing sealed batteries over flooded batteries, and AC drives versus DC drives, these labor costs could swing the other way in favor of eGSE.

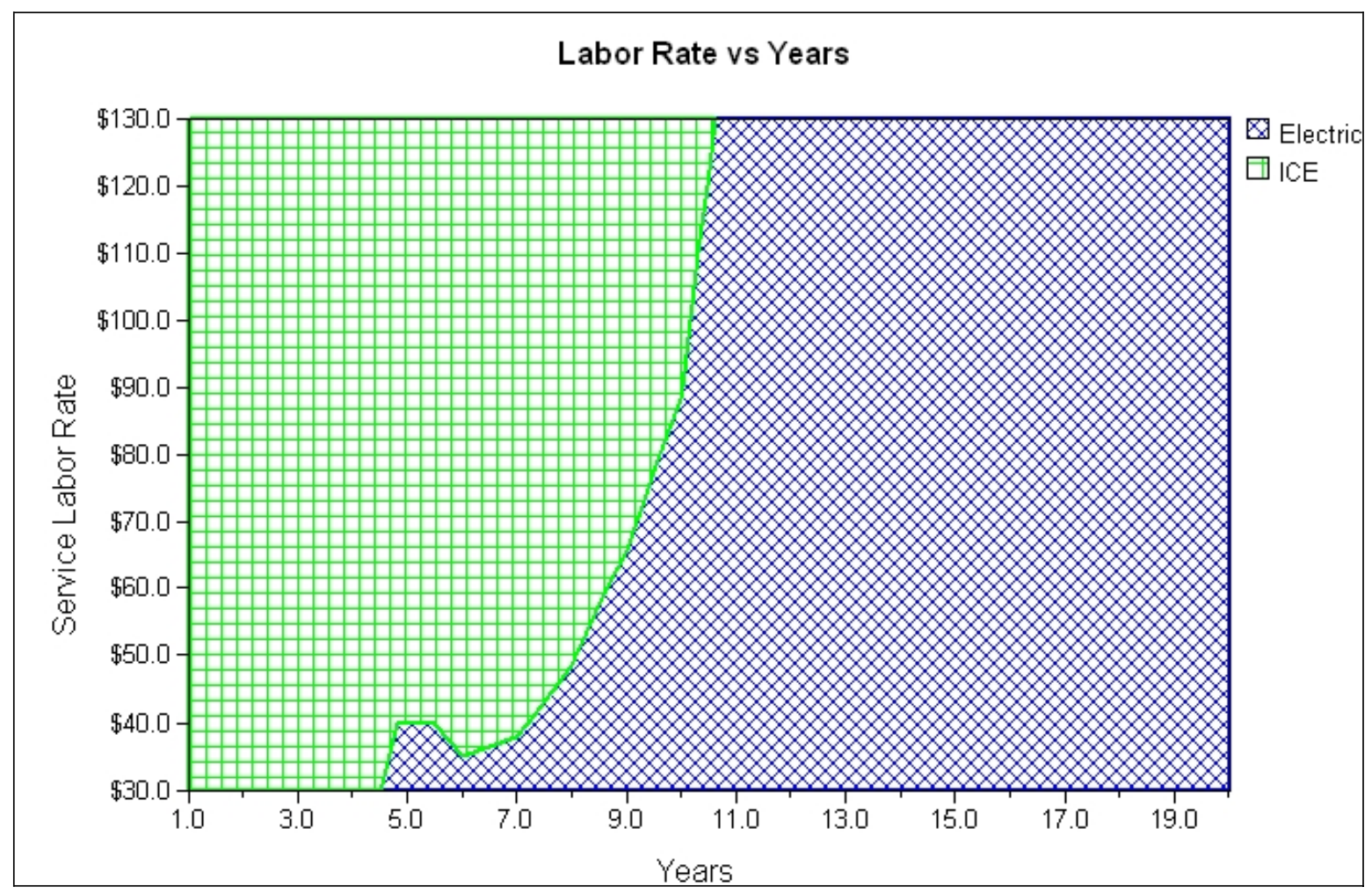

Figure 5-4. Service labor rates versus years. 


\section{COST-REDUCTION STRATEGIES}

Cost-reduction strategies for eGSE were reviewed as part of this study. Based on additional sensitivity analysis, the major costs associated with eGSE are as follows:

- Initial capital cost of GSE

- $\quad$ Battery replacement

- $\quad$ Charging infrastructure.

For eGSE, fuel costs, in the form of electricity, become a relatively small component of the overall costs because eGSE is more efficient and electricity costs from a \$BTU standpoint are generally less than gaseous fuels.

\subsection{Ground Support Equipment Capital Cost-Reduction Strategies}

Combining eGSE orders with other airlines to increase production run volumes may help in getting a reduced capital price on the equipment. The eGSE is still somewhat of a specialty item, even though production numbers are increasing. Higher volumes should result in lower costs for all those participating in these combined orders.

Properly sizing the battery pack for the application can help reduce the initial capital cost and O\&M costs for battery pack replacement. For light-duty to medium-duty applications, a smaller battery may meet your needs. This especially can be true when utilizing fast charging, which allows eGSE the opportunity to charge throughout the day.

\subsection{Battery Replacement}

Battery purchase costs are driven by market demand and cost of materials, primarily the cost of lead. It is best to ask for competitive bids and negotiate the best warranty possible. Proper operation and maintenance of batteries may allow an operator to extend the battery life well beyond the warranty period. Some ways of maximizing the battery life are controlling both the vehicle discharge parameters through proper vehicle controller settings and purchasing "smart" chargers with temperature compensation and battery protections built in.

\subsection{Charging Infrastructure}

Charging infrastructure costs can be broken down into the following three main sections:

- $\quad$ Capital purchase of chargers

- Electrical supply and installation

- O\&M expenses.

\subsubsection{Capital Purchase of Chargers}

When deploying universal fast chargers, the number of charge "ports" actually required based on amp-hour throughput and operational needs should be determined. In most cases, a single fast charge port can support two to four pieces of GSE equipment. Where sealed, valve-regulated, lead-acid batteries are deployed, equalizing can typically occur less often than with flooded lead-acid batteries, thus requiring fewer ports for the overall system. 
When considering conventional slow chargers, a specific charger and dedicated electrical circuit will be required for each piece of equipment and battery, leaving little flexibility.

\subsubsection{Electrical Supply and Installation}

Infrastructure costs can be the most difficult item to pin down early in the planning process, and although these costs can be significant, new strategies are now available to help minimize the installation cost such as sharing power with the jet bridge or other available circuits. Working with the local utility may also prove to be beneficial in developing some cost-saving strategies. Additionally, the fast charge systems that are currently available may have different approaches to sharing power; each should be thoroughly evaluated by a licensed electrician in order to ensure the most cost-effective decision is made.

\subsubsection{Operating and Maintenance Expenses (Including Electricity Costs)}

Charger O\&M expenses include DC output cords, charger power electronics, preventative maintenance (such as filters), and cost of energy used. Several different methods are now in use for connecting the charger to the vehicle. These methods should be evaluated by airline GSE personnel to understand the cost and operational tradeoffs of each design. If the utility bill is paid directly, checking with the local utility to understand whether or not they have preferred rates for electric equipment may be worthwhile. Additionally, if you are being charged for demand charges request, the local utility can monitor your energy use and utility bill to see if there are any strategies to help reduce costs. 


\section{ASSUMPTIONS}

Default numbers are based on actual data provided by two major commercial airlines: an international carrier and a "low-cost" provider. For the specific airports studied, available data for those particular sites were utilized; where no data existed, default parameters were used. The methodology for collecting data included site visits and personnel interviews, review of maintenance records with the airline's GSE departments or corresponding contract maintenance organizations, and spending time out on the ramp at the airport collecting and analyzing data to better understand the particular operations at each airport.

Capital Costs-Estimated capital costs for the vehicles and ancillary equipment required were provided by both the airlines and manufacturers. Because these items can vary based on quantity and other factors, the user can choose to input their own values.

Fuel Costs-Fuel costs (including gasoline, diesel, and electricity) used for the defaults were provided by airline participants, then an average of the various locations was used for the default numbers. Default inflation percentages were estimates based on looking at the previous 10-year increases. Because there are many differing opinions on this subject, the user is also able to input their own starting numbers and inflation estimates for each of the fuels.

Battery and Charger Efficiencies-To handle the various efficiencies of batteries and charger systems, the original model made assumptions for both conventional and universal smart chargers. Based on further review of the model by project participants, the model may be modified in the next version, allowing the user to provide the efficiency of the charger and the percent of estimated battery overcharge. The percent overcharge amount is assumed to be at only $20 \%$ of the maximum charge rate for a period of 2 hours. Although still under review at the time of this reporting, the anticipated default parameters considered for the conventional charger have an $85 \%$ efficiency rating; the universal smart chargers (multi-voltage, high-efficient insulated gated bipolar transistor IGBT or similar design) have a 90\% efficiency rating. For both charge systems, a $5 \%$ overcharge for a sealed battery and a $15 \%$ overcharge for a flooded battery are anticipated.

Maintenance Costs-Maintenance costs were gathered at each of the four airports and from corporate GSE staff members of each participating airline. Average numbers were utilized for the default parameters for both labor and material items. Where available, actual service work orders were reviewed and cataloged.

Emissions-Emissions data were taken from the EDMS Model Version 4.12. The model looks only at tailpipe emissions; therefore, for gasoline and diesel, it does not take into account emissions generated from mining and reforming the fuel, or emissions from transportation of the fuel to the site. Similar with eGSE, power plant emissions are not included in the calculations. 


\section{CONCLUSIONS}

The findings of this project show that the cost of fuel for ICE GSE is the main cost driver; therefore, it has the strongest influence on the payback period for electric over ICE GSE options. Where more fuel is used, such as with baggage tractors, the more profound the influence of fuel costs. The strongest influence on eGSE is the initial capital costs, infrastructure costs, and battery life-cycle costs.

Other findings include:

- The eGSE clearly has lower operating costs than ICE GSE for the baggage tractor, belt loader and pushback tractor GSE analyzed in this project.

- $\quad$ Capital costs for new ICE GSE are still significantly lower than new eGSE.

- $\quad$ Payback time for eGSE, when no cost-sharing is provided, generally ranges from 3 to 7 years.

- Where cost-sharing or grants are available, depending on the amount, payback for eGSE can be reduced from 0 to 3 years, with substantial life-cycle cost savings accruing over the life of the GSE.

- $\quad$ Strategies, such as converting old ICE vehicles to electric or implementing group purchases, can help lower the cost of eGSE.

- $\quad$ Strategies to lower infrastructure costs are available such as utilizing existing bridge supply power and utilizing smart power sharing charge systems to reduce supply requirements.

The cost model allows airlines and other interested stakeholders the opportunity to run various scenarios based on user-provided cost information and operating parameters, or by using the default parameters. Cost-saving strategies, that support a reduction in initial investments or O\&M expenses, can also be integrated into the model, which provides results associated with such strategies. 


\section{Appendix A - Airport "A" Input Data and Results Summary}


Appendix A

Airport "A" Input Data and Results Summary

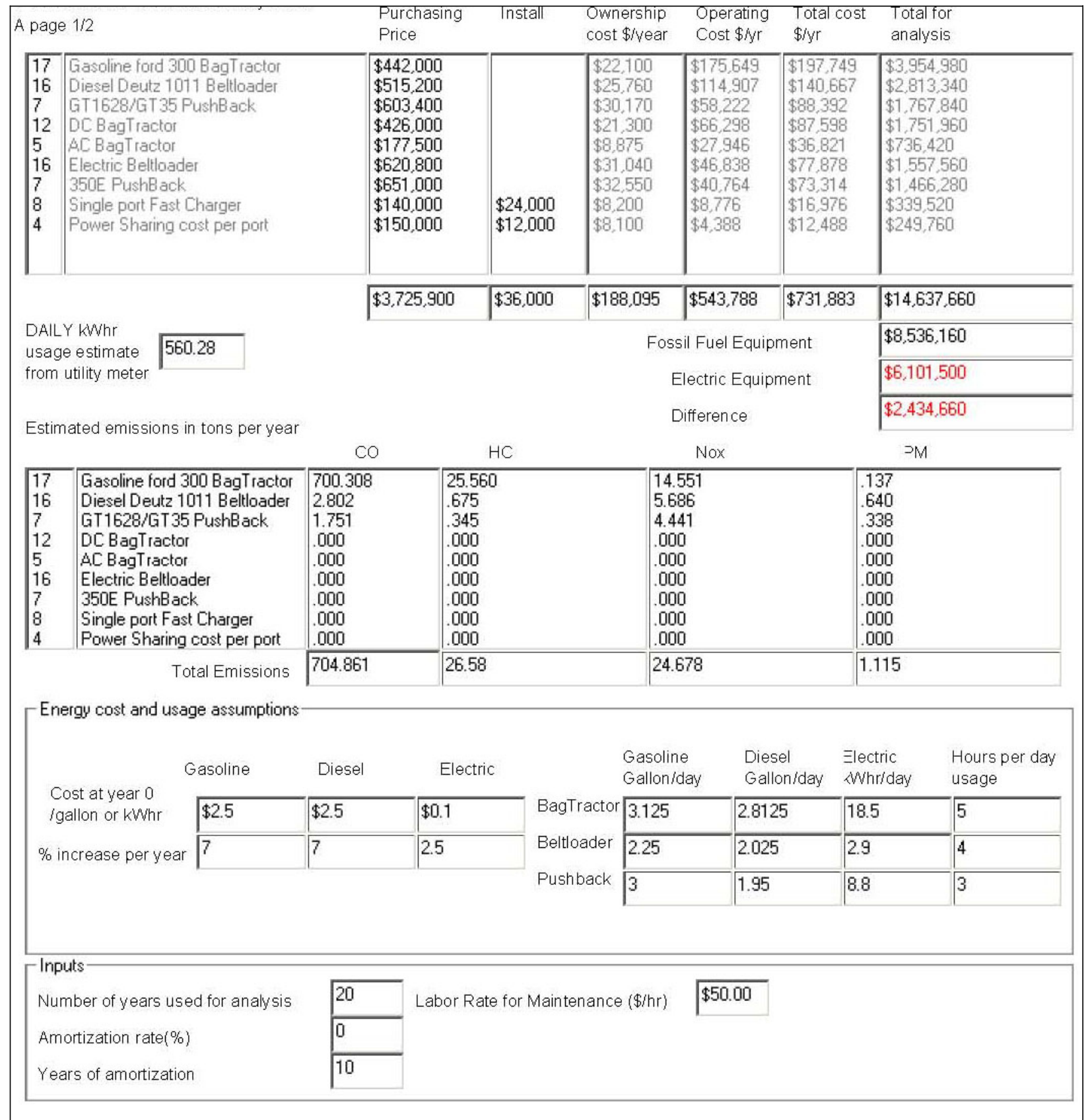


Appendix A

Airport "A" Input Data and Results Summary

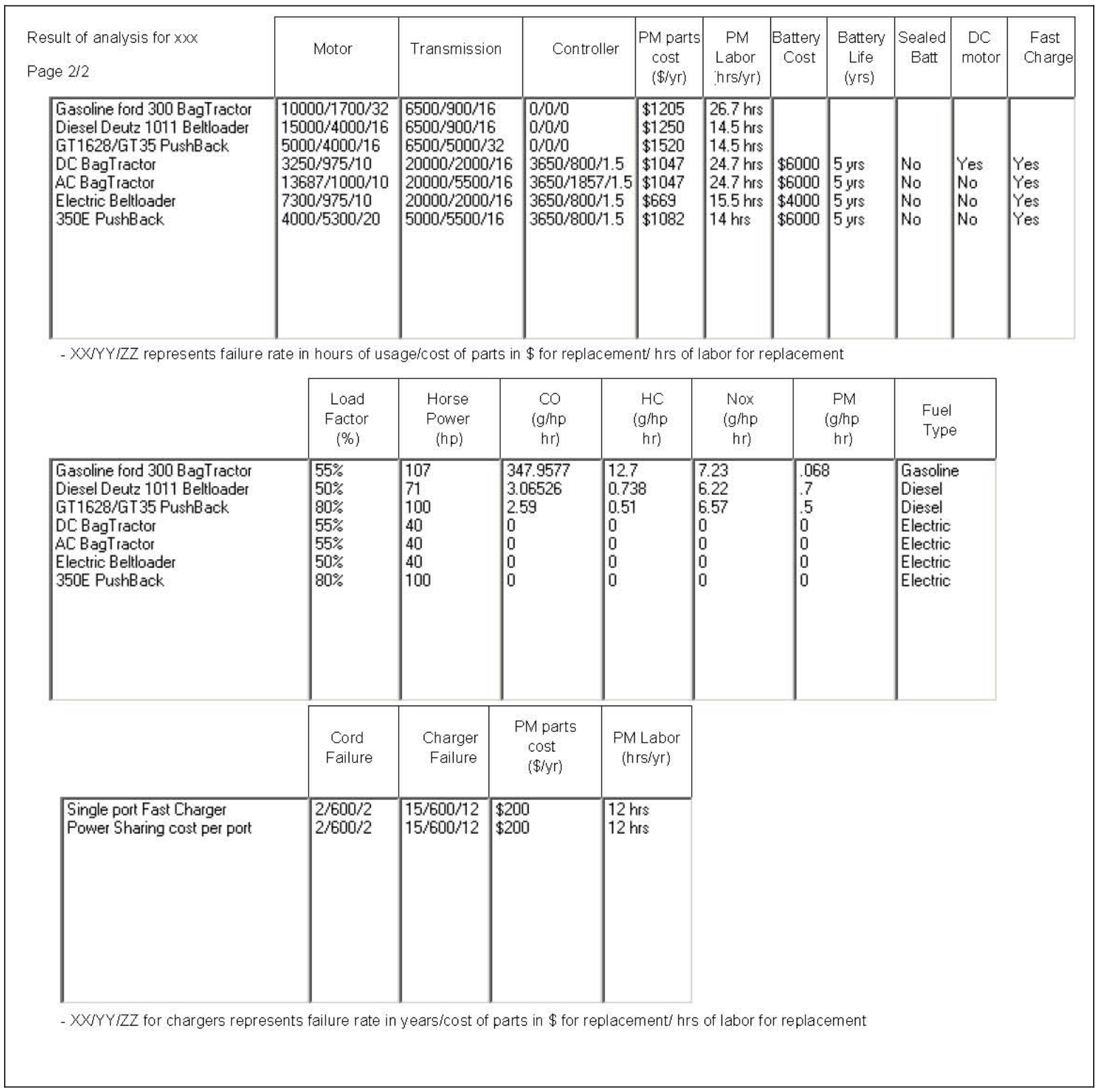


Appendix A

Airport "A" Input Data and Results Summary
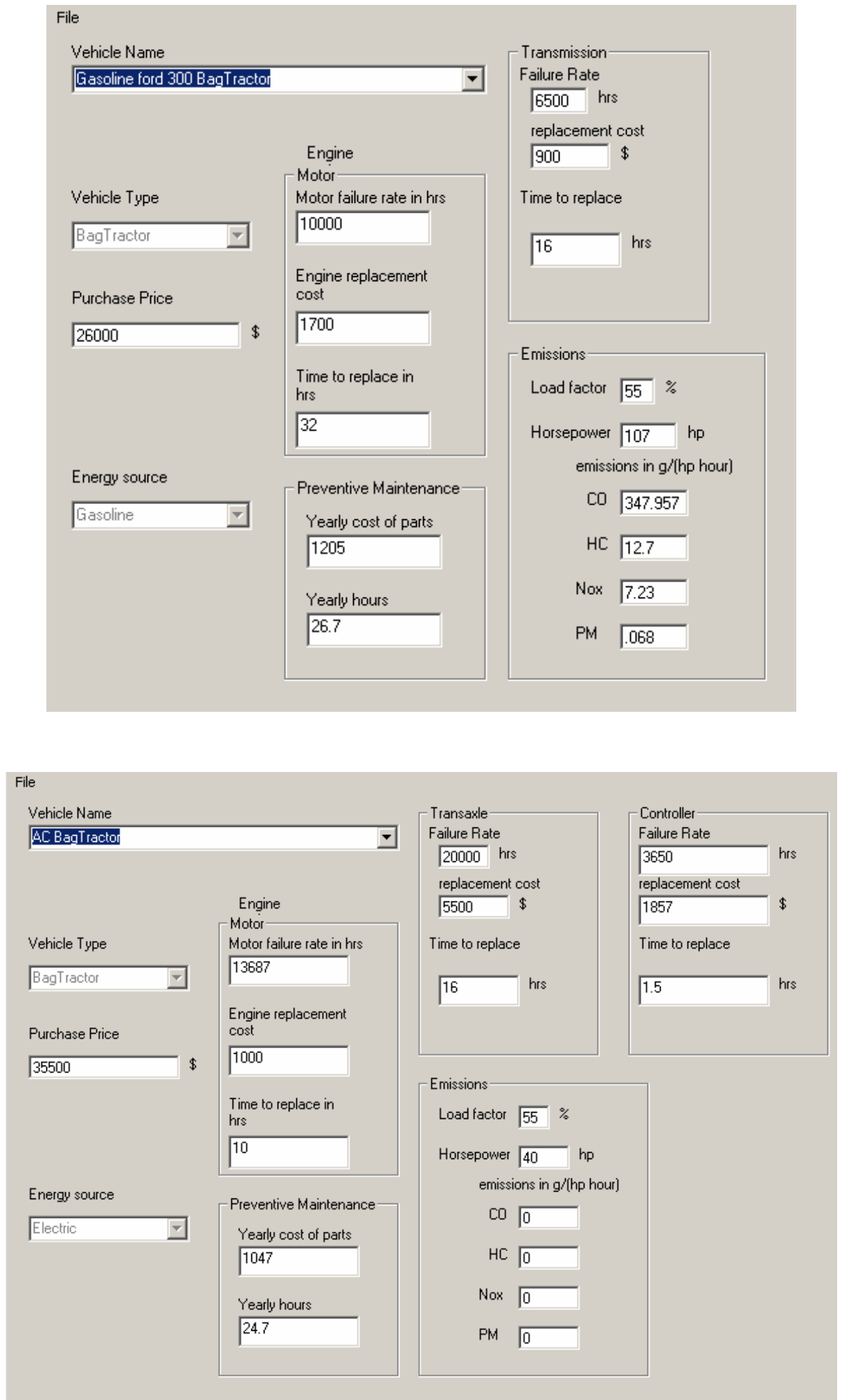
Appendix A

Airport "A" Input Data and Results Summary
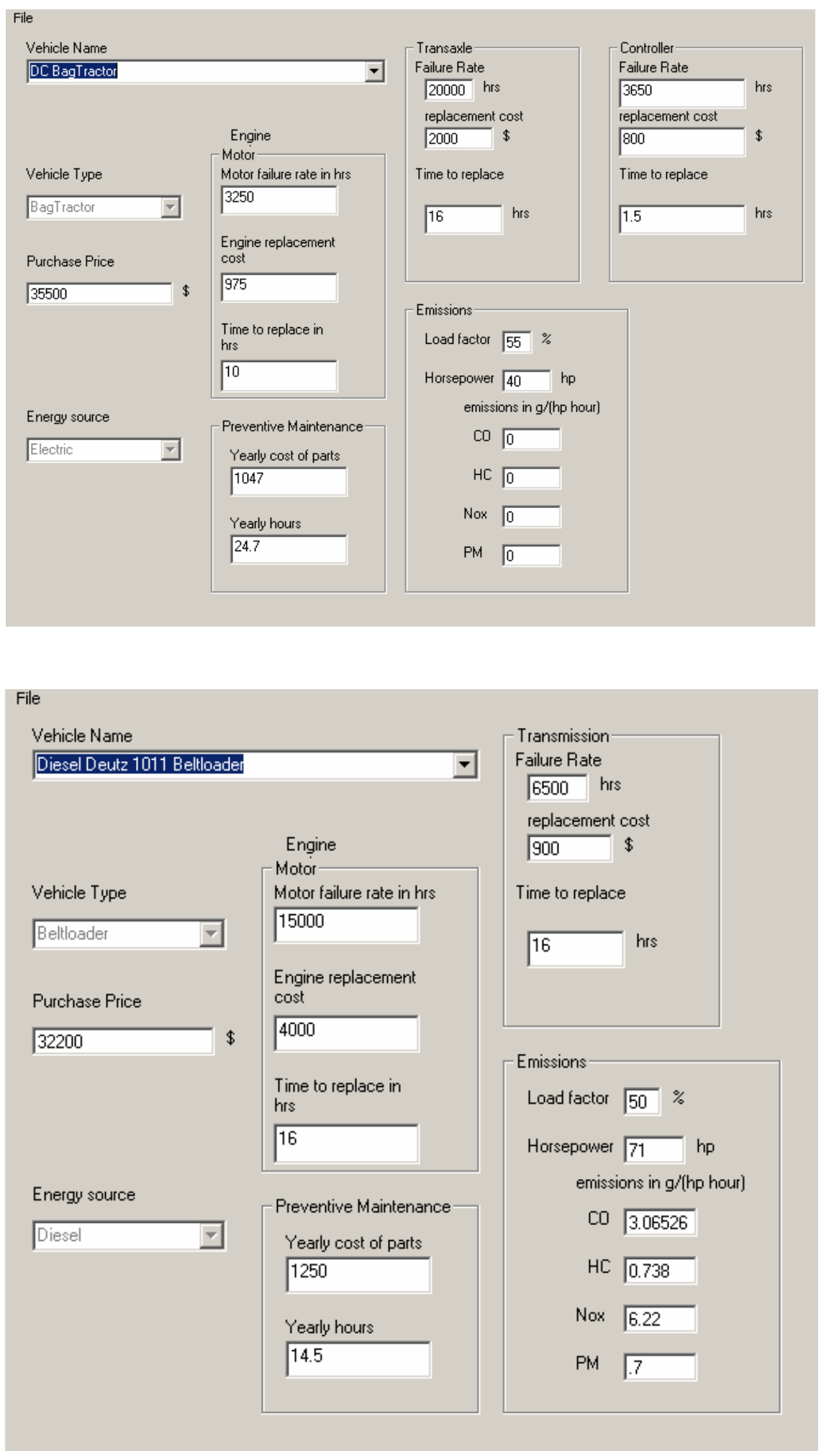
Appendix A

Airport "A" Input Data and Results Summary
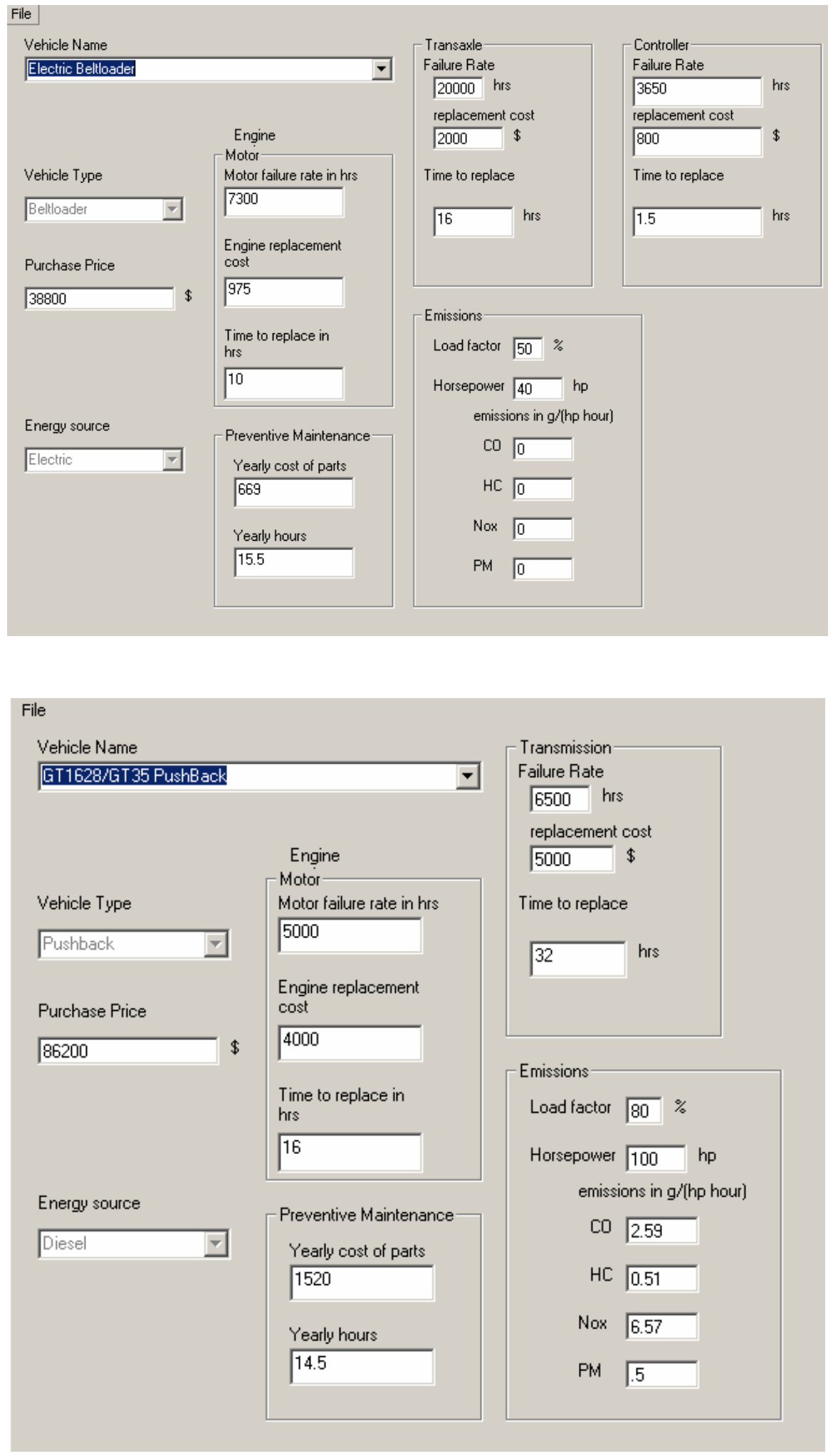
Appendix A

Airport "A" Input Data and Results Summary
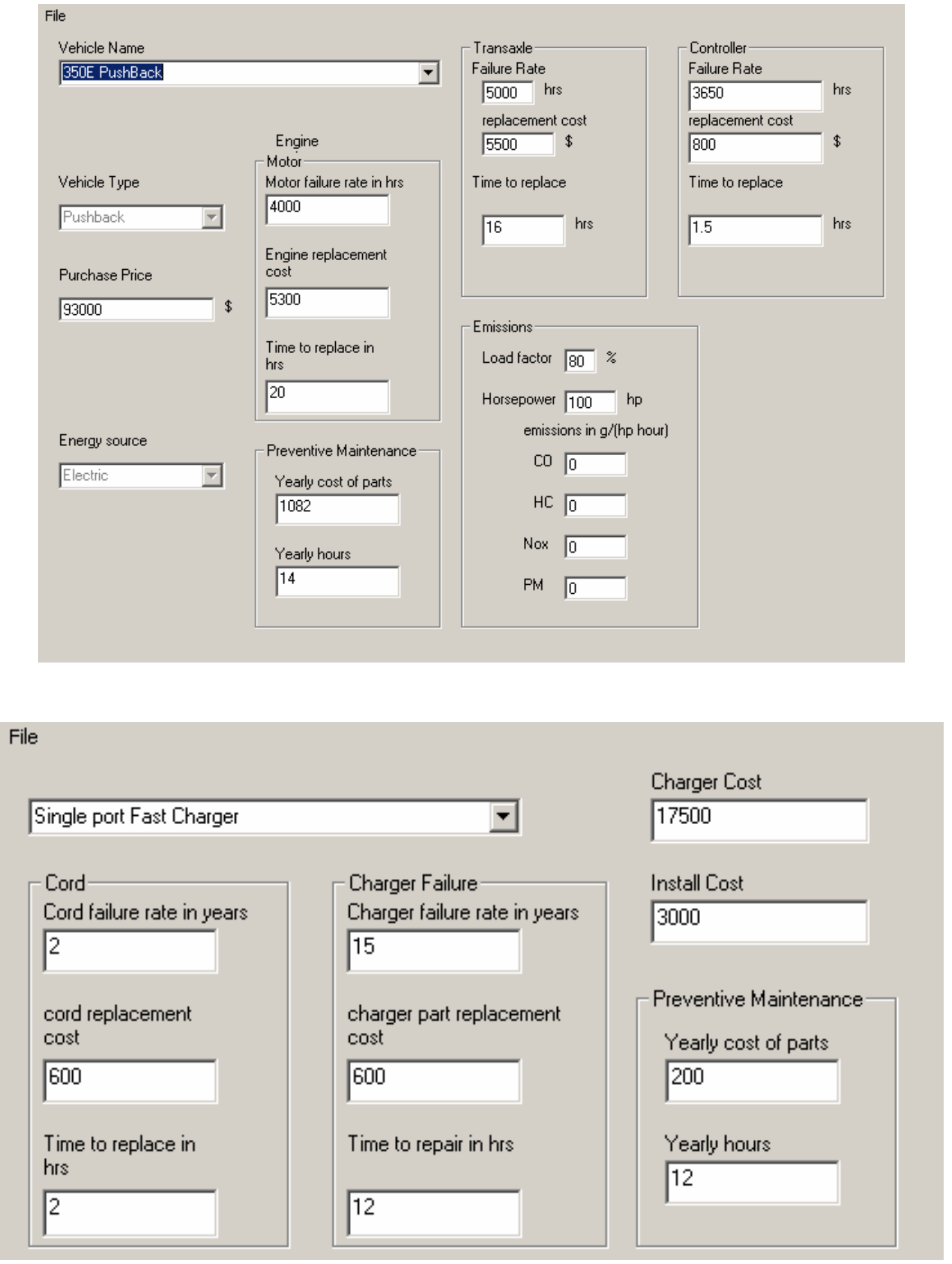
Appendix A

Airport "A" Input Data and Results Summary

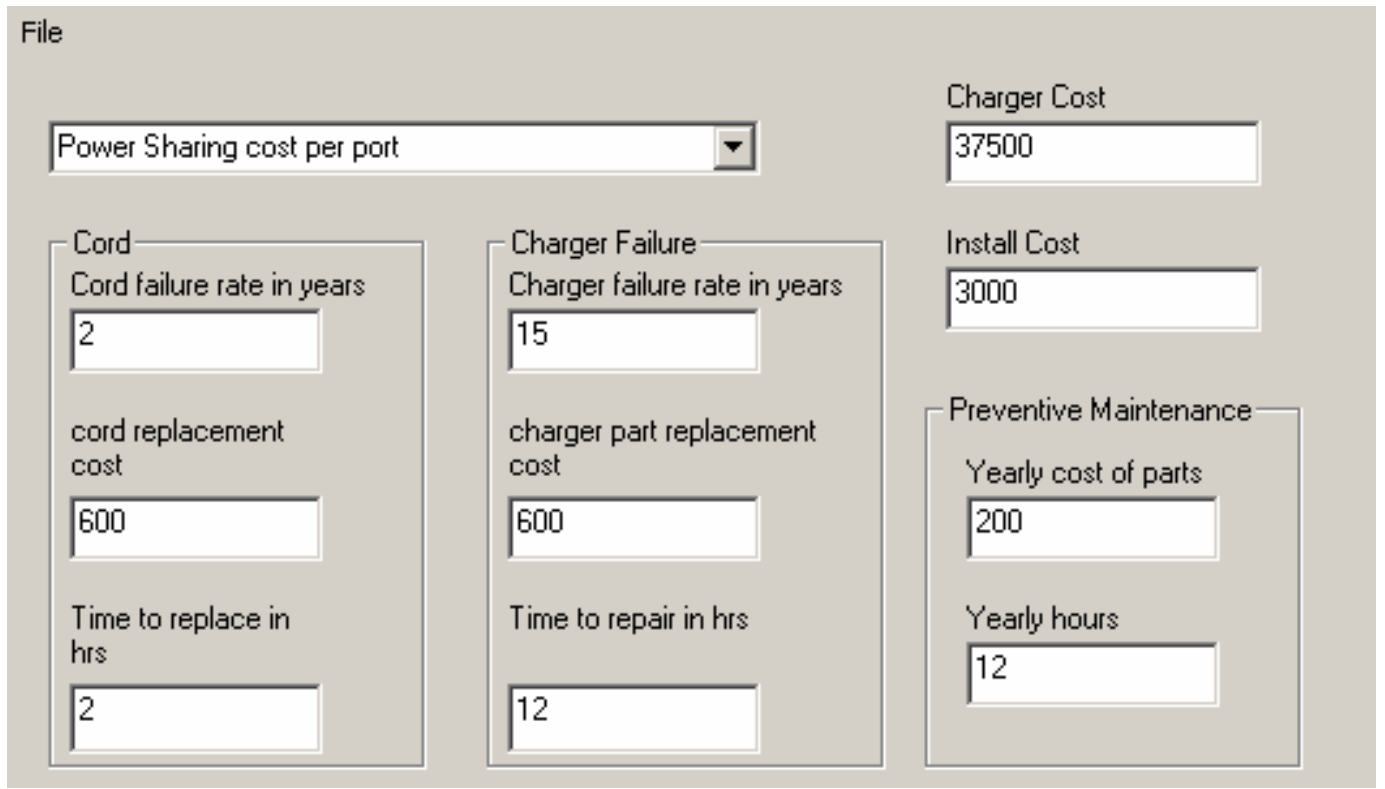




\section{Appendix B - Airport “B” Input Data and Results Summary}


Appendix B

Airport "B" Input Data and Results Summary

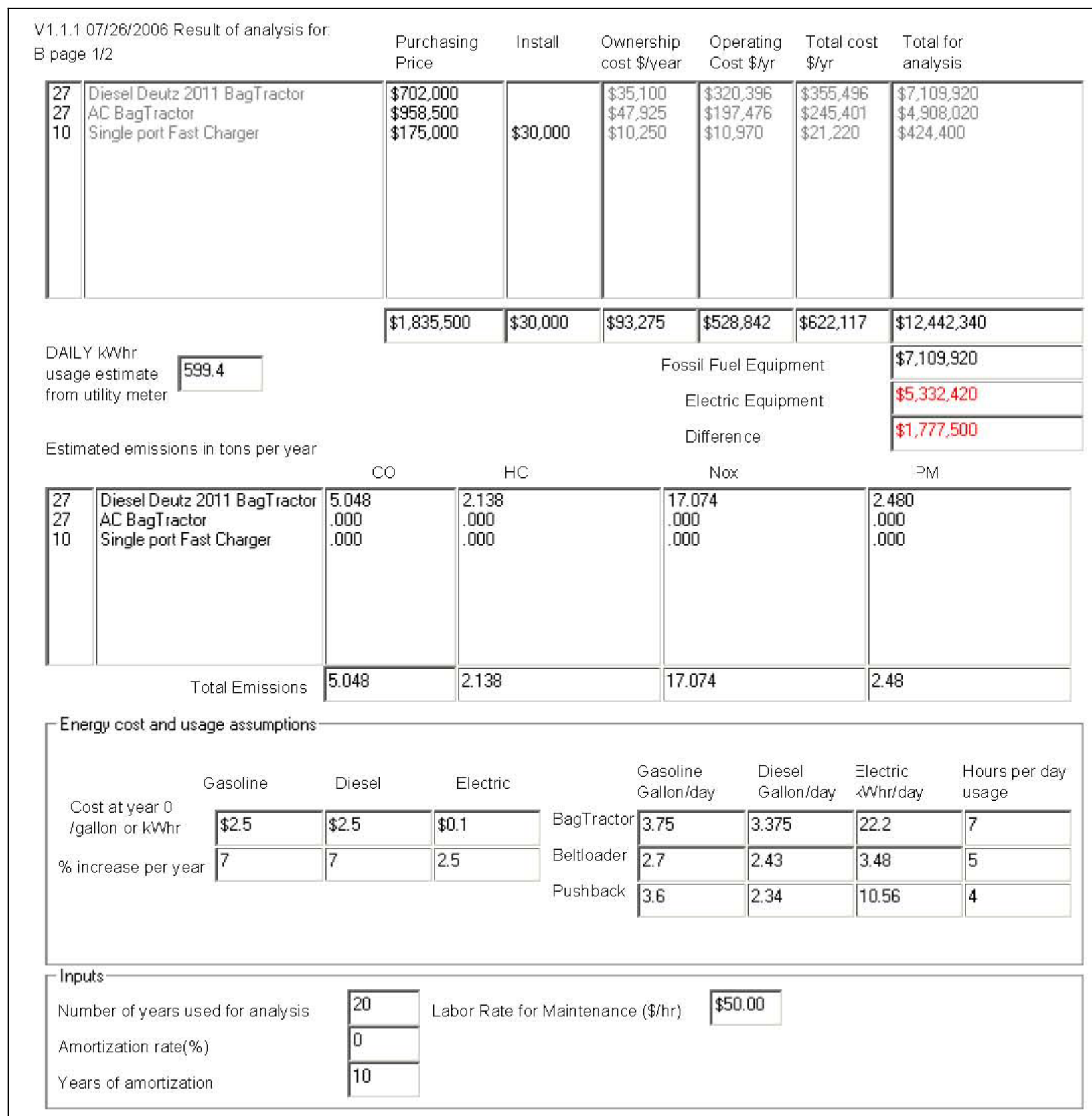


Appendix B

Airport "B" Input Data and Results Summary

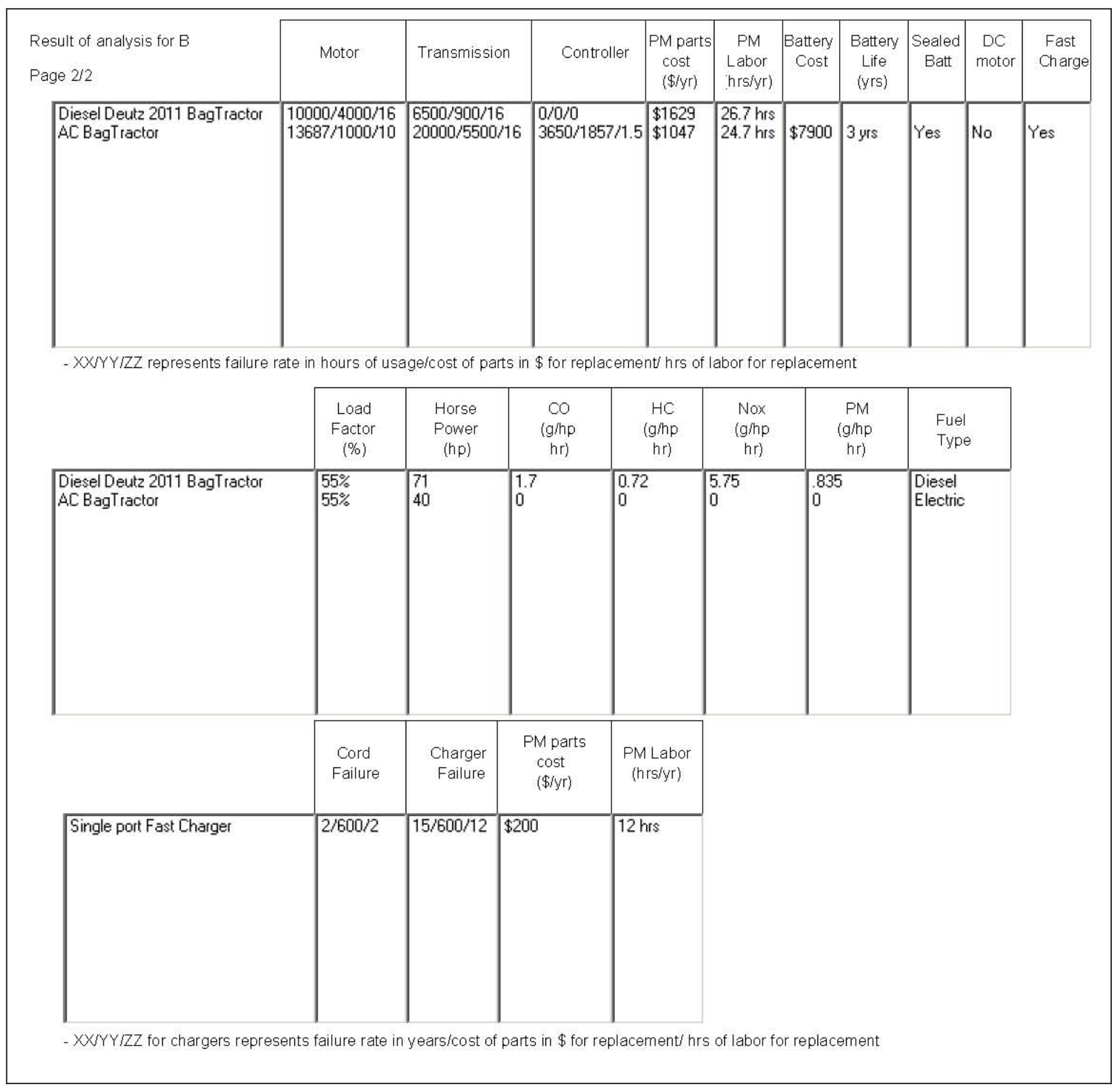

B-3 
Appendix B

Airport "B" Input Data and Results Summary

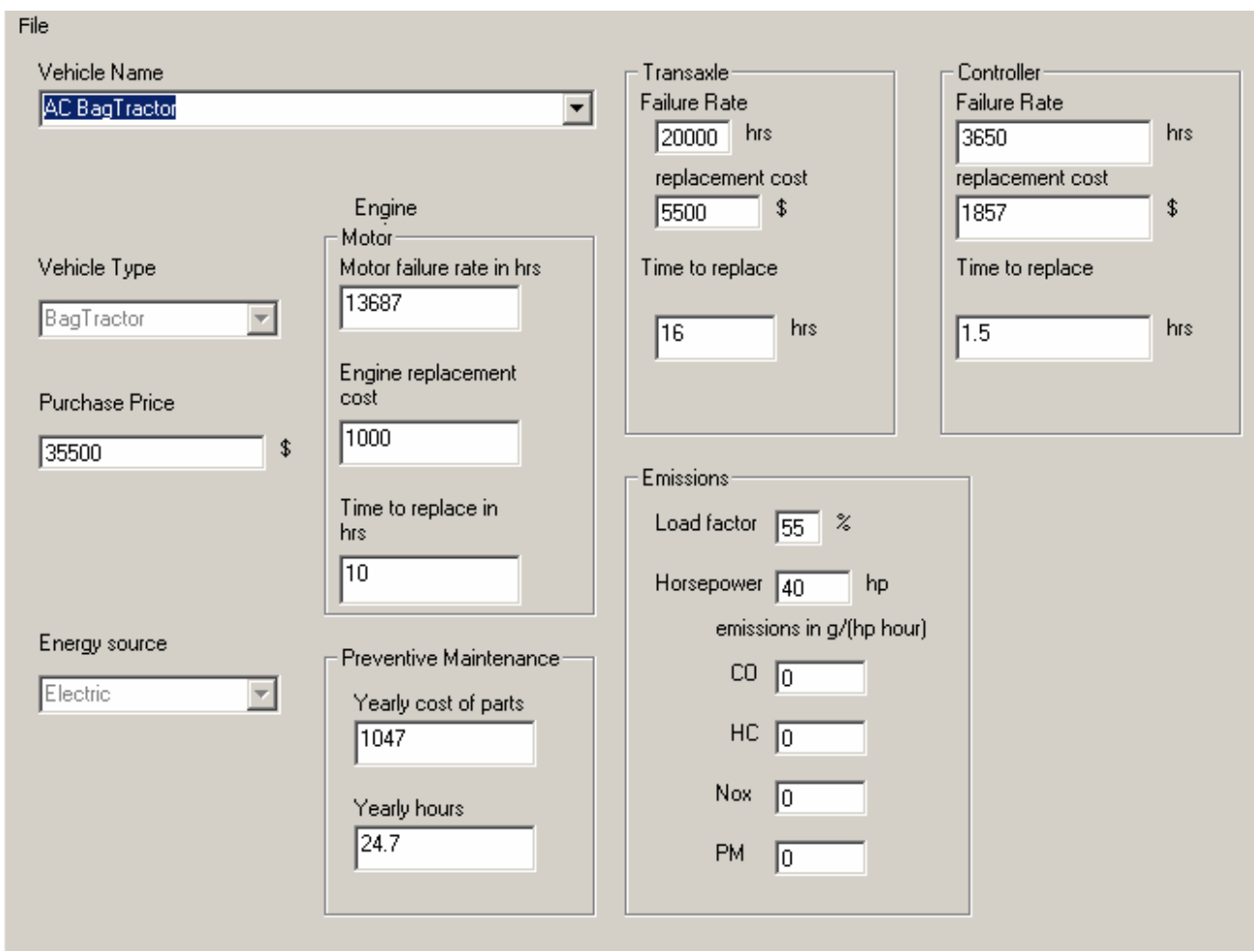

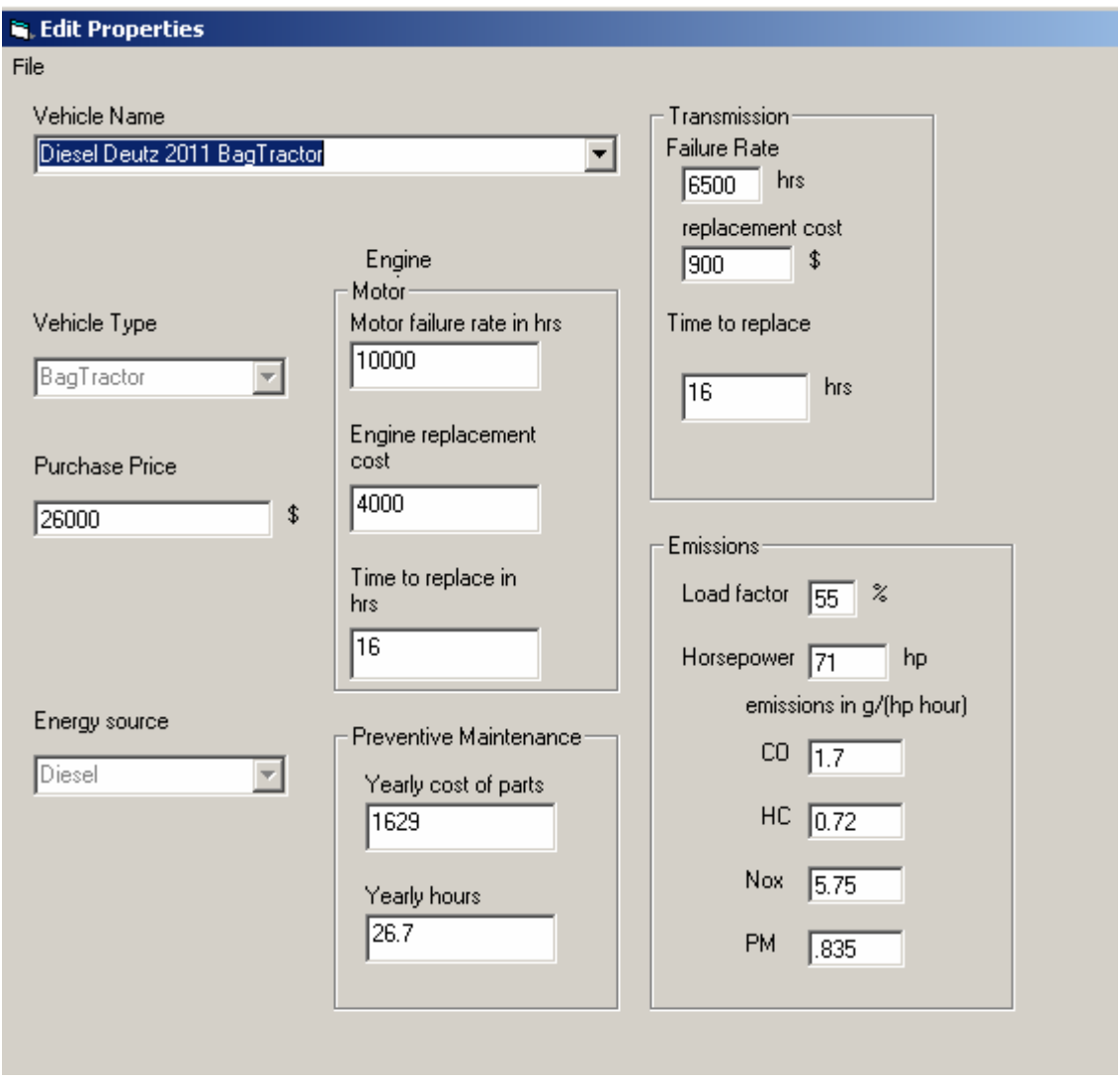


Appendix C

Airport "C" Input Data and Results Summary

\section{Appendix C - Airport "C" Input Data and Results Summary}


Appendix C

Airport "C" Input Data and Results Summary

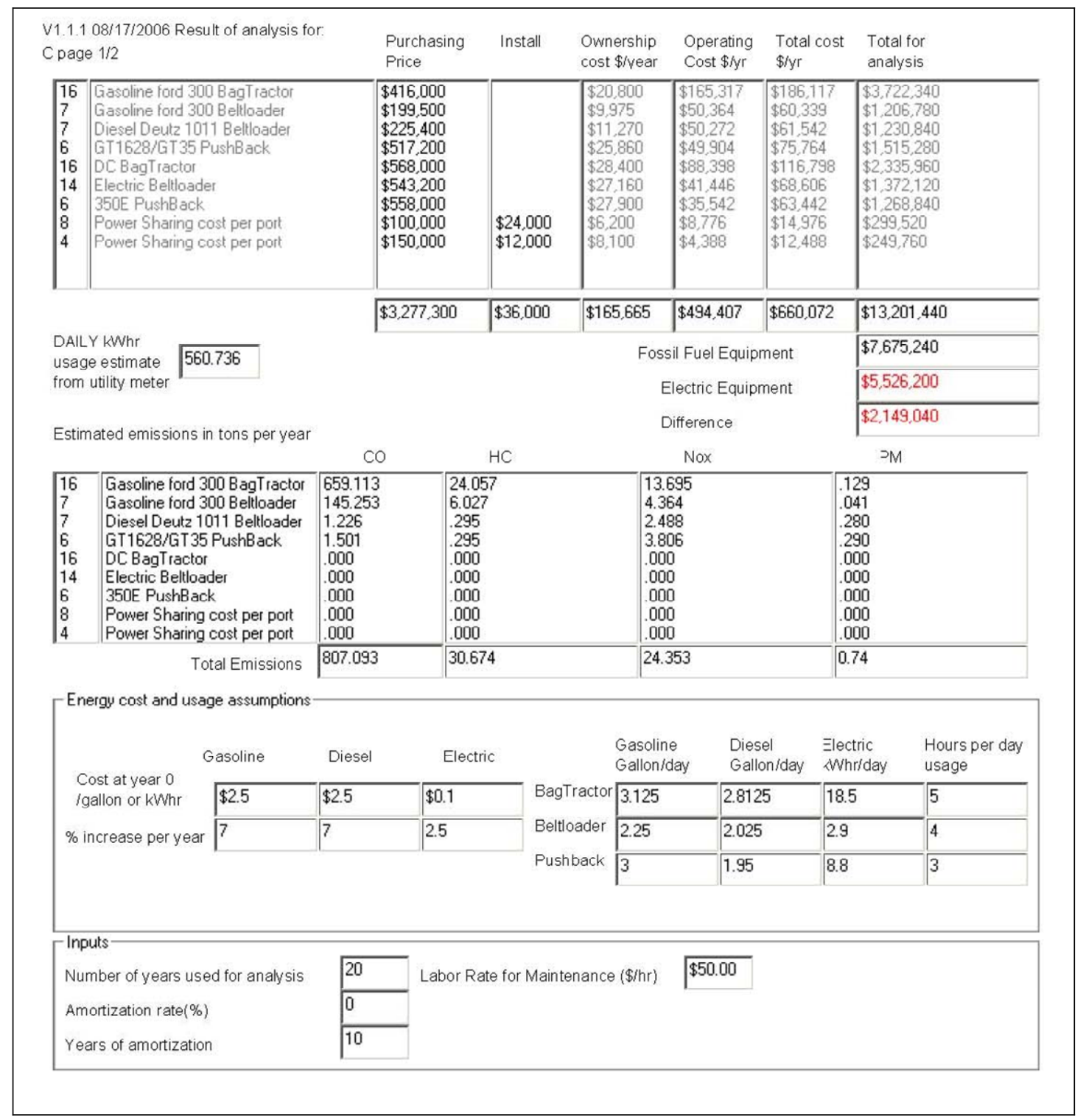


Appendix C

Airport "C" Input Data and Results Summary

\begin{tabular}{l} 
Result of analysis for C \\
\cline { 2 - 7 } \\
Page 2/2
\end{tabular}

- XWYYIZZ represents failure rate in hours of usage/cost of parts in $\$$ for replacement $\mathrm{hrs}$ of labor for replacement

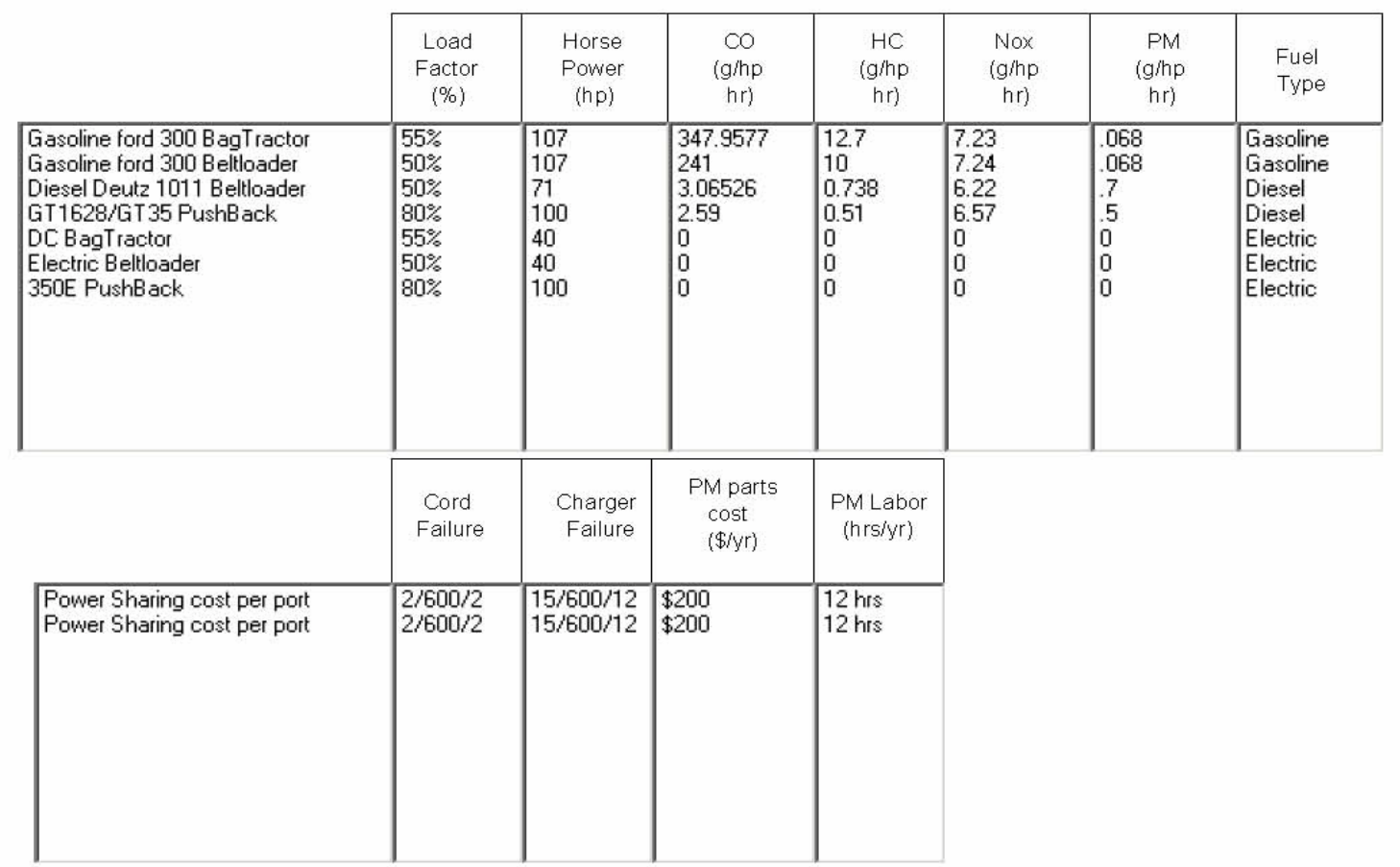

- XXYYIZZ for chargers represents failure rate in years/cost of parts in $\$$ for replacement/ hrs of labor for replacement 
Appendix C

Airport "C" Input Data and Results Summary
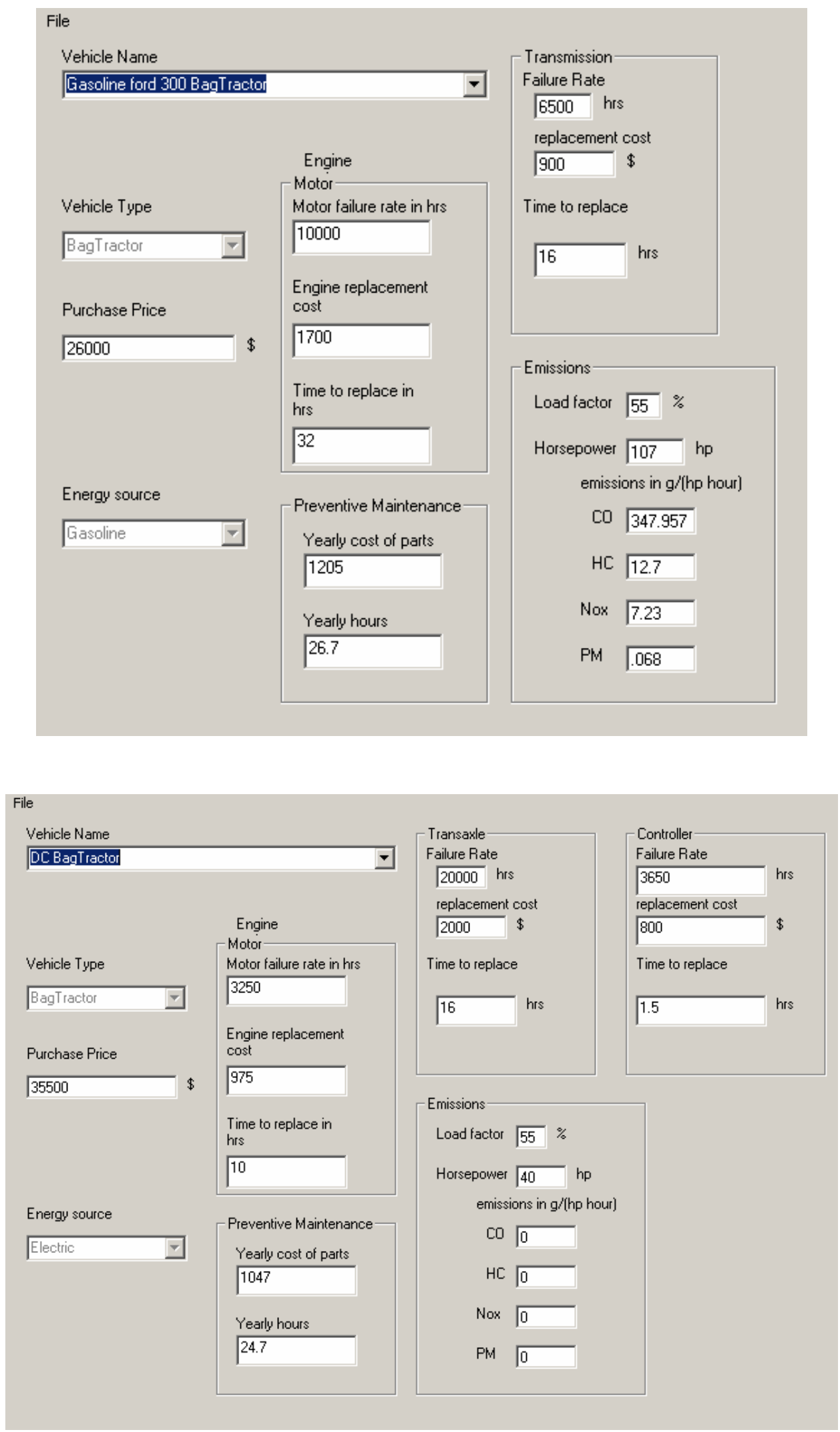
Appendix C

Airport "C" Input Data and Results Summary
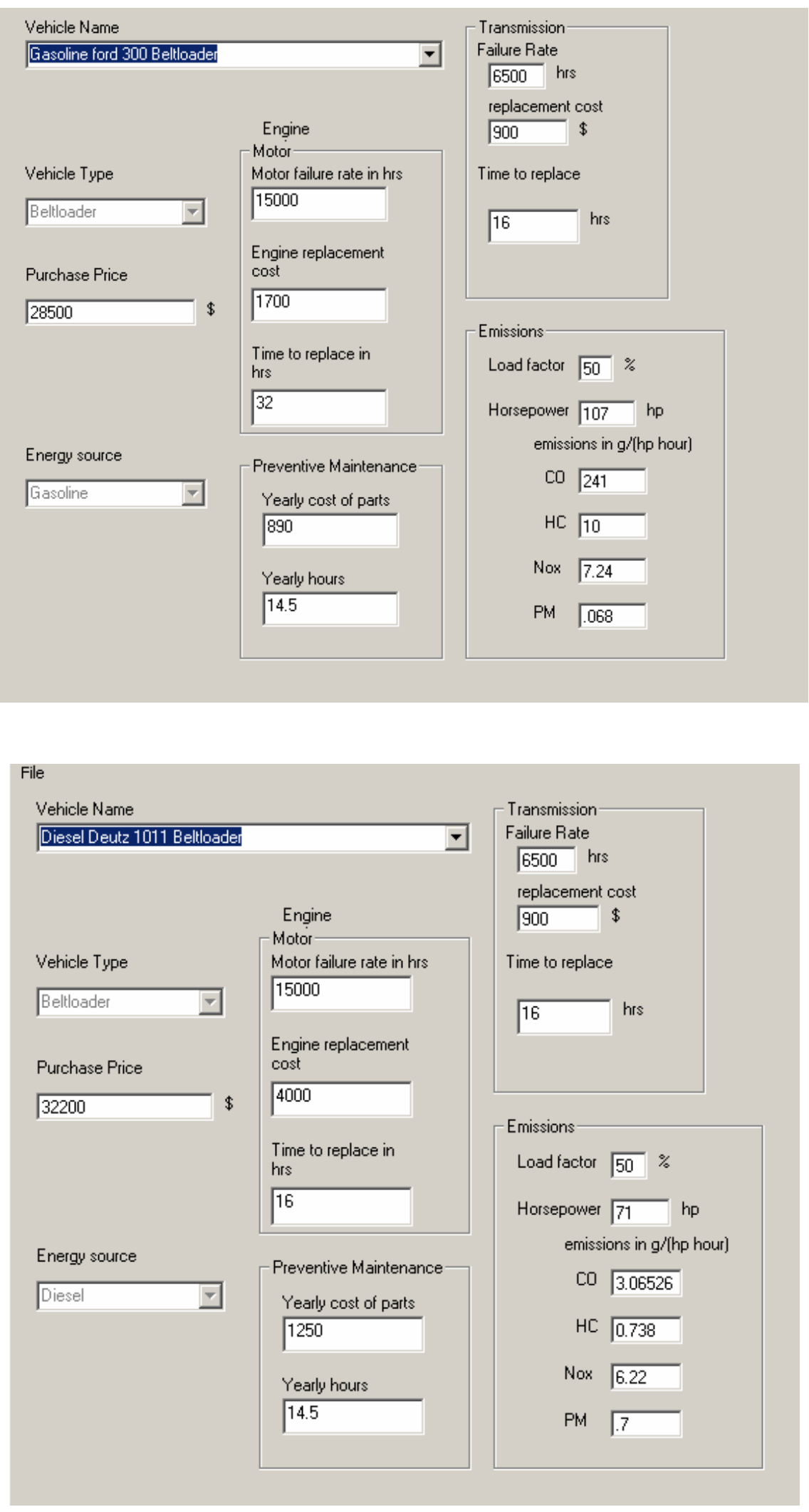
Appendix C

Airport "C" Input Data and Results Summary
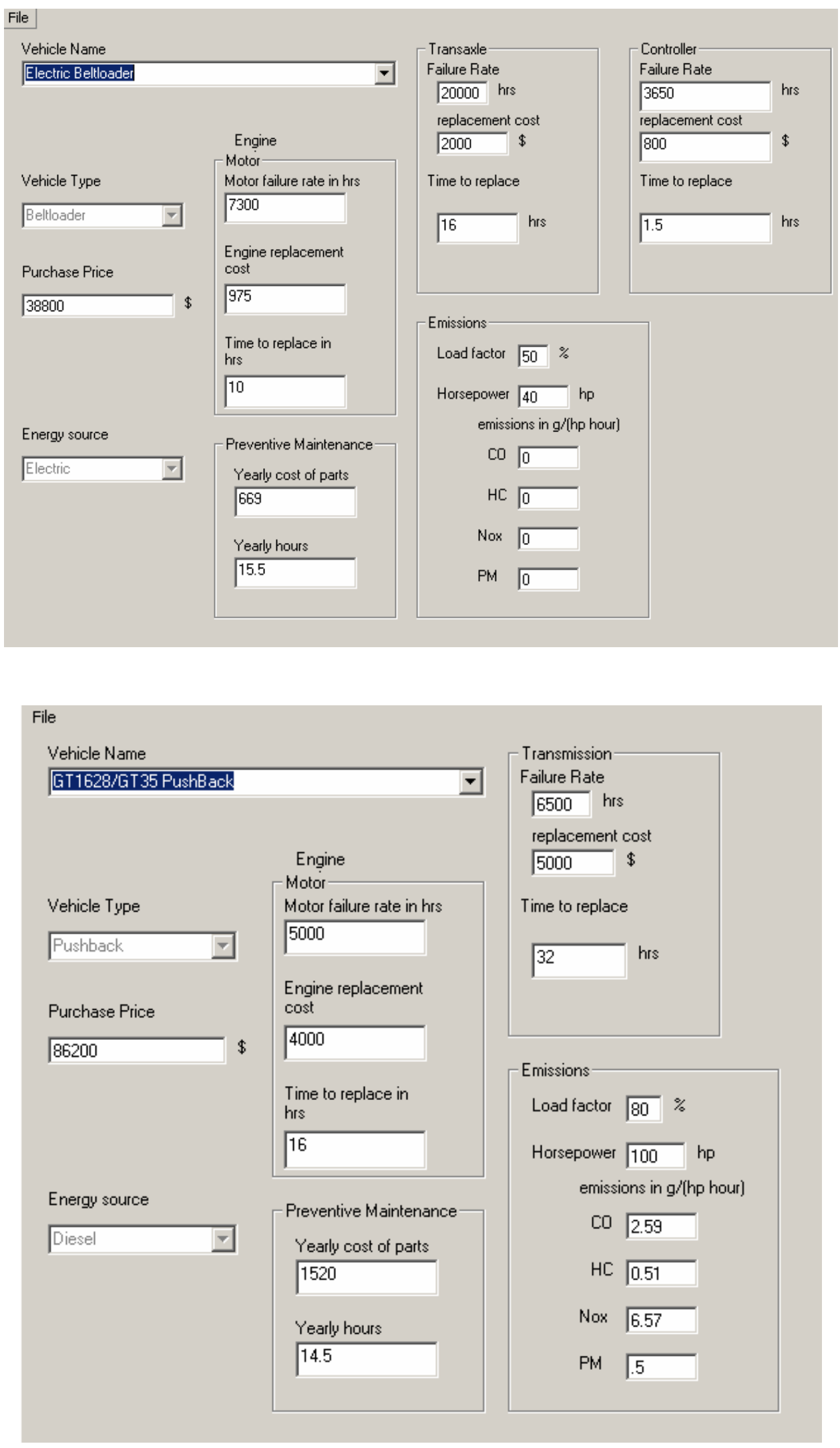
Appendix C

Airport "C" Input Data and Results Summary

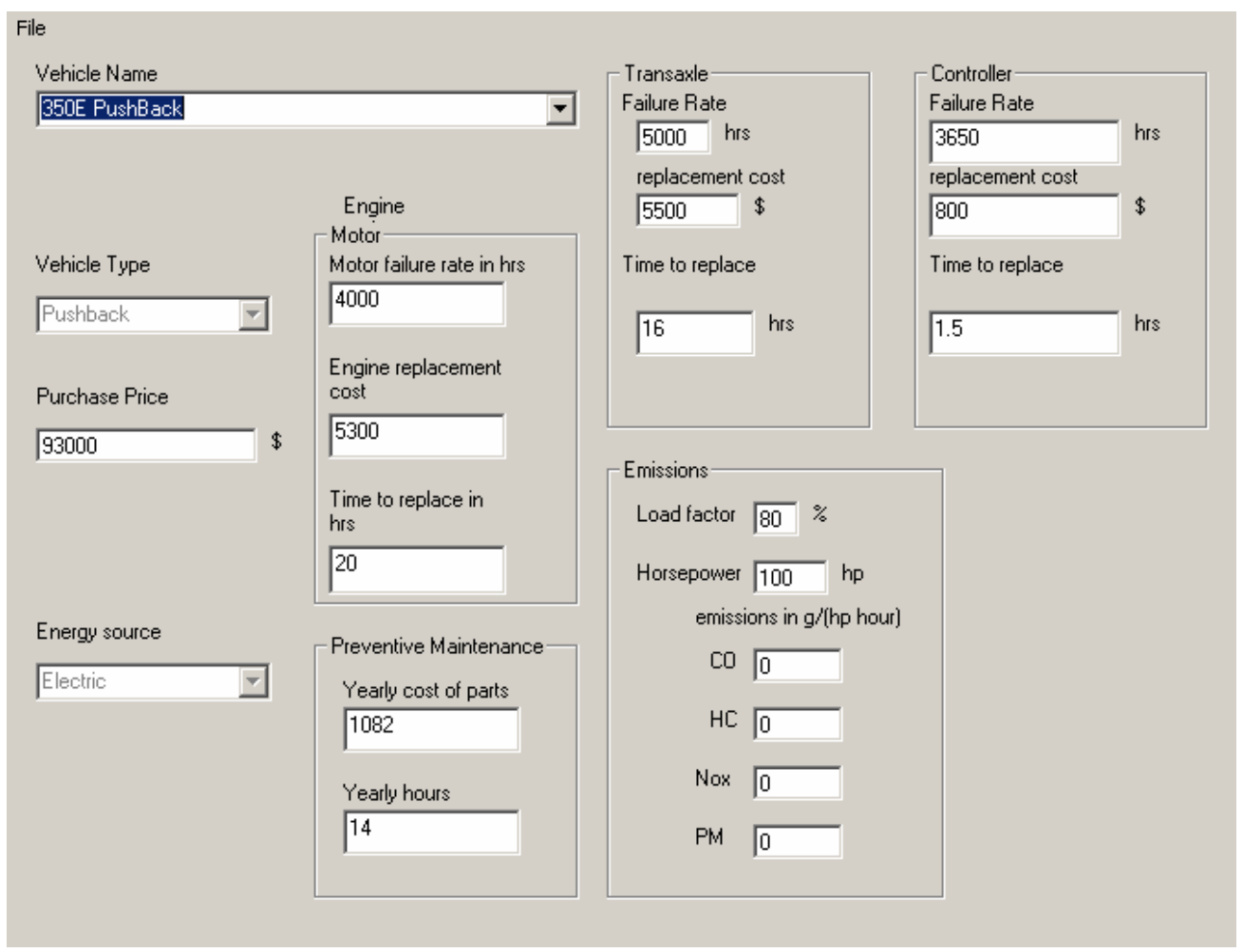

File

Power Sharing cost per port

- Cord-

Cord failure rate in years

2

cord replacement

cost

600

Time to replace in hrs

2
- Charger Failure

Charger failure rate in years

15

charger part replacement

cost

600

Time to repair in hrs

12
Charger Cost

37500

Install Cost

3000

-Preventive Maintenance

Yearly cost of parts

200

Yearly hours

12 
Appendix C

Airport "C" Input Data and Results Summary

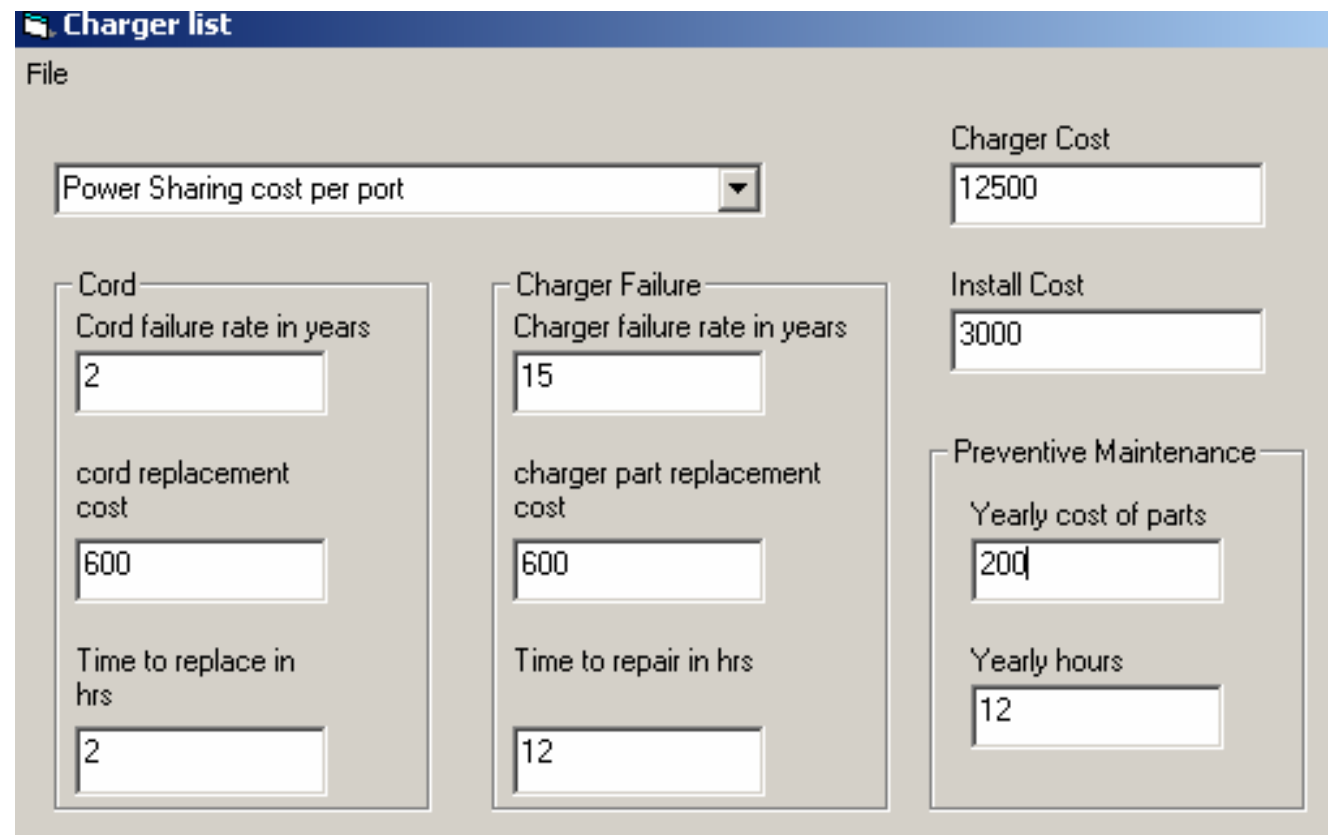




\section{Appendix D - Airport “D” Input Data and Results Summary}


Appendix D

Airport "D” Input Data and Results Summary

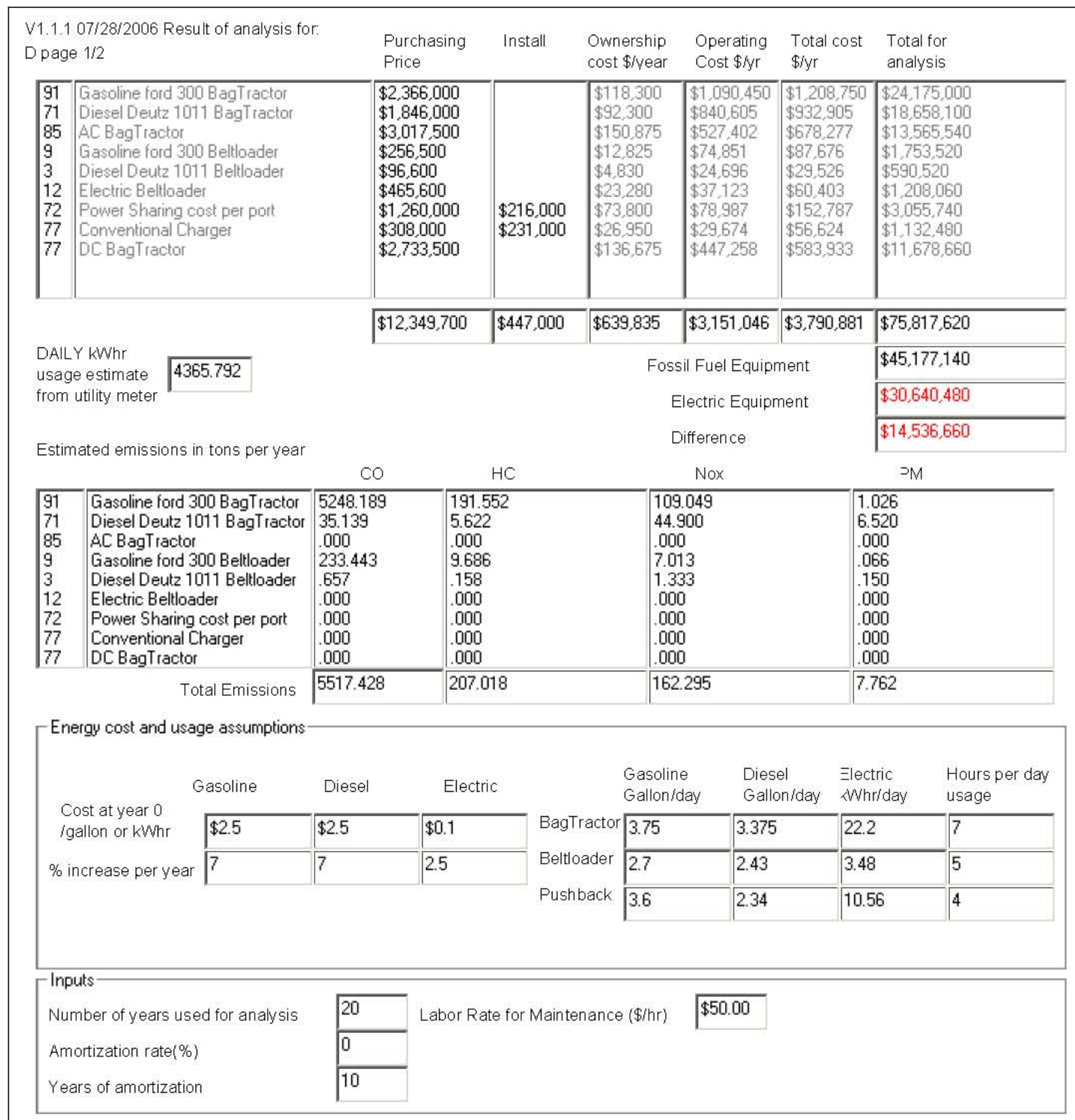


Appendix D

Airport “D” Input Data and Results Summary

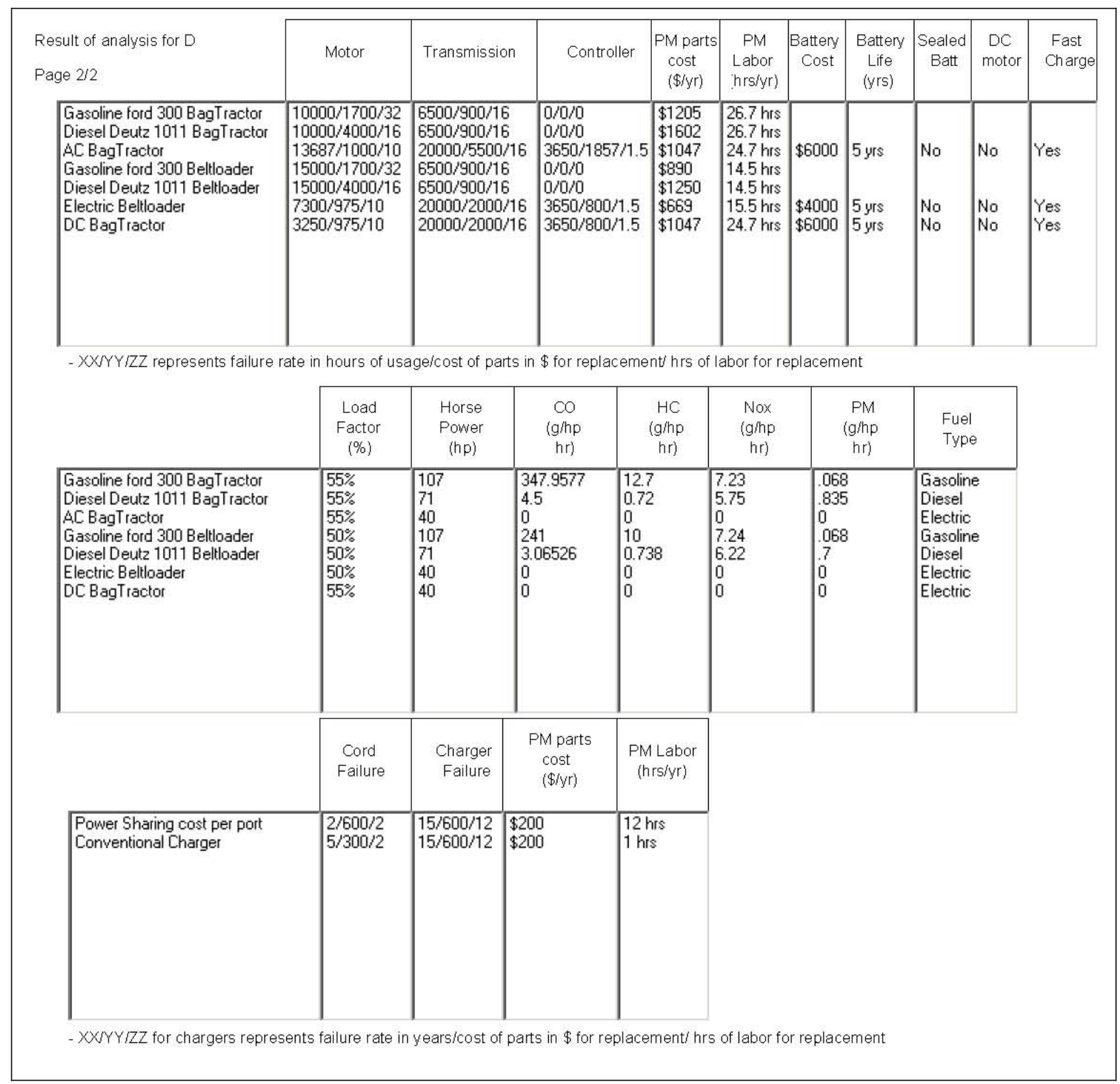


Appendix D

Airport “D” Input Data and Results Summary
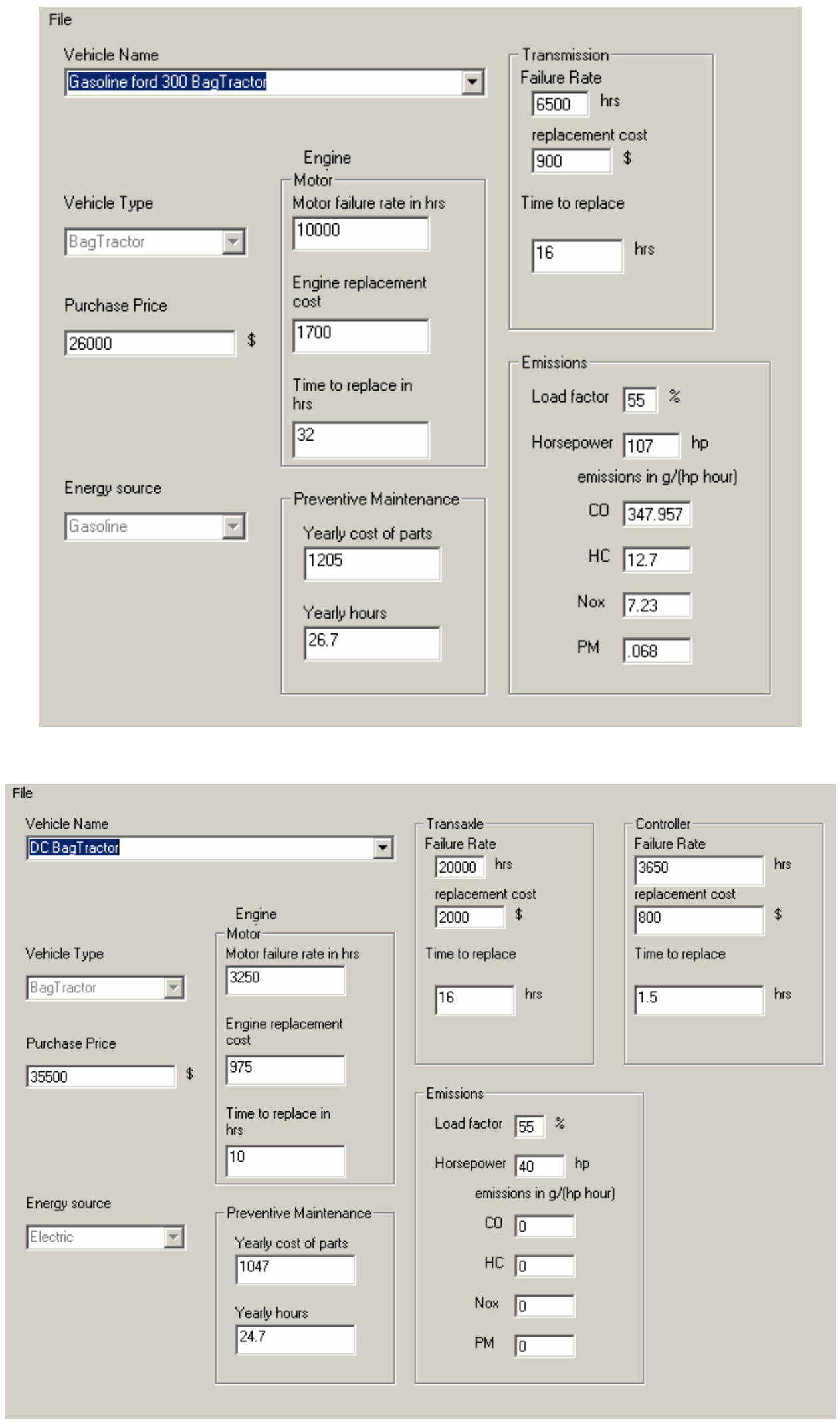
Appendix D

Airport “D” Input Data and Results Summary
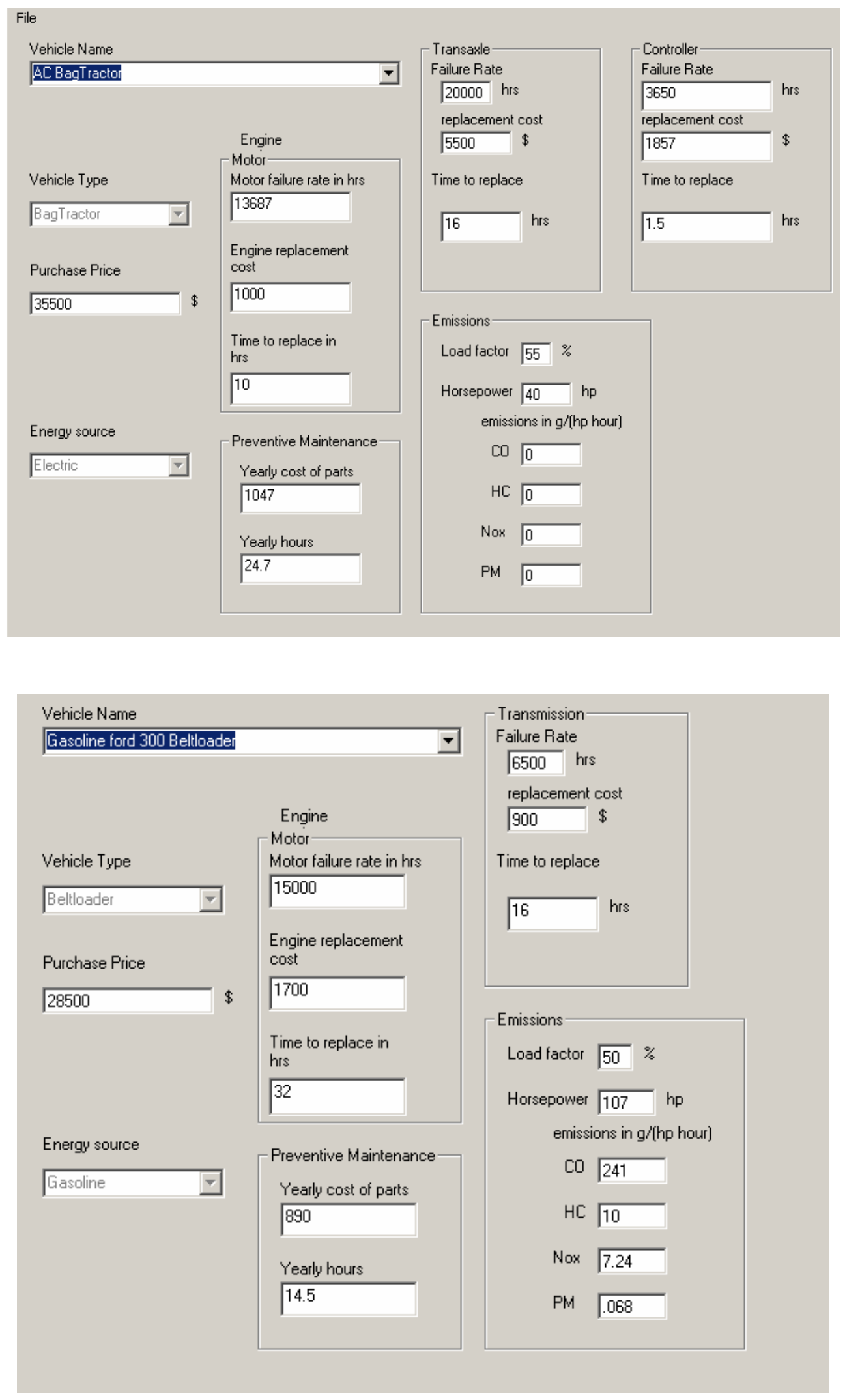
Appendix D

Airport “D” Input Data and Results Summary
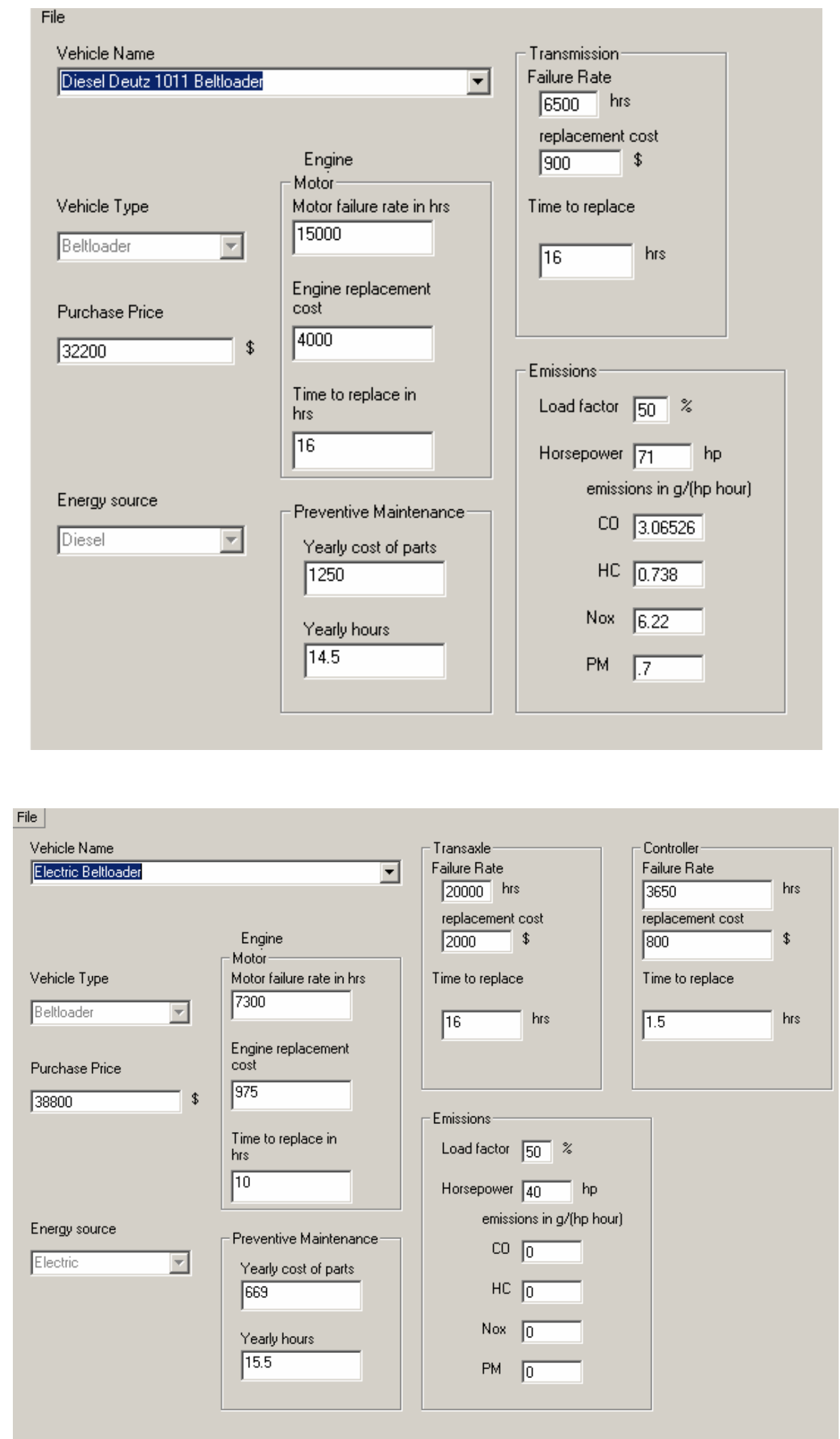
Appendix D

Airport "D" Input Data and Results Summary
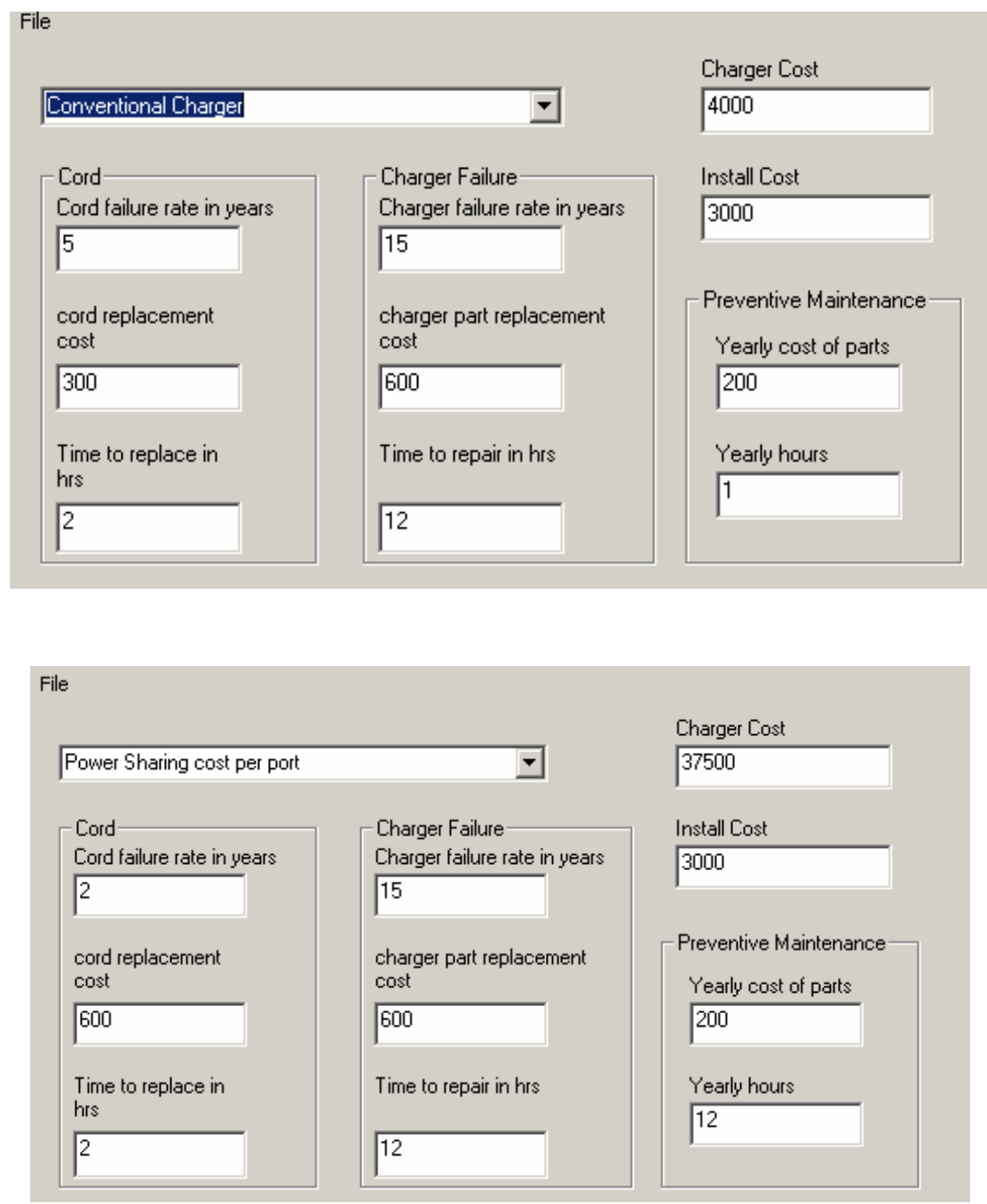
Appendix E

High Level Data Trees

\section{Appendix E - High-Level Data Trees}


Appendix E

High Level Data Trees

\section{GSE Equipment Capital Purchase Price}

\begin{tabular}{|c|c|c|c|c|}
\hline & & $\begin{array}{l}\text { Do you have actual GSE } \\
\text { Purchase Price? }\end{array}$ & Yes. & Enter Purchase Price \\
\hline & & No & & \\
\hline & & $\begin{array}{l}\text { What type of GSE } \\
\text { Equipment will you } \\
\text { purchase? }\end{array}$ & & \\
\hline $\begin{array}{l}\text { Bag Tractor - Electric, } \\
\text { Diesel or Gasoline }\end{array}$ & $\begin{array}{l}\text { Belt Loader - Electric, } \\
\text { Diesel or Gasoline }\end{array}$ & $\begin{array}{l}\text { PushBack - Electric, } \\
\text { Diesel or Gasoline }\end{array}$ & & \\
\hline $\begin{array}{l}\text { Est Values Provided by } \\
\text { Model }\end{array}$ & & & & \\
\hline $\begin{array}{l}\text { BT - Electric } \$ 29,500, \mathrm{BT} \\
\text { Diesel - } \$ 26,000, \quad \mathrm{BT} \text { - } \\
\text { Gasoline - } \$ 26,000\end{array}$ & $\begin{array}{l}\text { BL-Electric } \$ 34,800 \text {, } \\
\text { BL Diesel } \$ 32,200 \text {, } \\
\text { BL Gasoline } \$ 28,500\end{array}$ & $\begin{array}{l}\text { PB-Electric } \$ 87,000 \text {, } \\
\text { PB Diesel } \$ 86,200\end{array}$ & & \\
\hline $\begin{array}{l}\text { (Battery options - Sealed } \\
\$ 7900 \text {, Flooded } \$ 6000 \text { ) }\end{array}$ & $\begin{array}{l}\text { (Battery options - Sealed } \\
\$ 6200 \text {, flooded } \$ 4000 \text { ) }\end{array}$ & $\begin{array}{l}\text { (Battery Options - Sealed } \\
\$ 7900 \text {, flooded } \$ 6000 \text { ) }\end{array}$ & & \\
\hline $\begin{array}{l}\text { Notes: Sealed Battery - } \\
\text { 440Amphr; Flooded } \\
500 \mathrm{Amphr}\end{array}$ & $\begin{array}{l}\text { Notes: Sealed Battery - } \\
\text { 300Amphr; Flooded - } \\
\text { 300Amphr }\end{array}$ & $\begin{array}{l}\text { Notes: Sealed Battery - } \\
\text { 440Amphr; Flooded } \\
500 \mathrm{Amphr} \text {; Gasoline not } \\
\text { an option }\end{array}$ & & \\
\hline
\end{tabular}


Appendix E

High Level Data Trees

\section{Equipment Alterations Required?}

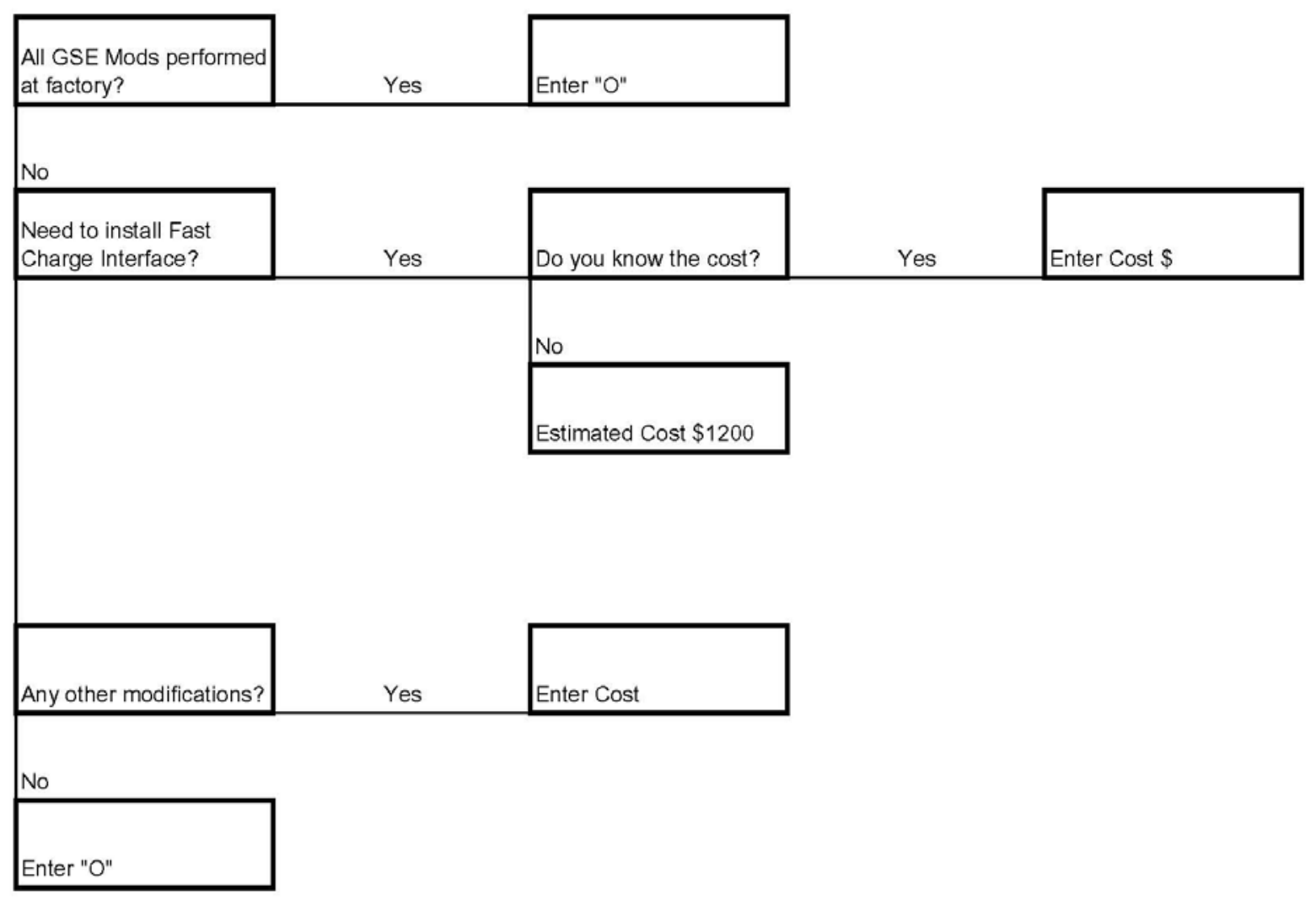


Appendix E

High Level Data Trees

\section{Charging Infrastructure Maintenance}

Input Annual Infrastructure

Maintenance Costs for PM,

Cords, General Maintenance

Input Separately:

PM, Cord, Chrgr

enter Repair

Unknown

General Charger PM - Filters,

Cleaning Etc.

Qtr per charger @

Enter actual PM

costs or Est. $1 \mathrm{hr} /$

$\$$ InHse Rate/hr

Cord Replacement due to general wear and pull-out (includes labor and parts to change out)

Replacement Rate

First Year - 5\%;

Second $\mathrm{Yr}-5 \%$;

Third Yr - 10\%;

est $\quad$ Fourth-plus - 15\%

Avg Replacement Cost: Enter

or $\$ 600$ plus $2 \mathrm{hrs}$ InHse labor

Other General Maintenance

(Outside of Warranty)

First Year - n/a;

Second $\mathrm{Yr}-5 \%$

(labor only);

Third Yr-6\%;

est $\quad$ Fourth-plus - $7 \%$

Avg Repair Cost (assume

Manufacture Rep): Enter or

$\$ 1,200$

Need:

1) Review replacement rate assumptions

2) Replacement hours - Inhouse labor

3) Review Cord Replacement Cost

4) General PM estimate 


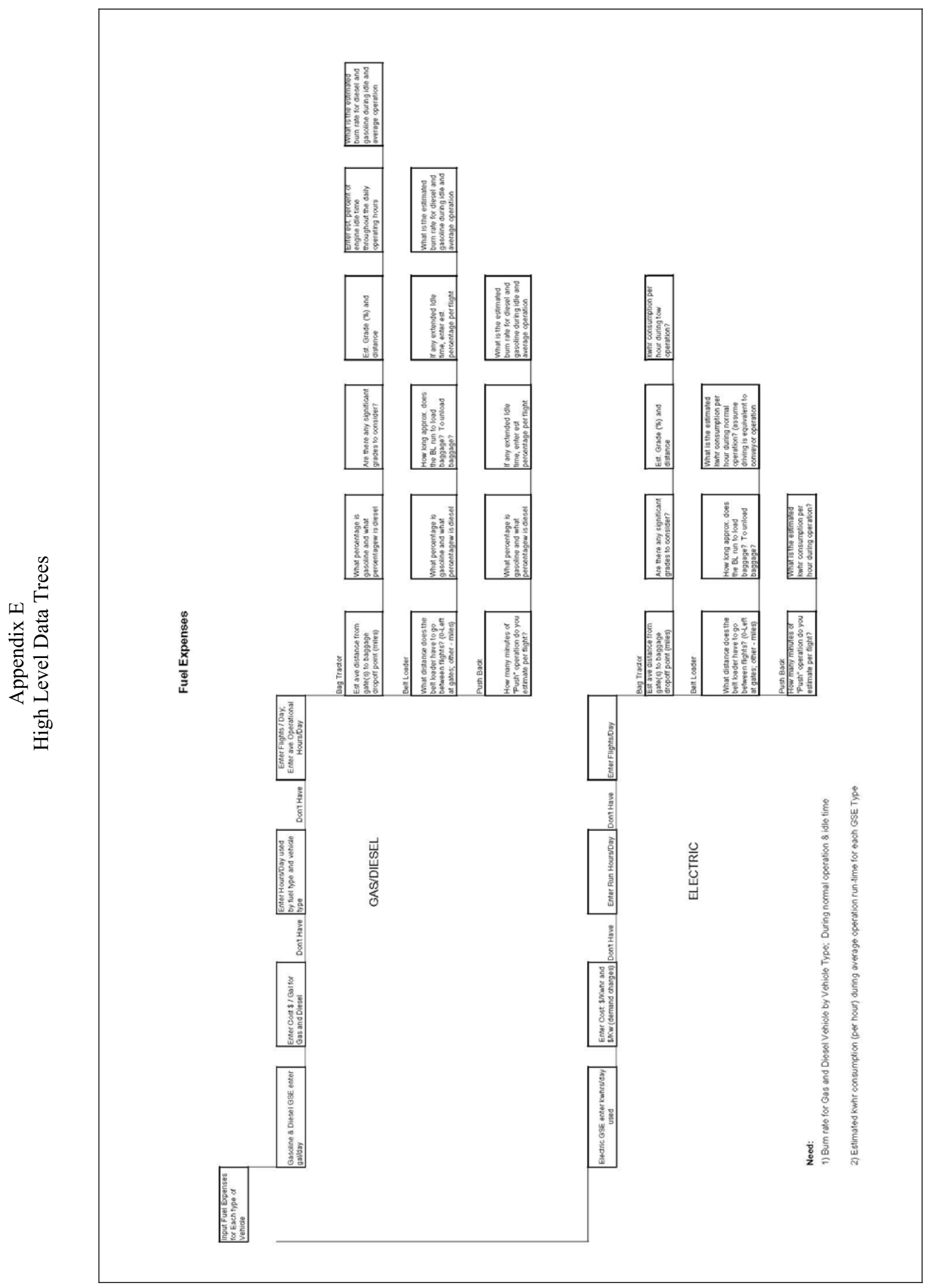


Appendix E

High Level Data Trees

GSE Maintenance

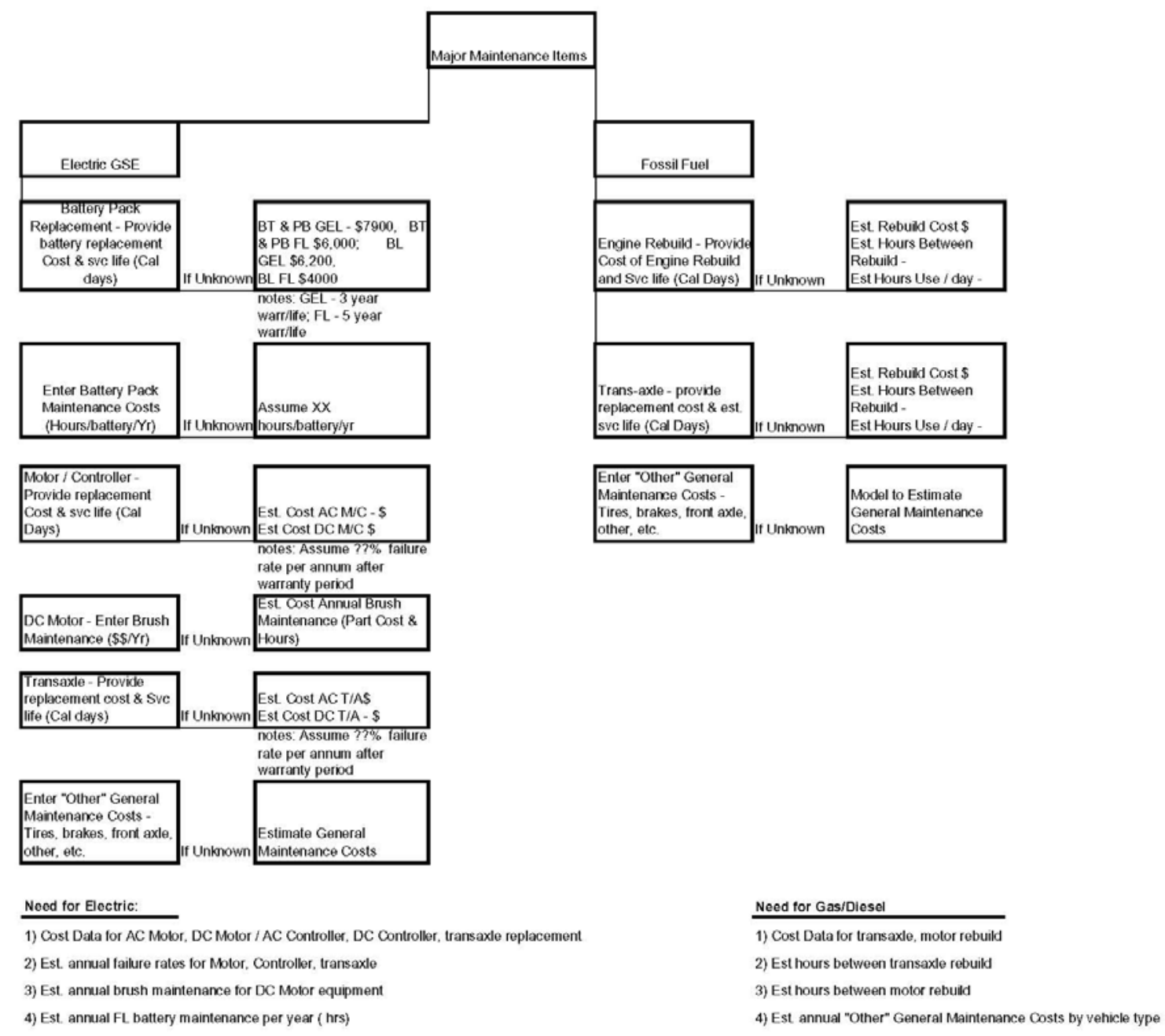


Appendix E

High Level Data Trees

\section{Charger Installation}

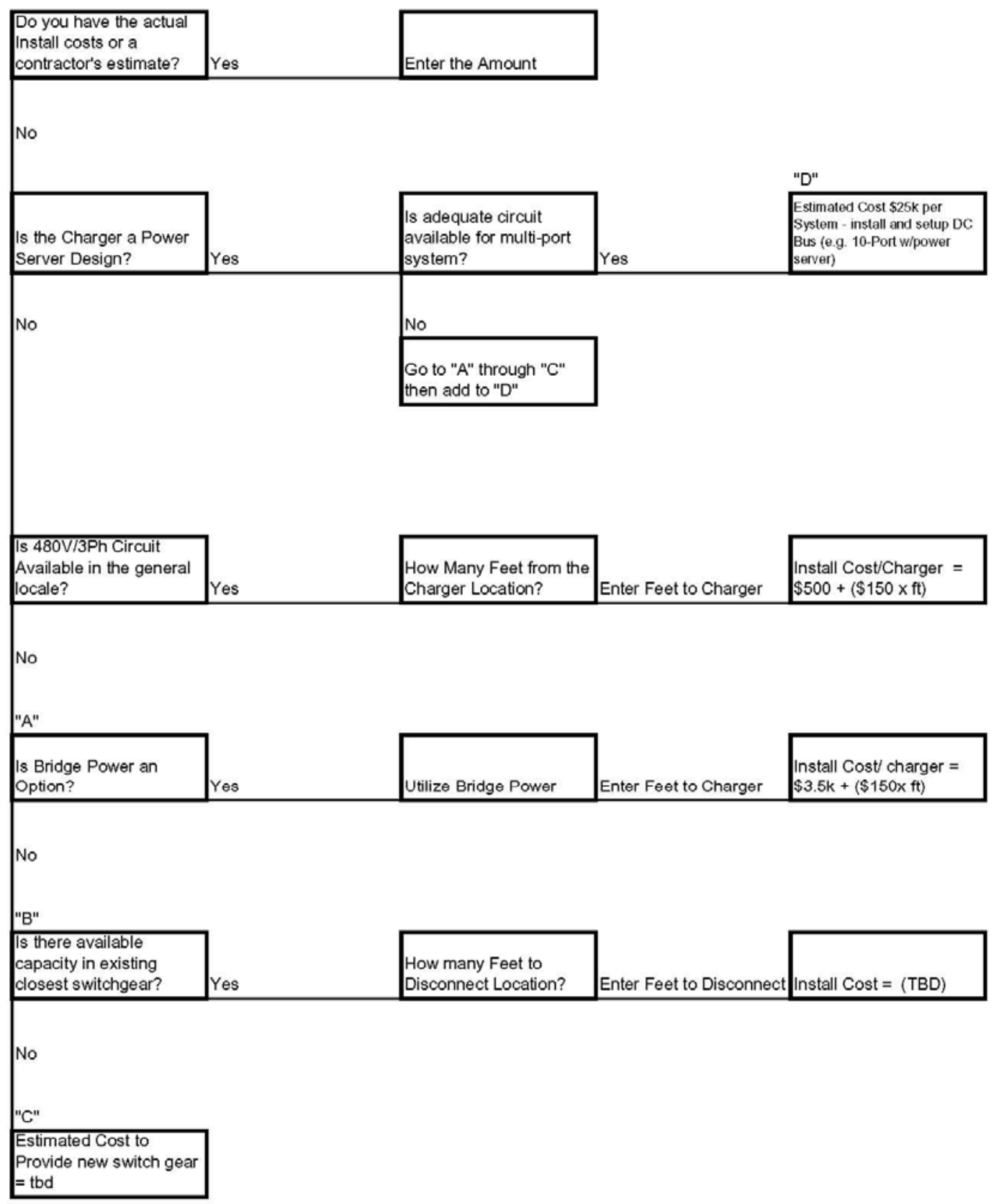


Appendix E

High Level Data Trees

\section{Battery Charging System}

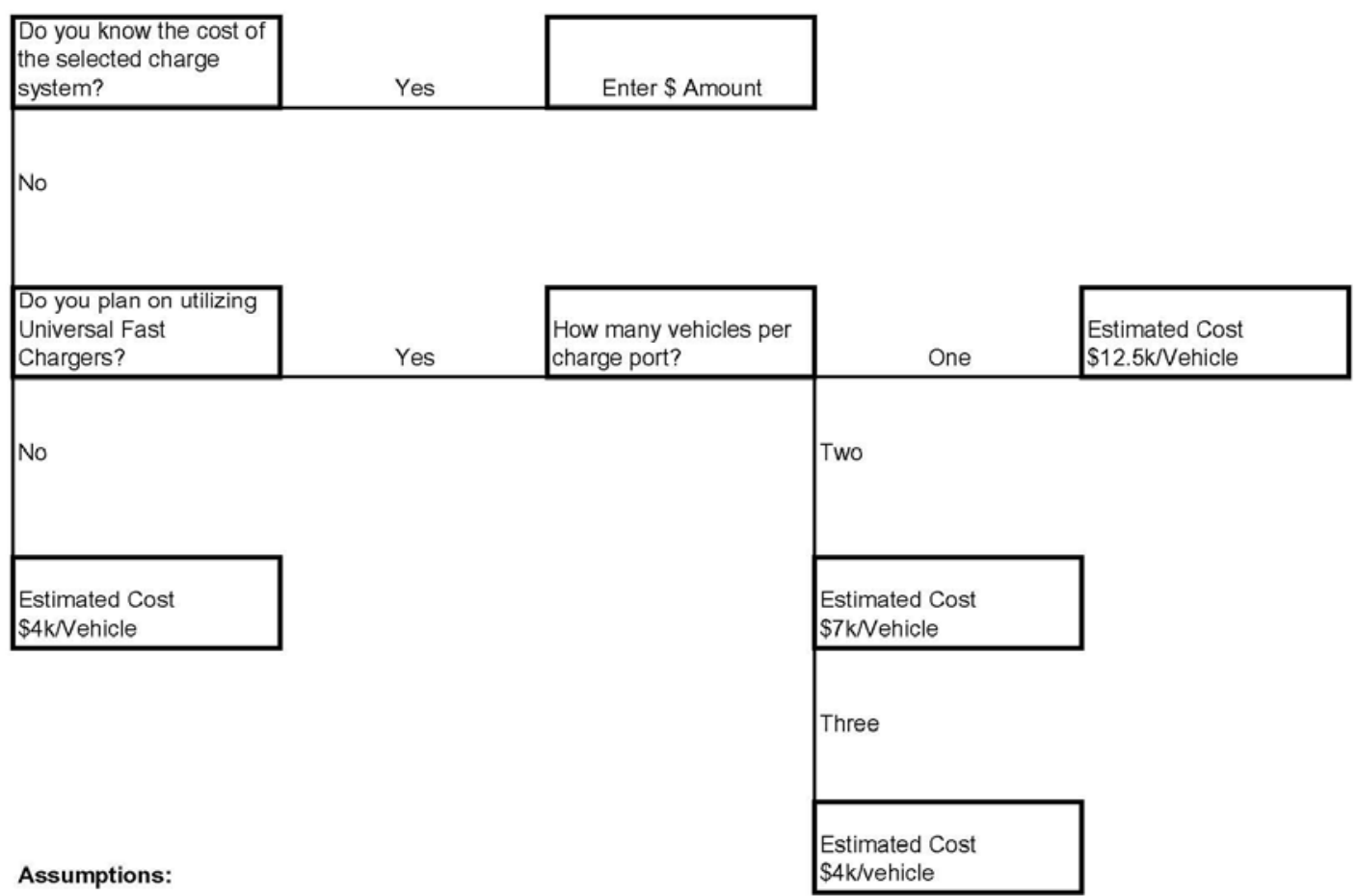

For Universal Fast Charge Systems; Either 15kW Dual Port Stand Alone Units or PowerServer Type 10-Port System

Conventional Charger based on Ferro-Resonant Design (Outdoor rated cabinet) - Single Voltage and Amphour Rating, 1 per vehicle 


\section{Attachment A - Ground Support Equipment Cost Model Operating Guide}




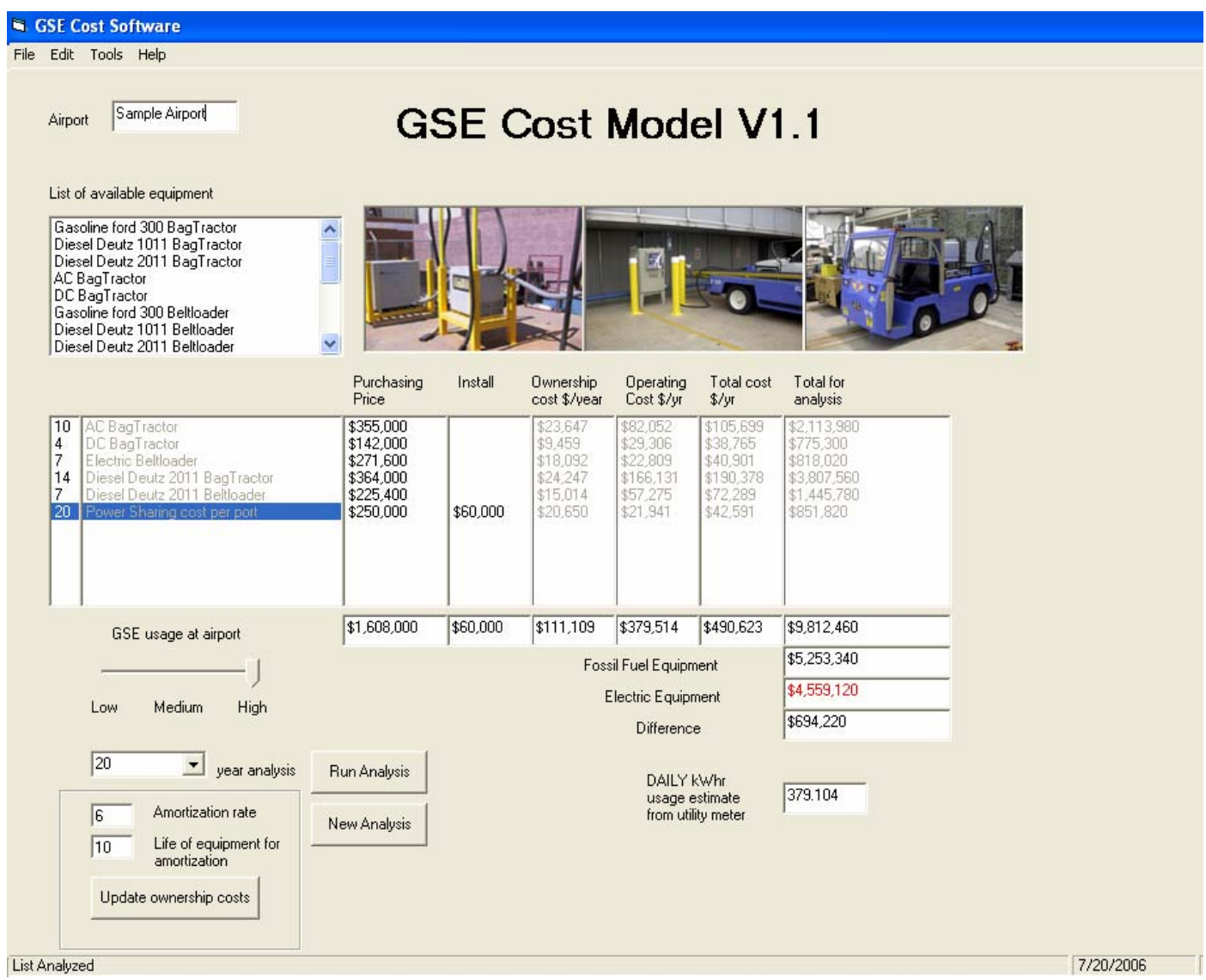




\section{Ground Support Equipment Cost Model Operating Guide Table of Contents}

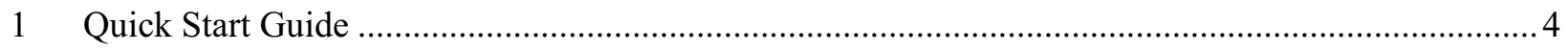

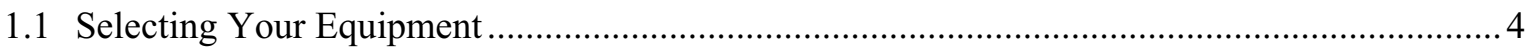

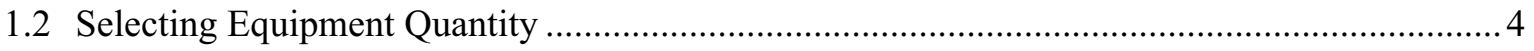

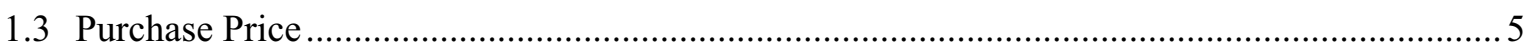

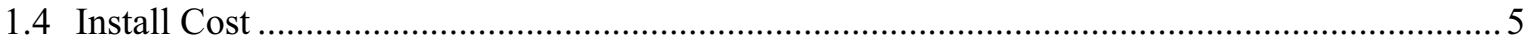

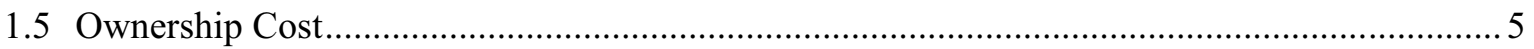

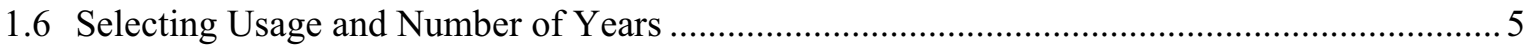

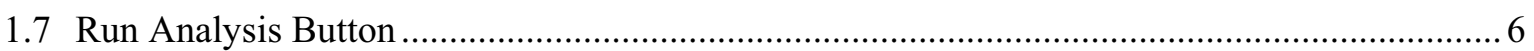

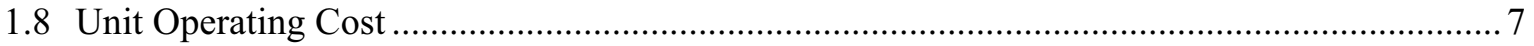

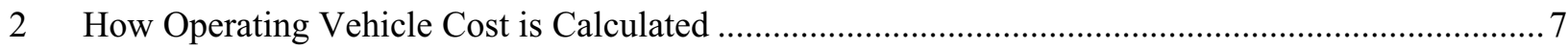

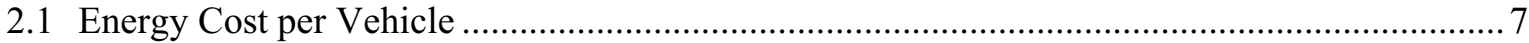

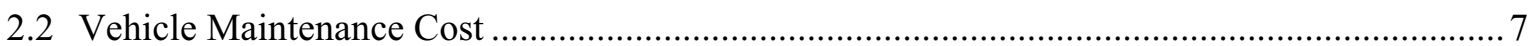

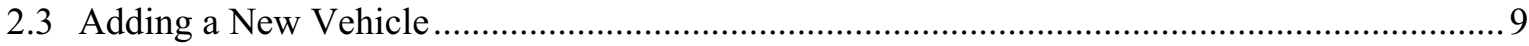

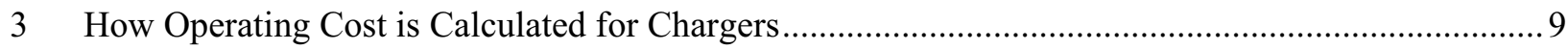

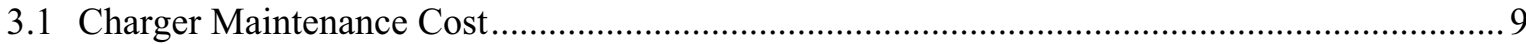

3.2 Adding a New Charger to the List of Available Equipment ................................................. 10

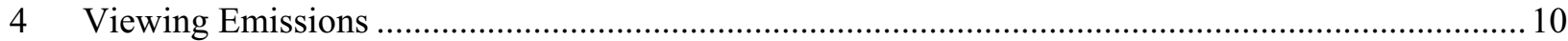

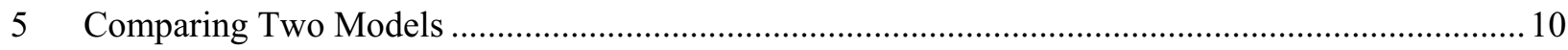


NOTE: This software is intended to predict the costs of different airline GSE options and their associated vehicle emissions. The model provides default values for three major pieces of equipment—-baggage tractors, belt loaders, and pushback tractors. This cost model utilizes actual cost data based on GSE operations by two major airlines at two airports on the west coast, one airport in the mid-west, and one airport in the northeastern United States.

\section{Quick Start Guide}

\subsection{Selecting Your Equipment}

Begin by naming the airport you desire to study. Select your equipment by double clicking on each type of equipment you wish to analyze on the top left list box. Your selection appears below for analysis. (Note: You can save this file at any time by selecting "File" at the top, then "Save.")

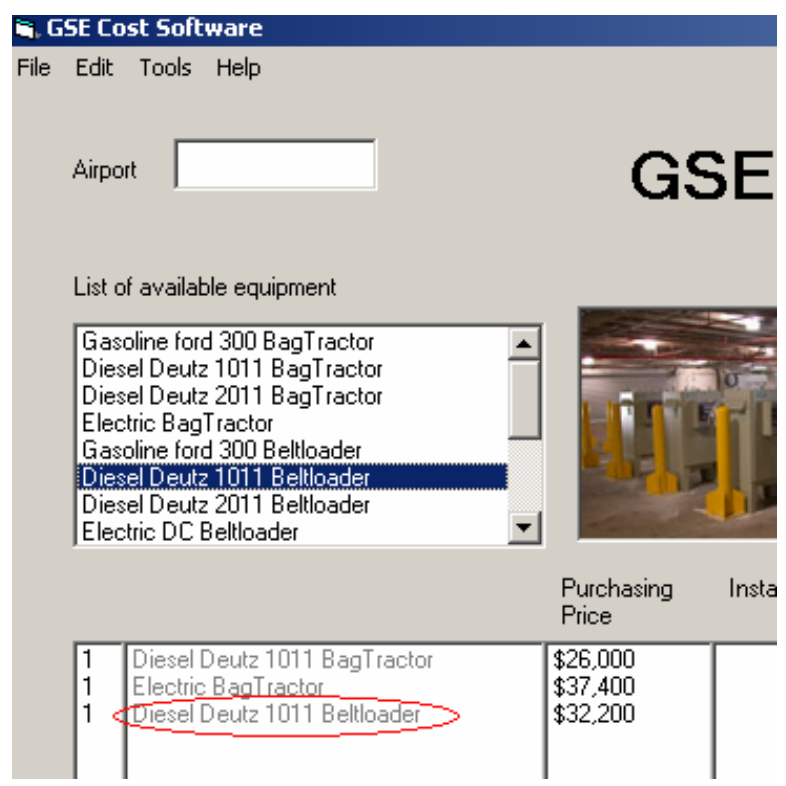

\subsection{Selecting Equipment Quantity}

Once you have selected your equipment, you can change your quantity by double clicking on the number on the left of the table for each corresponding piece of equipment.

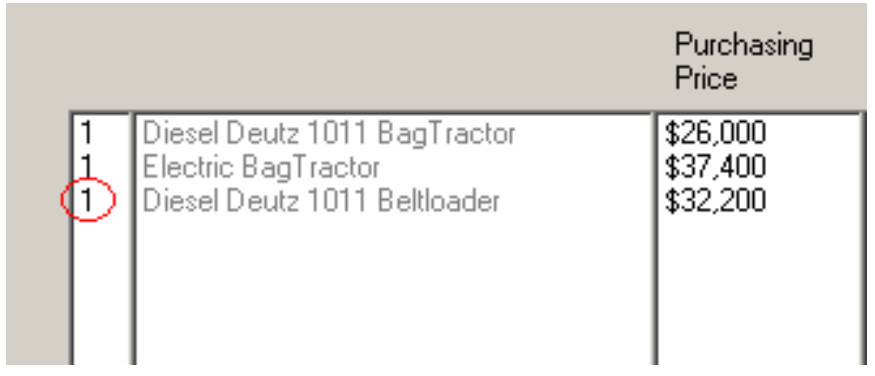

If you need to delete an item, just highlight the quantity of the equipment and hit "delete". If you want to delete all your selections or start a new analysis, click "New Analysis" or select "File" then "New." (Caution: If you have not saved the current file before performing this action, any previous data will be deleted.) 


\subsection{Purchase Price}

Default numbers are provided by the model for all GSE equipment and charger types listed. Purchasing price can be modified by double clicking on it. The price you will need to enter is the unitary price for that specific equipment.

\subsection{Install Cost}

Install cost applies to chargers; double clicking on that value can modify the default value. This is a unitary cost and applies only for one charger or one port in the case of multi-port systems. The default values assume that available power is within reasonable vicinity, and no major switchgear or utility feeds are required. These numbers are only defaults and can be modified by the user as necessary.

\subsection{Ownership Cost}

Ownership cost is a calculated number based on interest rate, life of equipment, purchasing cost, and install cost (if applicable).

Ownership cost spreads the cost of the equipment and installation over the life of the equipment at a given interest rate.

Default value is $6 \%$ and a 10 -year amortization. These parameters can be changed in the boxes below the usage selector.

\subsection{Selecting Usage and Number of Years}

Usage of the equipment can be selected by clicking on the desired level of usage under the title called "GSE Usage at Airport." This will set some default values that were used for the analysis (see the parameters table below for details).

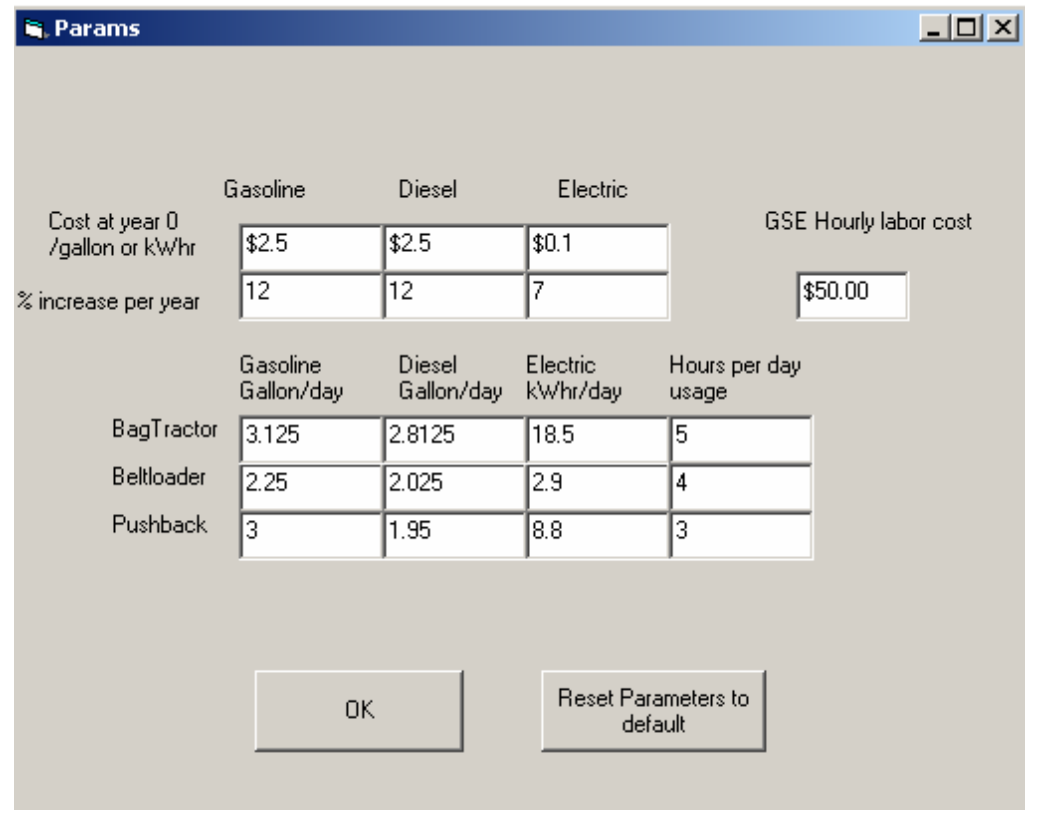


The "Year Analysis" combo box is also located under "GSE Usage at Airport." The "Year Analysis" affects your operating cost per year and your total cost for analysis.

\subsection{Run Analysis Button}

After you have selected the usage and the number of years for the analysis, click on the "Run Analysis" button. A new window pops up displaying parameters that are used for this analysis. If the default parameters are acceptable, click the "OK" button to get the operating cost, total cost, and total results.

If you desire to input your own values for your location, you can change any of the parameters in this window before you hit the "OK" button.

The tables below display the default parameters used depending on what GSE usage is selected on the main input screen.

Low GSE usage at airport default parameters

\begin{tabular}{|c|c|c|c|c|}
\hline & $\begin{array}{l}\text { Gasoline } \\
\text { Gallon/day }\end{array}$ & $\begin{array}{l}\text { Diesel } \\
\text { Gallon/day }\end{array}$ & $\begin{array}{l}\text { Electric } \\
\mathrm{kWh} / \text { day }\end{array}$ & $\begin{array}{l}\text { Hours per day } \\
\text { usage }\end{array}$ \\
\hline BagTractor & 2.5 & 2.25 & 14.8 & 3 \\
\hline Beltloader & 1.8 & 1.62 & 2.32 & 3 \\
\hline Pushback & 2.4 & 1.56 & 7.04 & 2 \\
\hline
\end{tabular}

Medium GSE usage at airport default parameters

\begin{tabular}{ll|l|l|l|}
\multirow{2}{*}{$\begin{array}{l}\text { Gasoline } \\
\text { Gallon/day }\end{array}$} & \multicolumn{1}{c}{$\begin{array}{l}\text { Diesel } \\
\text { Gallon/day }\end{array}$} & $\begin{array}{l}\text { Electric } \\
\text { kWhr/day }\end{array}$ & \multicolumn{1}{l}{$\begin{array}{l}\text { Hours per day } \\
\text { usage }\end{array}$} \\
\cline { 2 - 6 } Bagtor & 3.125 & 2.8125 & 18.5 & 5 \\
\cline { 2 - 5 } Beltloader & 2.25 & 2.025 & 2.9 & 4 \\
Pushback & 3 & 1.95 & 8.8 & 3
\end{tabular}

High GSE usage at airport default parameters

\begin{tabular}{c|l|l|l|l} 
& \multicolumn{1}{c}{$\begin{array}{l}\text { Gasoline } \\
\text { Gallon/day }\end{array}$} & \multicolumn{1}{c}{$\begin{array}{l}\text { Diesel } \\
\text { Gallon/day }\end{array}$} & $\begin{array}{l}\text { Electric } \\
\text { kWhr/day }\end{array}$ & $\begin{array}{l}\text { Hours per day } \\
\text { usage }\end{array}$ \\
\cline { 2 - 5 } BagTractor & 3.75 & 3.375 & 22.2 & 7 \\
Beltloader & 2.7 & 2.43 & 3.48 & 5 \\
Pushback & 3.6 & 2.34 & 10.56 & 4 \\
\cline { 2 - 5 } & & & &
\end{tabular}




\subsection{Unit Operating Cost}

The model provides a summary of unit operating costs for each piece of GSE and charging equipment for the entire period of the analysis. For example, if you select a 20 -year analysis, this would provide unitary cumulative costs over the period for each piece of equipment selected in the scenario. The following table is found under the "Tools" section.

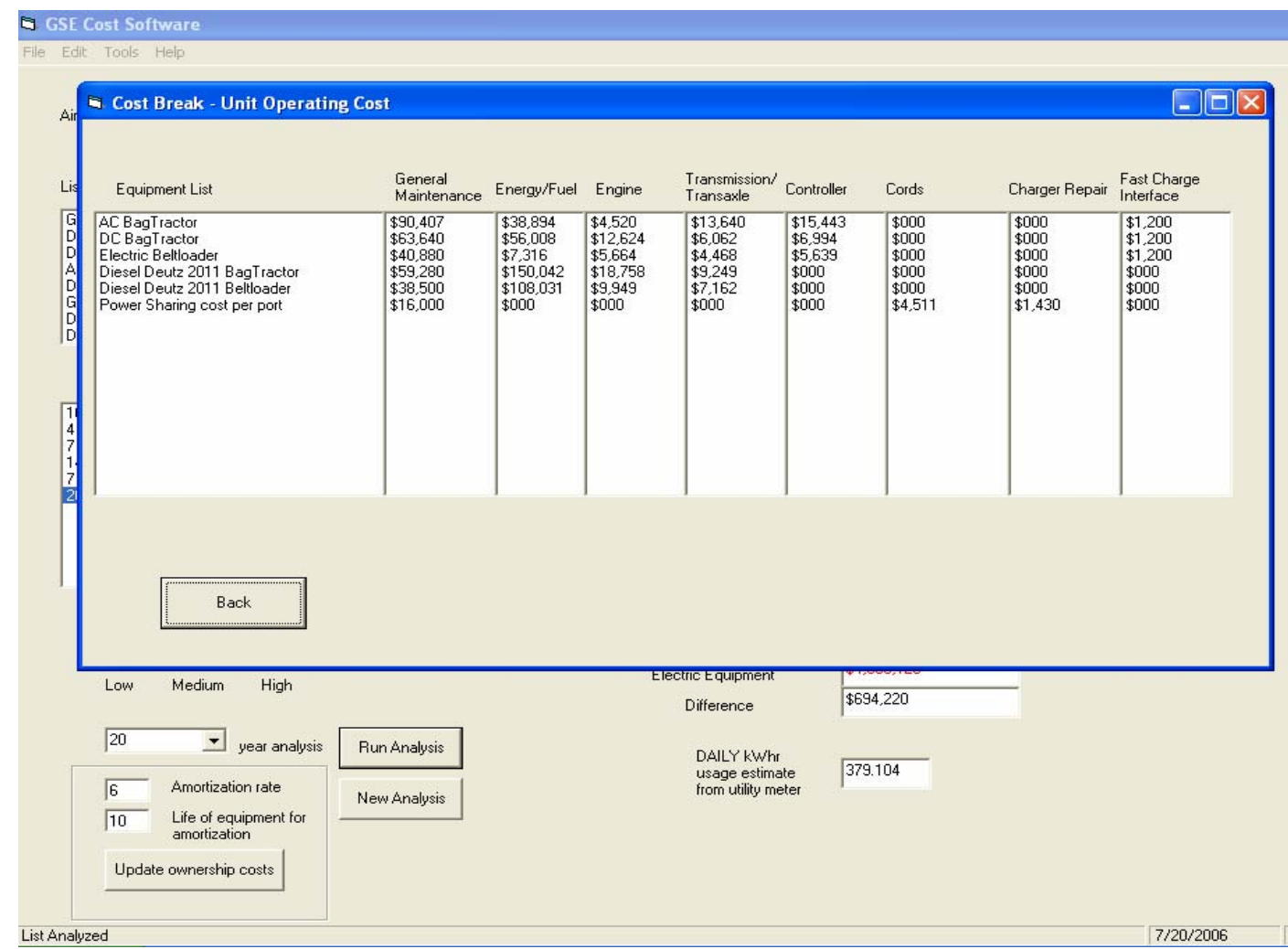

\section{How Operating Vehicle Cost is Calculated}

Operating cost consists of the sum of the energy cost, preventive maintenance cost, and repair/replacement cost for the equipment.

\subsection{Energy Cost per Vehicle}

Vehicle energy cost per year equals energy use per day times the average energy cost over the analysis period times 365 . This cost is the main cost among operating costs, especially with ICE vehicles.

\subsection{Vehicle Maintenance Cost}

Vehicle maintenance costs are divided into two major categories: preventative maintenance and repair maintenance. Preventative maintenance includes most service items typically found with GSE, including oil changes, service checks, tire replacement, brake jobs, front-end rebuild, starter repair, and motor brush replacement, when applicable. 


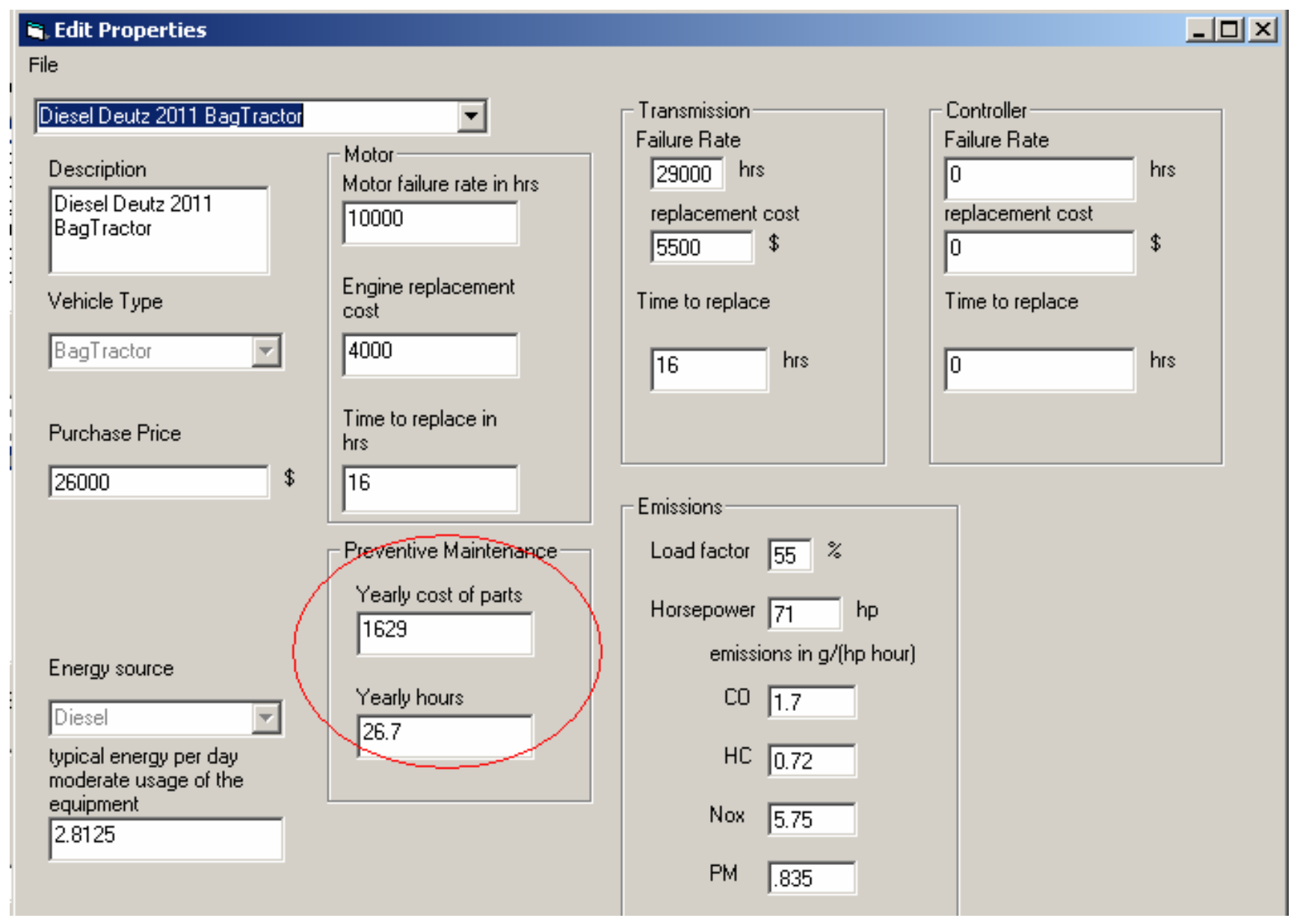

Maintenance cost is the cost of parts plus the number of hours times the labor rate that can be modified in the parameters window (default is $\$ 50$ per hour).

For example, the preventative maintenance cost for the vehicle above is $\$ 1,629+26.7 \times \$ 50=\$ 2,964$.

Repair maintenance is calculated based on failure rates for engines, transmissions, and controllers (if applicable). Battery replacement cost is also added to the repair maintenance cost and includes replacement cost and the period between replacements.

To view the vehicle maintenance cost parameters, select "Edit Vehicles" under the "Edit" header at the top of the screen. (Note: You cannot make changes to these pre-set parameters-see Section 2.3.) 


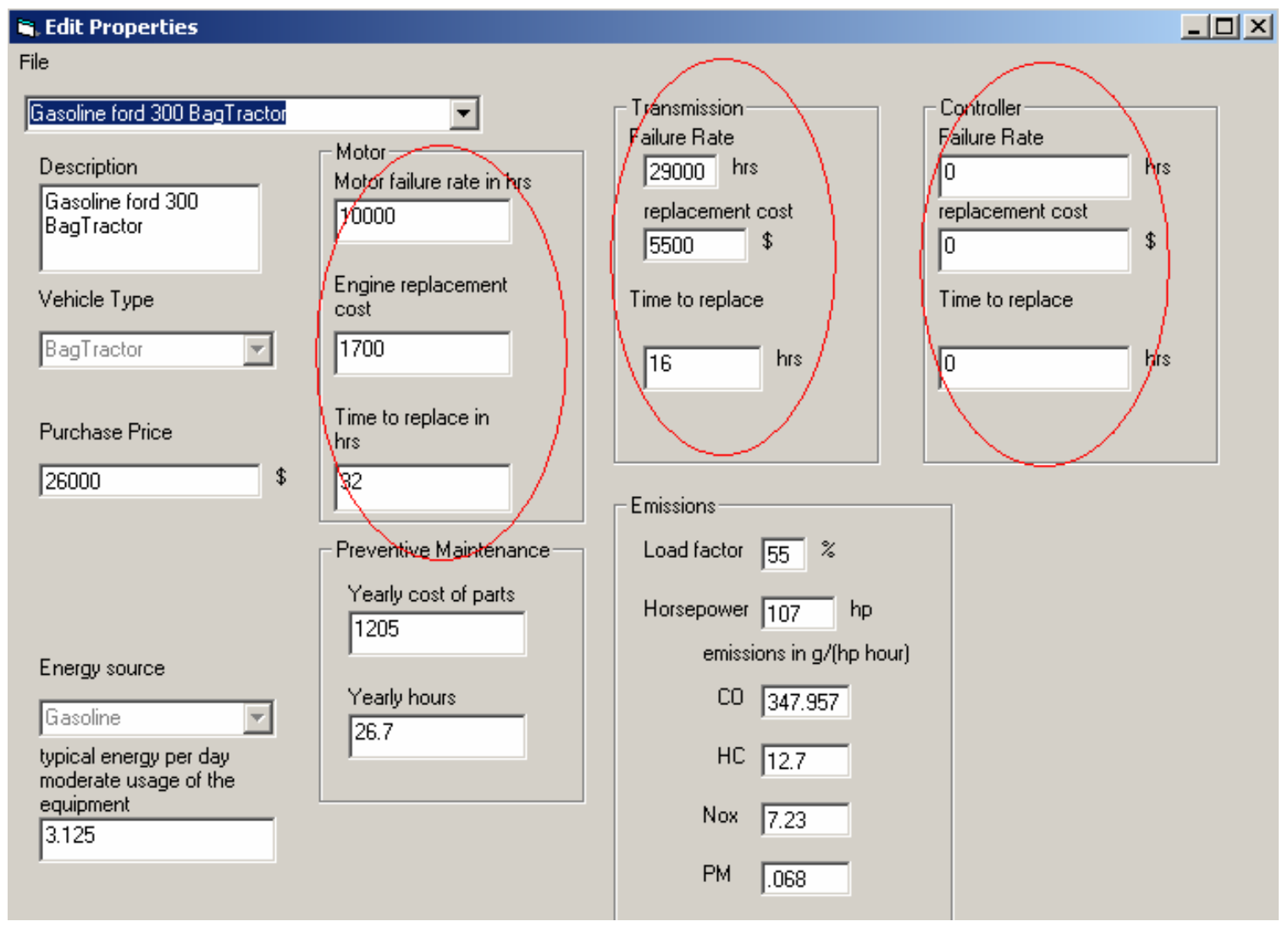

\subsection{Adding a New Vehicle}

To change the parameters, select "Add New Vehicle" under the "File" header and change the desired parameters. Click the "Save" box at the bottom of the screen to save this new item to the master list. Start with the file that closely resembles the new equipment you wish to create because the defaults for the current vehicle set on the screen will remain when you select "Add New Vehicle."

\section{How Operating Cost is Calculated for Chargers}

\subsection{Charger Maintenance Cost}

The charger operating costs are divided into two major categories: preventive maintenance and repair maintenance. Preventative maintenance includes items such as filters, general cleaning, and inspections that are recommended annually. They are shown as labor and materials in the preventative maintenance window. The preventative maintenance window under "Edit Charger" displays a part cost and number of hours per year that is replaced as part of the preventative maintenance. 
Repair maintenance includes all major repairs required during the year, including a separate category for the DC output cords. (Note: Charger repair cost is linked only to the number of years and not the daily usage selected.)

\subsection{Adding a New Charger to the List of Available Equipment}

To change the parameters, select "Add New Charger" under the "File" header, and change the desired parameters. Click the "Save" box at the bottom of the screen to save this new item to the master list. The defaults for the current charger set on the screen will remain when you select "Add New Charger;" therefore, you should begin with the file that closely resembles the new equipment you wish to create.

\section{Viewing Emissions}

After you have selected your equipment, you can view the yearly estimated emissions. Remember, this is based on your "GSE usage at airport" input that will affect the vehicle usage per day input. Results are based on emissions numbers, usage per day, load factor, and horsepower of the vehicle. The eGSE are considered to have zero tailpipe emissions.

\section{Comparing Two Models}

Different model scenarios can be compared with the GSE Cost Model software. Before running a comparison, have a least one model saved on your hard drive.

- First load (Select File and Open) a file you wish to compare with another one or create a list of equipment, run the analysis, and save the file (see Section 1 of this Quick Start Guide for more details).

- Select Tools and Compare with files. The software now prompts you to open a file that it will compare with the one currently loaded.

- A new window will display the costs of both scenarios and the differences between the two. 